\title{
Monika Konert-Panek
}

\section{From Mentalism \\ to Optimality Theory}

Notion of the Basic Phonological Segment

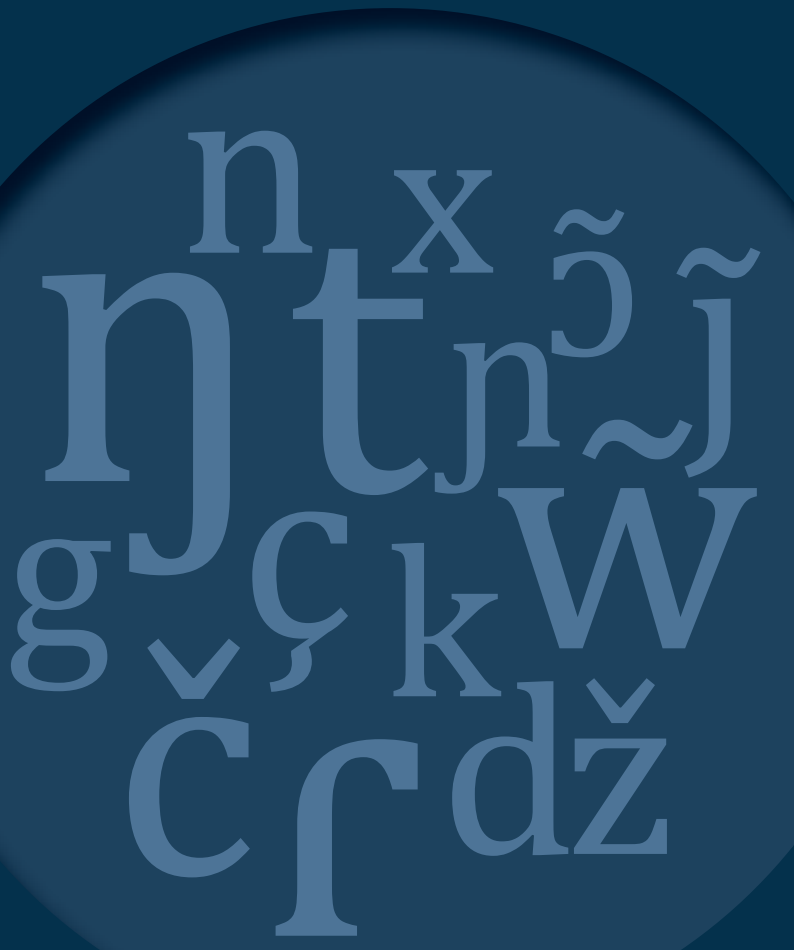




\section{From Mentalism to Optimality Theory}




\section{Monika Konert-Panek}

\section{From Mentalism \\ to Optimality Theory}

Notion of the Basic Phonological Segment 
Reviewers

Klementina Jurančič

Paula Orzechowska

Commissioning Editor

Małgorzata M. Przybyszewska

Editing and Proofreading

Krzysztof Heymer

Index

Monika Konert-Panek, Krystyna Komorowska

Cover Design

Anna Gogolewska

Layout and Typesetting

Dariusz Górski

Published with financial support of the University of Warsaw

(c) Copyright by Wydawnictwa Uniwersytetu Warszawskiego, Warszawa 2021

Monika Konert-Panek ORCID 0000-0002-1463-3357 Uniwersytet Warszawski

ISBN 978-83-235-5424-0 (print) ISBN 978-83-235-5432-5 (pdf online)

ISBN 978-83-235-5440-0 (e-pub) ISBN 978-83-235-5448-6 (mobi)

University of Warsaw Press

PL 00-838 Warsaw, 69 Prosta St.

e-mail: wuw@uw.edu.pl

www.wuw.pl

lst Edition, Warsaw 2021

Print and binding

POZKAL 


\section{TABLE OF CONTENTS}

Symbols and abbreviations . . . . . . . . . . . . . . 9

Acknowledgements . . . . . . . . . . . . . 11

Preface . . . . . . . . . . . . . . . . . . . . . . 13

Chapter 1. Theoretical background . . . . . . . . . . 19

1.1. The Kazan School: Kruszewski's theory of alternations . . . . 19

1.2. The Prague School: functionalist structuralism . . . . . . 22

1.3. Distributional structuralism _ . . . . . . . . . . . 27

1.4. Early Generative Phonology . . . . . . . . . . . . . . . 34

1.5. Natural Generative Phonology . . . . . . . . . . . . . . . . 41

1.6. Lexical Phonology . . . . . . . . . . . . . . . . . . . 43

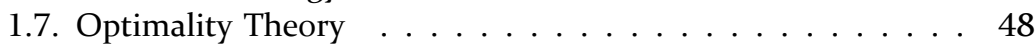

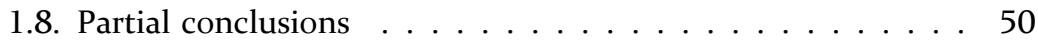

Chapter 2. Biuniqueness and overlapping . . . . . . 51

2.1. The status of flap in American English . . . . . . . . . 51

2.1.1. Basic generalisations . . . . . . . . . . . . . . . 52

2.1.2. The Kazan School: Kruszewski's theory of alternations . . . . . . . . . . . . . 52

2.1.3. The Prague School: functionalist structuralism . . . . . 55

2.1.4. Distributional structuralism _. . . . . . . . . . 56

2.1.5. Early Generative Phonology . . . . . . . . . . . . . 58

2.1.6. Natural Generative Phonology . . . . . . . . . . . . 60

2.1.7. Lexical Phonology . . . . . . . . . . . . . . . . . . 60

2.1.7.1. Borowsky's analysis . . . . . . . . . . . 60

2.1.7.2. Rubach's analysis . . . . . . . . . . . . . 62

2.1.7.3. Lexical Phonology: partial conclusions . . . . . 66 
2.1.8. Optimality Theory . . . . . . . . . . . . . . . 66

2.1.9. Flapping in American English: partial conclusions . . . 67

2.2. The status of angma in English _. . . . . . . . . 68

2.2.1. Basic generalisations . . . . . . . . . . . . 68

2.2.2. The Kazan School: Kruszewski's theory of alternations . . . . . . . . . . . . . 69

2.2.3. The Prague School: functionalist structuralism . . . . . 70

2.2.4. Distributional structuralism _.......... 71

2.2.4.1. Sapir's analysis . . . . . . . . . . 71

2.2.4.2. Jones's analysis . . . . . . . . . . . . . 72

2.2.4.3. Distributional structuralism: partial conclusions . . . . . . . . . . . 74

2.2.5. Early Generative Phonology . . . . . . . . . . . . . . . 74

2.2.6. Natural Generative Phonology . . . . . . . . . . . . 77

2.2.7. Lexical Phonology . . . . . . . . . . . . . . . . 78

2.2.8. Optimality Theory . . . . . . . . . . . . . . 83

2.3. Partial conclusions . . . . . . . . . . . . 87

ChAPter 3. Symmetry of a phonological system . . . . . . 88

3.1. Basic generalisations: Nasal Assimilation and Nasal Gliding . . 89

3.2. The Kazan School: Kruszewski's theory of alternations . . . . 90

3.3. The Prague School: functionalist structuralism . . . . . . . . . 95

3.4. Distributional structuralism . . . . . . . . . . . . . . 99

3.5. Early Generative Phonology . . . . . . . . . . . . . . 103

3.6. Natural Generative Phonology . . . . . . . . . . . . . . . 109

3.7. Lexical Phonology . . . . . . . . . . . . . . . . . . . . 114

3.8. Optimality Theory . . . . . . . . . . . . . . 116

3.9. Partial conclusions . . . . . . . . . . . . 120

Chapter 4. Levels of phonological representation . . . . 123

4.1. Phonemic representation . . . . . . . . . . . . . . . 124

4.1.1. Voice Asssimilation: basic generalisations . . . . . . . . 124

4.1.2. The Kazan School: Kruszewski's theory of alternations . . . . . . . . . . . . 126

4.1.3. The Prague School: functionalist structuralism . . . . . 128

4.1.4. Distributional structuralism vs. generativism:

Halle's analysis . . . . . . . . . . . . . . 130

4.1.5. Schane: The Phoneme Revisited . . . . . . . . . . . . . . 131

4.1.6. Natural Generative Phonology . . . . . . . . . . . 133

4.1.7. Lexical Phonology . . . . . . . . . . . . . . . . 134 
4.1.8. Optimality Theory . . . . . . . . . . . . . . . . . 140

4.1.9. Voice Assimilation: partial conclusions . . . . . . . . . 146

4.2. Morphophonological representation . . . . . . . . . 147

4.2.1. The problem of German ch: basic generalisations . . . 147

4.2.2. The Kazan School: Kruszewski's theory of alternations . . . . . . . . . . . . . . . 148

4.2.3. The Prague School: functionalist structuralism . . . . . 150

4.2.4. Distributional structuralism . . . . . . . . . 151

4.2.5. Early Generative Phonology . . . . . . . . . . . . . 156

4.2.6. Natural Generative Phonology . . . . . . . . . . . 157

4.2.7. Lexical Phonology . . . . . . . . . . . . . . . . . 159

4.2.8. Optimality Theory . . . . . . . . . . . . . . . . 165

4.2.9. The problem of German ch: partial conclusions . . . 168

Chapter 5. Conclusions . . . . . . . . . . . . . . . 170

References ....................... . . . . . . . . . . . .

Index of names $\ldots \ldots \ldots \ldots \ldots$

Index of subjects $\ldots \ldots \ldots \ldots$ 


\section{SYMBOLS AND ABBREVIATIONS}

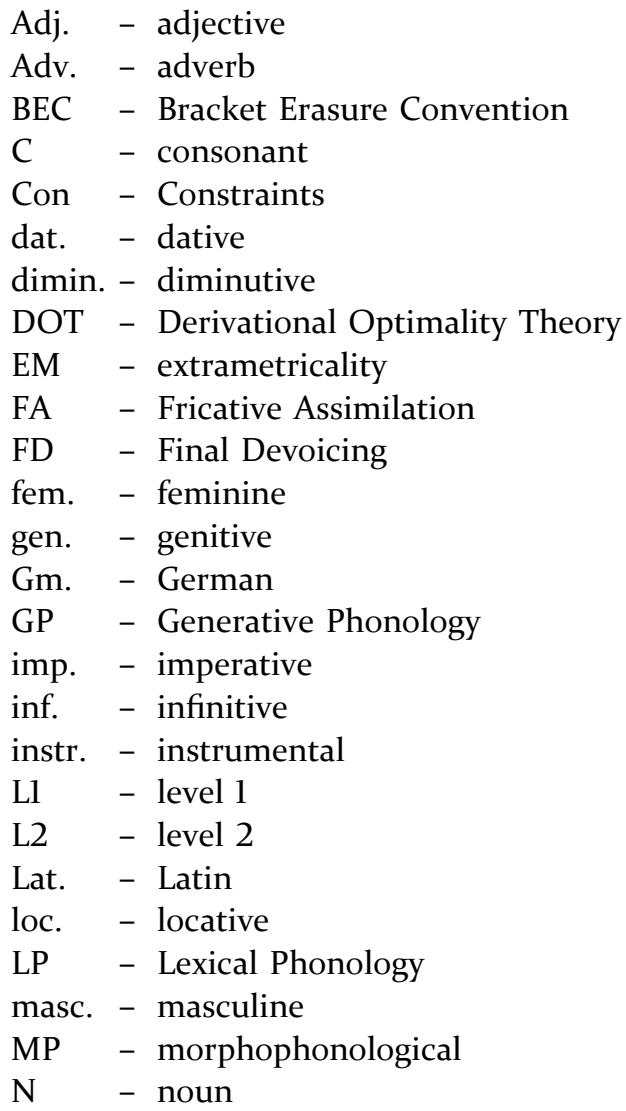


NA - Nasal Assimilation

NGP - Natural Generative Phonology

nom. - nominative

NP - Noun Phrase

$\mathrm{O}$ - Onset

OT - Optimality Theory

$\mathrm{P} \quad-$ phonological

p - person

Pl. - Polish

pl. - plural

PW - phonological word

R - Rhyme

sg. - singular

SP - Structure Preservation

SPE - Sound Pattern of English

WFR - Word Formation Rule

$\mathrm{V}$ - vowel

$\mathrm{V}$ - verb

VA - Voice Assimilation

VP - Verb Phrase

“” - citation or gloss

[ ] - surface representation

// // - underlying representation

* $\quad$ - incorrect statements; in a tableau * denotes violation of a constraint

$+\quad$ - morpheme boundary

\# $\quad$ - word boundary

$=\quad-$ SPE "ad hoc" boundary

$\sigma \quad-$ syllable

$>\quad$ - ranked higher than

! - fatal violation

$\$ \quad$ - winning candidate

๑ - incorrect winning candidate 


\section{ACKNOWLEDGEMENTS}

The present work is a revised and updated version of my $\mathrm{PhD}$ dissertation, written during my doctoral studies in the field of linguistics at the University of Warsaw. I would like to express my utmost admiration and gratitude to my supervisor, Professor Jerzy Rubach, for his support, encouragement and continued interest in my work. I am genuinely grateful for the invaluable time and work he devoted to our PhD seminars. Without his professional guidance, this dissertation would not have been written. To have learned phonology from Professor Jerzy Rubach is a challenging and inspiring experience and I feel fortunate that I have had this opportunity. Besides my supervisor, I am grateful to my PhD dissertation reviewers, Professor Ewa Waniek-Klimczak and Professor Jerzy Wełna, for their insightful comments and suggestions, which incented me to improve this study. I have also benefitted enormously from the advice given by my editorial peer reviewers, Professor Klementina Jurančič and Professor Paula Orzechowska, whose enthusiasm and support were truly invaluable. I would also like to thank my friends from the doctoral seminar for helpful discussions that we held. Last but not the least, I owe a special debt of gratitude to my family for their patience, encouragement and love.

Warsaw, 2021 


\section{PREFACE}

The present work discusses the notion of the basic phonological segment from the perspective of selected European and American phonological theories. The discussion consists in the analyses of selected phonological problems from the perspective of a given framework, starting with the Kazan School and ending with the Optimality Theory. The goal of this study is to show the differences in the methodology and predictions of each framework that prove significant in the process of establishing the basic phonological unit. The work elaborates on the data from English, Polish, German, and Russian. The analyses dealing with the selected phonological problems are either classic cases in the field or conducted by me on the basis of the tenets of a given framework.

The book consists of five chapters. Chapter 1 presents the theoretical background relevant for the discussion in the following chapters. Chapter 2 focuses on the structuralist principles of biuniqueness and overlapping, the discussion centring around the status of a flap and angma in English. Moreover, the notion of the syllable proves to be significant in the analyses. The principles of interest in Chapter 3 are biuniqueness and the ideal of the symmetry of a system. Nasal Assimilation and Nasal Gliding in Polish constitute the basis for the discussion. Chapter 4 deals with the issue of levels of representation and morphology-phonology interface. In particular, it discusses the notion of a juncture phoneme and the Structure Preservation Principle, with 
the analyses of Voice Assimilation in Russian and the problem of German ch serving as examples. Chapter 5 summarizes the conclusions. The principal issues that come to light while discussing the basic phonological segment are: the phoneme with its basic and subsidiary variants, distribution, decomposition into features, morphological and syntactic interface in phonological analysis, and the notion of the syllable.

The notion of the phoneme seems to be the most natural association while discussing the concept of the basic phonological segment. The origins and the authors of the term "phoneme" are debatable. Some linguists, e.g. Daniel Jones (1967: VI), attribute the term "phoneme" to the Polish linguist Mikołaj Kruszewski, who allegedly coined it in 1879 as a notion distinct from a "phone". The opinions, however, seem to differ. Roman Jakobson, for instance, argues (1967: XX) that Kruszewski took the notion of the phoneme from de Saussure in 1880, but Kruszewski's meaning assigned to it was slightly different. Ferdinand de Saussure, on the other hand, is said to have taken this term from a Romanist, Louis Havet in 1878 (Jakobson 1967: XXIII). Thus, pinpointing the sole inventor of "the phoneme" seems to be a difficult task.

What is crucial, however, is the evolution of its meaning in the twentieth century, for it covered a whole range of interpretations: physical, functional, abstract (i.e. abstracted from a number of utterances), and finally, mental, i.e., "psychologically real". One of the essential points in the debate was whether the phoneme should be analysed as a unitary object, or as a set of characteristic features. As a consequence of adopting the latter approach, the issue of the type of features that should be analysed emerged. Should the phoneme be fully-specified, or is it enough to have only distinctive features in its representation? What is the correlation between phonetics and phonology in defining the features? How abstract can representations be? What is the relation between the basic phonological unit and morphology or syntax? Can the establishment of this unit be interrelated with the analysis of syllable structure? These questions have 
posed problems for phonologists and opened heated debates in the field.

In the present study, I base the analyses on the works that have become classic within each framework, and thus in the history of phonology. Phonological theories selected ${ }^{1}$ for this study, and their most significant architects are listed below.

1. The Kazan School: Jan Niecisław Baudouin de Courtenay and Mikołaj Kruszewski

2. The Prague School (functionalist structuralism): Nikolai Trubetzkoy

3. Distributional structuralism: Leonard Bloomfield, William G. Moulton, Edward Sapir, Daniel Jones

4. Early Generative Phonology (Sound Pattern of English phonology): Noam Chomsky and Morris Halle

5. Natural Generative Phonology: Joan B. Hooper, Theo Vennemann

6. Lexical Phonology: Paul Kiparsky, Jerzy Rubach

7. Optimality Theory: Alan Prince and Paul Smolensky, John McCarthy

Trends in Phonological Theory by Eli Fischer-Jørgensen (1975) and Phonology in the Twentieth Century by Stephen R. Anderson (1986) constitute the basis of some analyses, as they provide the general theoretical picture for the debate.

The Kazan school of linguistics, with Baudouin de Courtenay and his student Kruszewski as its key figures, had its peak of activity in the 1870s and 1880s. Baudouin de Courtenay was the predecessor of mentalistic phonology. He emphasised the distinction between sounds, which are composed of physical features, and phonemes, which are abstract units with only those features that

${ }^{1}$ In particular, I will not consider Natural Phonology (Stampe 1979, Dressler 1984, Dziubalska-Kołaczyk 1995) and Government Phonology (e.g. Kaye 1990, Harris and Gussmann 1998). 
differentiate the meaning. In other words, the phoneme is a "psychological equivalent of a speech sound". Baudouin de Courtenay differentiated between, on the one hand, divergents-alternations that are conditioned contextually and psychologically are unitary phonemes, e.g. $k-g$ in róg, "horn" (nom.sg.) - rogu, "horn” (gen.sg.), and, on the other hand, correlations that are different phones that share a psychological reality, e.g. plotę, "plai"' ( $\left.1^{\text {st }} . s g.\right)$-plecie, "plait" ( $3^{\text {rd }}$ p.sg.). Baudouin and Kruszewski notice that alternations can be conditioned phonetically and morphologically, Kruszewski's distinction being strikingly similar to the types of rules in Natural Generative Phonology (see Chapter 1, section 1.1).

The most renowned phonologists within The Prague School (the 1920s and 1930s) were Nikolai Trubetzkoy, Vilém Mathesius and Roman Jakobson. They perceived language as a functional system and made a clear distinction between phonetics and phonology, of which only the latter was considered to belong to linguistics. One of Jakobson's main contributions to the history of phonology was his concept of the phoneme understood as "a bundle of concurrent features that differentiate meaning". The theory of distinctive features was later adopted in generative phonology. The concepts of the opposition, minimal pair, morphophoneme and archiphoneme (an abstract theoretical construct that shows the neutralisation of features) are further contributions of the Prague School to the history of phonology (see Chapter 1, section 1.2).

Distributional structuralism is an umbrella term for British structuralism, with Jones as the main representative, and American structuralism (descriptivism). ${ }^{2}$ American structuralists were, to a large extent, influenced by behaviourism and, as a result, they tried not to refer to mental processes, speculation and abstractness in their phonological analyses. According to the leading American structuralists (Leonard Bloomfield and post-Bloomfieldians-Bernard Bloch, Zellig Harris, Charles Hockett, Kenneth Pike, Morris Swadesh, George Trager, W. Freeman Twaddell), the

2 See e.g. Rubach (1982: 28). 
phoneme is a class of sounds rather than a bundle of concurrent features. By and large, with Sapir being an exception, no reference is made to the "mental reality" of phonemes.

Compared with other American structuralists, Sapir's ideas constitute an important exception because of his attitude towards "mental reality". On the basis of the studies that he conducted among American Indians, he states that a human being is equipped with an ideal linguistic system, the patterns of which are realised in an appropriate way depending on the context. In spite of the whole range of variants, however, a given sound is perceived as one entity because of the "psychological image" of the sound in the native speaker's mind. This view, though not shared by other American structuralists, is an essential concept in generative phonology. ${ }^{3}$

Generative grammar has its origins in Sapir's mentalism, Jakobson's universal phonetic features and Bloomfield's item and process morphophonology. It emphasises formalism, as well as the explanatory and predictive power of a phonological theory. The phoneme is a psychologically real underlying form, significantly more abstract than the basic form in structuralism. All surface variants of a given morpheme (allomorphs) are derived from one common underlying form. The classic works that revolutionised phonology are Halle's The Sound Pattern of Russian (1959) and Chomsky and Halle's The Sound Pattern of English (SPE, 1968). Daniel Kahn (1976) and George N. Clements and Samuel Jay Keyser (1983) develop the linear SPE phonology by recognizing further levels (tiers) of representation apart from the melodic: a segmental one, i.e. the syllable (Kahn) and the skeleton (Clements and Keyser). Processes such as flapping, glottalisation and $r$-deletion (Kahn 1976) can now be accounted for in a more elegant fashion (see Chapter 1, section 1.4).

${ }^{3}$ See Chapter 1, section 1.3, for the general account of the structuralist principles, and Chapter 2, section 2.2.4.1, for the discussion regarding Sapir's theoretical concepts. 
Natural Generative Phonology (NGP) originated in the 1970s. The major difference between the standard transformational generative theory as developed in the 1950s and NGP concerns the abstractness of phonological representations and rules. In the view of NGP, there is little evidence that native speaker competence is correctly represented by abstract analysis. The formal devices of natural generative theory are less powerful than those of previous generative theories (see Chapter 1, section 1.5).

Lexical Phonology (LP) is a development of standard generative phonology that accounts for the interactions of morphology and phonology in a more insightful way. Rules are organised in two components: lexical, where the rules require morphological information, and postlexical, where they require access to syntax and are not conditioned by the internal structure of words. Lexical and postlexical rules have distinct properties, for instance, lexical rules apply within words, whereas postlexicalwithin words and across word boundaries; lexical rules have exceptions, postlexical rules are exceptionless, and so forth. Three types of boundaries (SPE) are replaced by the concept of brackets that coincide with morphological junctures. At the end of each component Bracket Erasure Convention (BEC) applies, ensuring that the morphological brackets introduced at a certain level are erased before entering the next level (see Chapter 1, section 1.6).

The major "architects" of Optimality Theory (OT) are Prince, Smolensky and McCarthy (McCarthy and Prince 1993, Prince and Smolensky 1993). Generator (Gen), Constraints (Con), Evaluator (Eval) are the basic concepts in this framework. Gen provides each input form with a possibly infinite set of output candidates. Constraints are ranked, universal and violable. Their job is to eliminate all but the optimal, "desired" output candidate. The winner is determined by taking into consideration the language-specific ranking of the constraints. The winning candidate is the one with the least serious violations (see Chapter 1, section 1.7). 


\section{CHAPTER 1}

\section{THEORETICAL BACKGROUND}

The present chapter discusses the principal tenets of the linguistic frameworks that prevailed in the $19^{\text {th }}$ and $20^{\text {th }}$ centuries, starting with Kruszewski's theory of alternations (the Kazan School) and concluding with Optimality Theory. I focus on selected examples that constitute typical theoretical problems in each of the frameworks, the analyses being either cited from the original source or conducted by me. The main aim of this introductory chapter is to provide an overview of the basic mechanisms of selected frameworks, while further features and principles are elaborated on in the succeeding chapters, in which I account for selected problematic issues from the perspective of each framework. For example, the notions of resyllabification (Selkirk 1982, Borowsky 1986) and amibisyllabicity (Anderson and Jones 1974, Kahn 1976, Rubach 1996) are introduced in Chapter 2, Derivational Optimality Theory (Rubach 1997) is introduced in Chapter 2 and further discussed in Chapter 3, while more intricate problems of the phonology-morphology interface are investigated in Chapter 4.

\subsection{The Kazan School: Kruszewski's theory of alternations}

Kruszewski (1967 [1881]: 28-37) made a distinction between two major categories of phonological alternations: divergents and 
correlatives, the latter one being further divided into two subtypes. Divergents are characterised as closely related (phonetically) ${ }^{4}$ and the cause of this alternation as such is based on phonetic grounds. Moreover, the contexts in which an alternation takes place are visible and can be well defined, and the alternation itself is exceptionless. Divergents are modifications (fission) of one and the same sound, and not two or three distinct sounds. In modern terms, divergents would be regarded as allophones of a single phoneme. One of Kruszewski's examples is the rule of Surface Palatalisation ${ }^{5}$ in Russian, which states that consonants become palatalised before front vowels $e$ and $i$ (la). The process is not active in the context of back vowels (lb).

(1) а. T’ексас [t'e] “Техаs”; на свет'e [t'e] "world” (loc.sg.) b. света [ta] "world" (gen.sg.)

The alternants of the second category are called correlatives. This type of alternations is not purely phonetic but is conditioned by morphological categories. Furthermore, the alternating sounds are not as similar as those from the first category. They are not considered modifications of one sound, but separate sounds. In modern terms, they would be regarded as two phonemes, since they contrast meaning, as I explain below.

As has already been mentioned, correlatives are further divided into two subtypes. One of the examples of the alternations that belong to the first subtype, presented by Kruszewski, is the process called Velar Palatalisation in Russian, via which $k, g$, become $\check{c}$, $\check{z}$ before, in Kruszewski's terms, palatal vowels (the notion that Kruszewski uses interchangeably with front vowels). Yet, it is only through historical research that we can discover that the front

${ }^{4}$ Kruszewski's theory of alternations seems to resemble the claims of $\mathrm{Na}$ tural Generative Phonology, according to which all phonological rules should be grounded in phonetics.

5 This is how the process would be called today. Kruszewski did not use this name. 
vowels were a triggering factor of that process. Synchronically, there are numerous exceptions to this generalisation, as can be observed in: руки "arm" (nom.pl.) and боги "god" (nom.pl.), in which we would rather expect to find $\check{c}$ and $\check{z}$ instead of $k$ and $g$. Furthermore, even though one can still find the alternations: $k$ : $\check{c}, g: \check{z}$ in conjugation, it is not the case in declension. There are instances in which $k, g$ are followed by front vowels and $\check{c}$, $\check{z}$ followed by back vowels. Furthermore, $k, g$ may become $k^{\prime}, g$ ' and not $\check{c}$, ž, e.g. Косk'uн [kosk'in], Браг'uн [brag'in] (proper names). The same process occurs in foreign words such as z'eограф'uя [g'eografija] "geography" (nom.sg.).

In Kruszewski's view, the alternations belonging to the second subtype of correlatives develop out of the second category, which happens after language users start to associate certain morphological differences with semantic ones. The crucial difference between the first and the second subtype of correlatives is that the latter are exceptionless within their restricted morphological scope. Kruszewski gives the examples of German umlaut, as in (2).

(2)

\begin{tabular}{l|l|l}
\hline \multicolumn{1}{c|}{ singular } & \multicolumn{1}{c}{ plural } & \multicolumn{1}{c}{ diminutive } \\
\hline a. Haus "house" & Häus+er & Häus+lein \\
b. Rad "bicycle" & Räd+er & Räd+lein \\
c. Loch "hole" & Löch+er & Löch+lein \\
d. Buch "book" & Büch+er & Büch+lein \\
\hline
\end{tabular}

The morphological motivation in this case is the one stated in (3).

(3)

the stem $\left\{\begin{array}{c}\mathrm{a} \\ \mathrm{o} \\ \mathrm{u} \\ \mathrm{au}\end{array}\right\} \rightarrow\left\{\begin{array}{c}\ddot{a} \\ \ddot{o} \\ \ddot{u} \\ \mathrm{a} u\end{array}\right\}+$-er, -lein

Though Kruszewski himself does not refer to this process, the alternations involved in what we know as Second Velar Palatalisation 
seem to serve as good examples of the second subtype of correlatives. Velar stops $k$ and $g$ alternate with dental affricates $t s$ and $d z$, respectively. The context of the alternation is morphologically restricted in Polish, namely, the affricates occur before $e$ and $i$ in the nominative case of plural masculine nouns, dative and locative cases of singular feminine nouns, as well as in a couple of deadjectival adverbs, as shown in (4) below. The instances of $k$ and $g$ occur elsewhere.

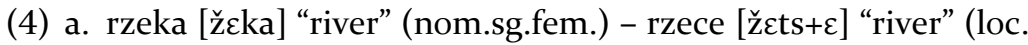
sg.fem.)

b. noga [noga] "leg" (nom.sg.fem.) - nodze [nodz+c] "leg" (dat. sg.fem.)

c. rybak [ribak] "fisherman" (nom.sg.masc.) - rybacy [ribats+i] "fishermen" (nom.pl.masc.)

d. daleki [dalsk'+i] "remote" (Adj.nom.sg.) - dalecy [dalcts+i] "remote" (Adj.nom.pl.)

The alternation is exceptionless, although restricted morphologically. In Kruszewski's view, the alternants of this type are distinct phonological segments.

\subsection{The Prague School: functionalist structuralism}

The opposition is the key concept in the Prague School of phonology (Trubetzkoy 1971 [1939]). On this basis, the distinction between phonetic sounds is made depending on their position in the sound system and their potential contrastive or non-contrastive function in a given language.

Let us consider the example of Polish labial stops $p$ and $b$. In a pair of words such as prać, "to wash", and brać, "to take", we see that the choice between $p$ and $b$ results in the change of meaning. As there are no other labial stops in Polish, this opposition is classified as bilateral. The only distinction between the segments is that of the voice parameter, and there is no third 
degree of voicing in Polish. Thus, the distinction between prać and brać is actually stated in terms of features rather than whole segments. Other pairs of stops exhibit the same type of contrast: velar $k$ and $g$ in $k r a$ "ice float" and gra "game" and dental $t$ and $d$ in trzeć "to rub" and drzeć, "to tear". Yet, these sounds can also be analysed with regard to their place of articulation. Within this opposition, there are three sounds that contrast meaning: the labial stop $b$ in bo "because", the dental stop $d$ in do "to" and the velar stop $g$ in go "him". In the case of voiceless stops, the situation is equivalent, as the following contrasts can be observed: pory "season" (nom.pl.), tory "track" (nom.pl.) and kory "bark" (gen.sg.). This type of opposition is classified as multilateral, as there are three members and three distinctive places of articulation.

The oppositions can also be isolated or proportional. Trubetzkoy (1971 [1939]: 70) points to the German $l-r$ pair as an example of the isolated opposition, since there is no other pair of phonemes in this phonological system that would exhibit the same contrast. Proportional oppositions, on the other hand, bring out the contrast that occurs in other pairs of phonemes in a given language, such as the abovementioned oppositions: $t-d, k-g$ and $p-b$. The idea of a proportional (symmetrical) system of oppositions remained in the phonological theories and was used as an argument in the process of establishing the phonemic inventory in a given language (Rubach 1982: 25).

Other types of sets that Trubetzkoy analyses are privative, gradual and equipollent oppositions. Privative oppositions refer to the presence or absence of a given feature. There are no "mid" values: a sound can be either voiced or voiceless, rounded or not rounded, nasal or not nasal. Thus, the $p-b, t-d$ or $k-g$ oppositions are privative in terms of voice. If a feature under analysis can be graded, the opposition is called gradual, as in the case of the vowel height $(e-i)$. Finally, equipollent oppositions involve sounds that are "logically equal", as they do not share any feature that would be labelled as privative or gradual $(p-t, f-k)$. 
Oppositions are employed to define the phoneme, that is, a functional, abstract unit that encompasses only the features that are distinctive in the system of oppositions. Let us focus on one of the examples given above, namely, prać, "to wash" and brać, "to take". These two labial stops cannot replace each other without changing the meaning of the word, which means that they occur in what would later, in structuralist phonology, be called contrastive distribution. Consequently, they are classified as the phonemes of Polish. In the Prague School framework, the phoneme is a minimal phonological unit, which can be decomposed into features that are not independent entities. The phoneme contains only relevant properties. Combinatory variants of the phoneme occur in mutually exclusive contexts, while facultative variants occur in the same contexts.

Trubetzkoy (1971 [1939]: 46-49) presents three fundamental rules that must be followed in order to establish the status of a given segment:

(Rule I) Two sounds of a given language are merely optional phonetic variants of a single phoneme if they occur in exactly the same environment and are interchangeable without a change in the lexical meaning of a word. (Rule II) If two sounds occur in exactly the same position and cannot be interchanged without a change in the meaning of the words or without rendering the word unrecognisable, the two sounds are phonetic realisations of two different phonemes. (Rule III) If two sounds of a given language, related acoustically or articulatorily, never occur in the same environment, they are to be considered combinatory variants of the same phoneme (Trubetzkoy 1971 [1939]: 46-49).

The distinction between "altering the meaning" and "making the word unrecognisable" is exemplified by the German $a-i$ alternation in pairs of words such as Lippe, "lip" - Lappe, "Sami" and Fisch, "fish" - Fasch. In the former pair, the replacement of a vowel alters the meaning of the word, while in the latter, it only makes the word unrecognisable. Contextual variants of the same phoneme are supposed to be phonetically similar. 
Fischer-Jørgensen (1975: 26) emphasizes the superiority of Trubetzkoy's explanation of phonetic similarity as compared with other phonological schools in which the same notion is used. In Trubetzkoy's view, phonetically similar sounds should possess common properties which distinguish them from all other sounds in a given language. For instance, in spite of their virtually complementary distribution, it would not be possible to subsume English $h$ and $\eta$ under one phoneme, since they share only the consonantal feature.

However, there are contexts in which the voice opposition between $p$ and $b$ in Polish disappears, or rather becomes suspended. The voicing contrast is neutralised (suspended) in the case of obstruents that occur in word-final position before a pause and word-medially before voiceless obstruents. Thus, the phonetic form of the word chleba, "bread" (gen.sg.), is [xleba] and the pronunciation of chlebek, "bread" (nom.sg.dimin.), is [xlebsk], whereas the pronunciation of the nominative singular form chleb is [xlep] and the pronunciation of chlebka (gen.sg.dimin.) is [xlepka]. To account for these facts, Trubetzkoy created the notion of the archiphoneme, which encompasses the features common to both members of a pair, with the neutralised feature being unspecified. Here, the archiphoneme is represented by the capital letter $P$, specified only for the "labial" and "stop" features. In Trubetzkoy's view, archiphonemes are separate objects in the phonological network, that is, they coexist with "regular" phonemes, transcribed with small letter symbols. In the example under consideration, it is the feature "voice" that is left unmarked. The representation of positions in which the obstruents $p$ and $b$ can occur is presented in (5) below.

(5) Lexical form: $\{b+a\}\{b+e\}\{b \#\}\{b+k\}$

Phonemic form: / $b+a / / b+e / / P \# / / P+k /$

Phonetic form: $[\mathrm{b}+\mathrm{a}][\mathrm{b}+\mathrm{e}][\mathrm{p} \#][\mathrm{p}+\mathrm{k}]$

The archiphoneme $\mathrm{P}$ represents the neutralisation of the contrast between $/ \mathrm{p} /$ and $/ \mathrm{b} /$, hence its lack of value for voicing. 
Trubetzkoy claims that only bilateral oppositions may become neutralised. Thus, $p$ and $b$ can be neutralised, because the only feature that they do not share is "voice". This combination of features does not occur in other phonemes in Polish. Thus, neutralisation would not be possible between e.g. $p$ and $k$.

Neutralisation may be context-determined or structure-determined. Context-determined neutralisation is conditioned by the immediate phonemic environment, while structure-determined neutralisation-by the position in the word or syllable. The process of Final Devoicing (FD) can serve as the example of structure-determined neutralisation. In Polish, voiced obstruents devoice word-finally, as shown in (6).

(6) a. krowa [v] "cow" (nom.sg.) - krów [f] "cow" (gen.pl.)

b. obstr $\rightarrow$ obstr / _ \# [+voice] [-voice]

In German, on the other hand, devoicing takes place syllable-finally.

(7) a. Magdeburg [k] "Magdeburg"

b. obstr $\rightarrow$ obstr / — ) [+voice] [-voice]

Only minimal contrasts are covered by neutralisation, that is, phonemes that undergo neutralisation should share common qualities that do not occur in other phonemes. The common features are symbolised by the archiphoneme.

The Prague School of phonology is the study of representations rather than rules. Access to the rules is indirect, as they are encoded in the representation, namely, in the concepts of neutralisation, the archiphoneme and the morphophoneme. The morphophoneme is a complex unit consisting of a list of alternating phonemes in a given morpheme, together with the contexts in which they occur. For instance, the morpheme mrok, "darkness", has different phonemic realisations depending on the morphological context in which it occurs. 
(8) a. mrok+u [k] “darkness" (gen.sg.)

b. mrok+i [k'] "darkness" (nom.pl.)

c. mrocz+ny [č] “dark” (Adj.)

Morphophonology as a discipline situated between morphology and phonology has a separate status in the Prague School system. Trubetzkoy intended to develop the concept of morphophonology in the second volume of Grundzüge, which was never written. Morphophonology deals solely with morphological conditioning of the alternation, e.g. if a given segment occurs only in a specified morphological class. ${ }^{6}$ Neutralisation and the archiphoneme are phonological rather than morphophonological tools. The same applies to the alternation between variants of the same phoneme. Morphophonology deals with the alternations between independent phonemes.

\subsection{Distributional structuralism}

To review the major principles of the descriptivist-structuralist analysis, let us consider the variants of the sound [t] in English. We notice that in certain contexts the pronunciation of this consonant varies, as shown in (9).

(9) a. eighth [ert $\theta$ ]: dental [t]

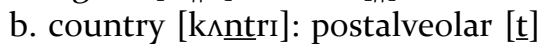

c. that chair [ðæt tea]: palato-alveolar [t]

The sound $[t]$ is always dental before dental [ð] or $[\theta](9 a)$; it is postalveolar before postalveolar $[\mathrm{r}](9 \mathrm{~b})$ and palato-alveolar before palato-alveolar [t] (9c). Elsewhere, the place of articulation of $[t]$ is alveolar. Distinct variants of [t] occur in clearly defined contexts and they are mutually exclusive. This type of distribution

${ }^{6}$ Anderson (1986: 113) points to the similarity with one of the subtypes of correlatives in Kruszewski's framework. 
is called complementary. Contextually-conditioned variants of [ $t]$ constitute allophones of this phoneme. The other type of distribution by which sounds may be classified as allophones of the same phoneme is defined as facultative (free variation). This distribution is illustrated by the word-final voiceless stop in the English word let, where the stop can be pronounced with or without glottalisation, that is, as [let'] or [let], respectively. The glottalised variant is the allophone of the plain voiceless stop [t], as it is pronounced in isolation.

The final type of distribution is called contrastive. ${ }^{7}$ To show what is at stake, let us focus on the distribution of the dental stops $t$ and $d$ in Polish. In a pair of words such as tom [tom], "volume" and dom [dom], "house", the change of the word-initial stop produces a change of meaning. The two sounds form a minimal pair and, therefore, they constitute separate phonemes. One minimal pair is enough to establish the phonemic status of the relevant sounds. This follows from the principle called once a phoneme, always a phoneme (Pike 1947: 96):

[...] when, by contrast in identical environments, two segments are once proved to be phonemically separate, they must each be considered as phonemically distinct wherever they occur, regardless of the mechanical, arbitrary, or grammatical substitutions which they may undergo elsewhere (Pike 1947: 96).

However, there is a context in which the contrast between the analysed dental stops disappears. Let us consider the relevant examples in (10).

${ }^{7}$ However, contrastive distribution alone is not enough to indicate the status of given sounds. Another requirement is that of phonetic similarity. The classic example is the complementary distribution of [h] (never in final position in a word) and [y] (never in initial position) in English. Given the distributional procedure alone, these two sounds should be recognized as allophones of one phoneme. This solution would be odd, so the way to avoid it is to state that these sounds differ too much to be subsumed under one phoneme. The problem with the procedure is that the term phonetic similarity is never precise. 
(10) a. kot [kot] "cat" (nom.sg.)

b. koty $[\mathrm{kot}+\mathrm{i}]$ "cat" (nom.pl.)

c. kod [kot] "code" (nom.sg.)

d. kody $[\mathrm{kod}+$ i] "code" (nom.pl.)

The plural forms $k o t+y$ and $k o d+y$ constitute a minimal pair (10b and $10 d$, respectively), which proves the phonemic status of both dental stops. In the case of singular forms (10a and 10c), the contrast between $t$ and $d$ disappears in word-final position. However, as Fischer-Jørgensen (1975: 90) points out, structuralists “[...] are interested in the establishment of phoneme inventories rather than in the notion of opposition as such. Hence, the suspension of contrasts in certain positions is not a crucial concept in this framework". ${ }^{8}$ In other words, it is assumed that the $/ \mathrm{t} /$ phoneme occurs both in (10a) and in (10c). Since in Polish there are no voiced obstruents in word-final position, one could try to capture the alternation between $\operatorname{kod}[\mathrm{t}]$ and $k o d y[\mathrm{~d}]$ by postulating the allophonic status of it $t$. The voiceless allophone of the /d/ phoneme occurs in word-final position, so the context is predictable and, consequently, $[t]$ could be analysed as the contextual variant of $/ \mathrm{d} /$. However, this solution is not possible.

The predictability criterion is restricted by the principle of biuniqueness (Bloch 1941), which requires that a given sequence of phones should be represented by a unique sequence of phonemes, and that a given sequence of phonemes should be represented by a unique sequence of phones. In other words, phonemic representations should be uniquely recoverable from phonetic data alone. In accordance with the principle of biuniqueness and the principle of once a phoneme, always a phoneme, once the phonemic status of a given sound has been established, it is not possible

8 As Fischer-Jørgensen (1975: 90-91) points out, the majority of post-Bloomfieldians adopted this principle as one of the core tenets of their theory. Only Twaddell (1935) does not reject the concept of neutralisation. Moreover, he constitutes an exception with regard to the treatment of syllable boundaries. Einar Haugen (1969) also adopts neutralisation in the form of "phonemic indeterminacy." 
to analyse the same sound as an allophone of another phoneme. The principle of biuniqueness is therefore more significant than the principle of predictability. In the example under consideration, it prohibits postulating the allophonic status of [t] in kod. We have to conclude that in final position in Polish, only a voiceless dental stop is allowed, which results in the exclusion of its voiced counterpart. It seems that the analysis conducted in accordance with the tenets of distributional descriptive structuralism does not preserve the insights of the earlier research, specifically that of the Prague School, in which the relatedness between the dental stop in kod and kody would be captured under the label of neutralisation.

As a rule, an allophone cannot belong to two or more phonemes. In certain cases, however, partial overlapping (Bloch 1941) is allowed (see Chapter 2, section 2.1.4). A variant of one phoneme can be phonetically identical with a variant of another phoneme if they occur in distinct environments (hence partial overlapping). Overlapping in the same position is prohibited.

Another central tenet of structuralism is called no level mixing, that is, each linguistic level is supposed to have its own basic units that should be analysed separately. Phonology does not have access to morphological or syntactic information. As stated earlier, the main discovery procedure in phonological analysis is distribution and not meaning. If two allophones are in complementary distribution (they appear in mutually exclusive environments) or in free variation, they are said to belong to one phoneme. The consequence is that they do not contrast meaning. If, on the other hand, they are in contrastive distribution, they are different phonemes, the result being the differentiation of meaning. This procedure was supposed to exclude meaning from phonology, yet, as Rubach (1982: 30) points out, in practice the procedure was reversed. Minimal pairs, such as, for instance, pin-fin, pin-pill, pin-pan - an obvious reference to semantics - were used to establish the set of phonemes, i.e. those alternants that contrast meaning.

As mentioned above, due to the structuralist principle of no level mixing, access to morphological information is not allowed 
and, consequently, the system of oppositions is of lesser importance than in the Prague School phonology. The study of alternations belongs to the morphophonemic rather than phonemic linguistic module. The classic structuralist analysis conducted by Bloomfield concerns the English plural (1933: 70). Three alternants can be observed : /-s/, /-z/ and /-iz/, as shown in (11).

(11) a. cat [kæt] - cats [kæt+s], rat [ræt] - rats [ræt+s], lamp [læmp] - lamps [læmp+s]

b. cod [kpd] - cods [kpd+z], creed [kri:d] - creeds [kri:d+z], knob [nob] - knobs [nob+z]

c. bus $[\mathrm{b} \wedge \mathrm{s}]$ - buses $[\mathrm{b} \wedge \mathrm{s}+\mathrm{Iz}]$, watch [wot $]$ - watches [wot $+\mathrm{zz}]$, ash [æ] - ashes [æf+Iz]

Bloomfield argues that it is easier to formulate the rules governing the distribution of alternants if one of the forms is chosen as the "basic alternant" or "underlying form". In the case of the English plural, Bloomfield posits /-iz/ as the basic alternant. The vowel disappears if it is not preceded by sibilants and affricates. The voiced fricative $z$ becomes $s$ after voiceless sounds (lla) and it maintains its voice value after voiced sounds (llb). Since the analysis involves morphological information (the study of the suffixes that mark plurality), it belongs to the morphophonemic and not to the phonemic module.

However, there are instances in which the principle of no level mixing is discarded. In English, the following contrasts can be observed: that stuff [ðætstıf] (unaspirated $t$ ) versus that's tough [ðætst ${ }^{\mathrm{h}} \Lambda \mathrm{f}$ ] (aspirated $t$ ). According to distributional principles, both the unaspirated $(/ \mathrm{t} /)$ and aspirated $\left(/ \mathrm{t}^{\mathrm{h}} /\right)$ voiceless alveolar stops should be regarded as separate phonemes, since they constitute a minimal pair. In order to avoid the multiplication of phonemes, boundary phonemes called junctures are put forward (Trager and Bloch 1941). A juncture phoneme is the only possible tool to refer to non-phonological information. Previously, it was semantics that was allowed to enter the phonological level (the notion of meaning employed in the discussion of minimal pairs); now 
it is morphology, though in a covert form. Structuralists argued that juncture phonemes are not established to show grammatical boundaries and the fact that they frequently coincide with them is purely accidental. It is possible to find junctures without a grammatical boundary, e.g. in Pla+to ${ }^{9}$ and a grammatical boundary without juncture, e.g. find her, which is frequently pronounced as finder in English (Fischer-Jørgensen 1975: 96). Harris (1951) also maintains that junctures and grammatical boundaries need not coincide, but at the same time he states that "the great importance of junctures lies in the fact that they can be so placed as to indicate various morphological boundaries" (1951: 87 after FischerJørgensen 1975: 96). Fischer-Jørgensen (1975: 96) points out that a juncture phoneme is somewhat peculiar in being characterized by heterogeneous features. As a result, the criterion of phonetic similarity cannot be maintained. ${ }^{10}$

The most important reason behind the establishment of juncture phonemes was the economy of the inventory principle, according to which the phonemes should not be excessively multiplied. To see what exactly is under consideration, let us look at the examples in (12) (Gimson 1970: 214).

(12) a. you [ju:]

b. who [hu:]

c. hue [çju:]

The initial sounds of the words in (12) occur in contrastive distribution. The phonemic status of the glide [j] and the glottal fricative $[\mathrm{h}]$ is independently motivated, as illustrated in (13).

${ }^{9}$ In the word Plato, flapping does not occur, although the alveolar stop is in the foot position. The process is assumed to be blocked by a juncture.

${ }^{10}$ For a discussion of the juncture phoneme, see Chapter 4, section 4.2.4. The majority of post-Bloomfieldians adopted the notion of a juncture phoneme. However Fischer-Jørgensen (1975: 96) points out that Hockett (1955: 172) was the only structuralist who criticised this concept by calling it "a most unfortunate and misleading kind of hocus-pocus." 
(13) a. yet [jet] - bet [bet]; yet [jet] - let [let]; yet [jet] - set [set]

b. hat [hæt] - cat [kæt]; hat [hæt] - rat [ræt]; hat [hæt] - mat [mæt]

In accordance with structuralist principles, the palatal fricative [ç] should have the phonemic status as well, as it has the potential of contrasting the meaning, as in (12). However, Alfred Gimson observes that the distribution of this segment is restricted. The list of possible contexts is provided in (14) below.

(14) a. pure [pçjoə]

b. tune [tçju:n]

c. cure [kçjoə]

d. human [çju:mən]

The palatal fricative [ç] occurs after aspirated voiceless stops $(14 \mathrm{a}-\mathrm{c})$ and word-initially before the [j] glide (14d). Taking into account the minimal pairs presented in (12), the obvious interpretation would be to posit the phonemic status of [ç]. Yet, this solution would violate the economy of inventory principle, as the /ç/ phoneme would excessively increase the number of English phonemes. Thus, Gimson postulates to interpret $[c ̧]$ as the effect of the coalescence of $/ \mathrm{h} / \mathrm{and} / \mathrm{j} /$.

Finally, the economy of the inventory seems to be indirectly related with the principle of pattern congruity, which requires a symmetry of phonemic systems. It is assumed that languages have the tendency towards symmetry. Pike (1947: 116) argues that if there are contrasts such as $p-b$ and $t-d$ in a given language, it can be assumed that there is also a $k-g$ contrast, even if the data do not allow to state this decisively. The notion of the symmetry of phonemic systems is developed in Chapter 2 (the analysis of the angma in English) and Chapter 3 (the analysis of nasal glides in Polish).

In conclusion, it can be stated that the phoneme in the structuralist framework is an abstract theoretical tool. No references are made to its mental reality. Structuralists focus on the establishment 
of phonemes, not on alternations (Kruszewski's theory) nor oppositions (the Prague School). However, some structuralists have quite original conceptions regarding the basic phonological segment. Sapir refers to the psychological reality of the phoneme (see Chapter 2, section 2.2.4.1). Jones (the London School), on the other hand, defines the phoneme as a family of sounds. He holds the view that, although the phoneme encompasses a group of segments, it refers to concrete, physically observable speech sounds .

\subsection{Early Generative Phonology}

In generative phonology, basic segments are not defined by means of the analytical procedures that operate directly on corpus, "physical, raw data", as it is the case in structuralism (Halle 1959)." Rather, theoretical entities are used to make general and simple ("stateable") descriptions of all the facts, so the close relation with the physical entities is not necessary. As a result Halle, like Sapir, does not recognise the need for the phonemic representation, in addition to the morphophonemic one. There are only morphophonemes, whereas phonemes are replaced by segments, which, in turn, are composed of binary distinctive features. ${ }^{12}$ Another crucial entity is the boundary that is characterised by its effects on segments. In the SPE framework (Chomsky and Halle 1968), boundary features are given in the universal theory of language, together with the segmental features. They have no phonetic content and are divided into three main types, represented as: + (formative boundary), \# (a major syntactic or lexical category)

11 With regard to the status of analytical procedures in science, Halle makes an excellent comparison to chemistry. He argues that in chemistry there are "no distinct categories for the substances that can be identified by visual inspection vs. those that are identified by more elaborate techniques."

12 For details regarding the rejection of the phonemic level of representations, see Chapter 4 , sections 4.1 .4 and 4.1 .5 , in which the process of voice assimilation in Russian is analysed. 
and = (an "ad hoc boundary") that is used to prevent the application of certain rules. The + boundary is used to indicate the morphemic structure of a given word, as in (15a) below. The \# boundary signifies a major lexical (N, V, Adj) or syntactic (NP, VP) category, as in (15b). A phonological word is defined as a unit which is bounded by two such junctures and which contains no internal \#\# boundary. The example in (16c) illustrated the representation of a phrase (Chomsky and Halle 1968: 13).

(15) a. + tele+graph

b. blackboard: $\left[_{\mathrm{N}} \#\left[{ }_{\mathrm{A}} \# \text { black\# }\right]_{\mathrm{A}}\left[{ }_{\mathrm{N}} \# \text { board\# }\right]_{\mathrm{N}} \#\right]_{\mathrm{N}}$

c. telegraphic communication: \#\#\# tele+graph \#ic \# \#\# communicate \# ion \#\#

Certain affixes carry the \# boundary, e.g. -ing, -er (agentive), -ly as in (16).

(16) a. sing\#ing

b. sing\#er

c. halting\#ly

The justification for this representation is given by Chomsky and Halle (1968: 85). The phonological behaviour of certain affixes is the same as the behaviour of words. For example, the final $g$ is dropped after nasals in word-final position but it is present word-medially. As a result, the word sing, with the underlying representation being $/ / \mathrm{siNg} / /$, is pronounced as [sin], whereas the word mingle, with the underlying representation being $/ / \mathrm{mINgl} / /$, is pronounced as [mingl]. Before some affixes, such as -ing, - er, -ed, -ly the velar stop is deleted, hence, the difference in pronunciation between singer [sinr] and finger [fingr]. ${ }^{13}$

Let us now see how the generative SPE framework is implemented by considering an example of morphological alternations in Polish. The aim of the analysis of morphological alternations is

${ }^{13}$ For the discussion of the status of angma in English, see Chapter 2. 
to establish the underlying representation, from which the remaining forms are derived. Let us focus on the examples presented in section 1.2. The relevant forms are repeated in (17).

(17) a. chleb [xlep] "bread" (nom.sg.)

b. chlebka [xlep+k+a] "bread" (dimin. gen.sg.)

c. chleba $[\mathrm{xl} \varepsilon \mathrm{b}+\mathrm{a}]$ "bread" (gen.sg.)

d. chlebek $[\mathrm{xl} \varepsilon \mathrm{b}+\varepsilon \mathrm{k}]$ "bread" (dimin. nom.sg.)

The alternation concerns the voiced and voiceless labial stops $b$ and $p$. The voiceless sound [p] appears word-finally (17a) or before a voiceless consonant (17b), whereas its voiced counterpart [b] occurs before vowels (17c-d). Rubach (1982: 45-47) offers a generative account of this alternation.

There are two logical possibilities regarding the possible underlying form: either [b] is derived from //p// by a voicing rule, or [p] is derived from //b// by a devoicing rule. Yet, as Rubach points out, the potential rule of voicing would apply not only to [p] in chleba and chlebek, but also to [p] in words such as rzepa "turnip" or sklepem "shop" (instr.). Thus, the assumption of a voicing rule delivers an undesirable result.

The other logical possibility is to posit an underlying //b// that becomes voiceless in certain contexts. The devoicing rule proves to be common in Polish, as confirmed by the examples in (18). In Polish, all obstruents are devoiced before a pause or before a voiceless consonant.

(18) a. brzeg [bžદk] "egde" (nom.s.g) - brzegu [bžદg+u] "edge" (gen.sg.) b. krowa [krova] "cow" (nom.sg.) - krówka [kruf $+\mathrm{k}+\mathrm{a}]$ "cow" (nom.sg.dimin.)

Let us now reconsider the relevant examples stated in (17). The word chlebka [xlcpka] has two morphemes. After establishing the underlying representation of $/ / \mathrm{xl} \mathrm{cb} / /$, Rubach provides a generative account for the diminutive suffix. Again, two logical solutions are considered. Either the vowel $[\varepsilon]$ is inserted or it is 
deleted. In the former case, the underlying suffix is $/ / \mathrm{k} / /$, in the latter- $/ / \varepsilon \mathrm{k} / /$. However, adopting the insertion rule would lead to the analysis flawed from both the methodological and empirical points of view, as in words such as Irenka "Irene" (dimin.) $[\varepsilon]$ would have to be inserted and subsequently-deleted. The reason for this is the non-application of Nasal Assimilation (NA) in Irenka [irenka]. Thus, at a certain derivational level, the vowel blocks the assimilation process but in the end it deletes. The deletion rule, on the other hand, is independently motivated by pairs of words such as dech "breath" (nom.sg.) - tchu "breath" (gen.sg.) or pies "dog" (nom.sg.) - psa "dog" (gen.sg.). Rubach's formulation of $e$-deletion is the rule stated informally in (19) (1982: 47).

(19) $/ / \varepsilon / /$ is deleted if a vocalic ending is appended to the stem.

By combining the results, we arrive at the derivation of the word chlebka as presented in (20). The ordering of rules is crucial in achieving the correct result. After the application of the rule given in (19), the voiced obstruent [b] devoices in the context of the following voiceless obstruent [k]; thus, the direction of the process being leftward, the voice assimilation process is defined as regressive.

$$
\begin{array}{ll}
\text { (20) } / / \mathrm{xl} \varepsilon \mathrm{b}+\varepsilon \mathrm{k}+\mathrm{a} / / & \\
\mathrm{xl} \mathrm{b}+\mathrm{k}+\mathrm{a} & \text { e-deletion } \\
\mathrm{xl} \mathrm{p}+\mathrm{k}+\mathrm{a} & \text { Regressive Devoicing }
\end{array}
$$

In conclusion, the most significant issues in the SPE framework are: the rejection of phonemic representation, the concept of phonological boundaries and the idea of ordered rules. What is not emphasised, however, is the notion of the syllable.

In the SPE framework, the syllable is not recognised as a unit in formal analysis. However, Kahn (1976) argues that it is a necessary element in generative grammar, as it offers superior solutions in comparison with the linear, non-syllable-based accounts. One of the examples of rules that involve syllable-structure conditioning 
is $r$-Deletion in some dialects of English (called $r$-less). The relevant examples are presented in (21).
(21) a. rat [ræt]
b. cry $[\mathrm{krar}]$
c. pours $[\mathrm{po:z}]^{14}$
d. pour [po:]

The $[\mathrm{r}]$ is deleted before a consonant (2lc) or a word boundary (2ld). In the SPE view, the contexts in which [r] is deleted are represented by a linear rule as depicted in (22).

$$
\text { (22) } r \rightarrow \varnothing / \perp\left\{\begin{array}{l}
C \\
\#
\end{array}\right\}
$$

Kahn (1976: 23) points out that this is a "strange environment", since the two contexts have no phonological features in common and thus they do not form a natural class. The potential solution would be to modify the distinctive feature system so that the consonant and word-boundary would constitute a natural class. As Kahn mentions, Lightner (1972) associates word-boundary with silence. This assumption seems to be similar to Moulton's (1947) structuralist analysis of juncture in German (Chapter 4). Kahn argues against the attempts to specify word-boundaries for phonological features. First of all, it is not possible to construct a universal set of features, since in English alone, there are rules of both types: $[\mathrm{C}, \#]$ and $[\mathrm{V}, \#]^{15}$. Secondly, boundaries do not function in the same way as segments do. In particular, they do not occur in focus position of phonological rules (Kahn 1976: 25).

14 The evidence for having $r$ in the underlying representation is the word pouring [po:rin] or the phrase pour it [po:rit], in which $r$ is present in the surface representation. Kahn's original example is the word cart. However, there is no synchronic evidence for underlying $r$ in this word.

${ }^{15}$ For instance, the rule of vowel tensing. 
A syllable-based analysis of the rule in (18) involves the concept of coda. The instances of [r] that are deleted follow a vowel and-in Kahn's terms-stand "fully within that vowel's syllable" (1976: 106), which means that they appear in a coda position. Pre-vocalic [r] is never deleted, as in the word Mary or in the phrase Mister Adams ${ }^{16}$, which means that $[\mathrm{r}]$ is retained in an onset position. The syllabic representation of the words in (21) is given below. ${ }^{17}$

(23) a.

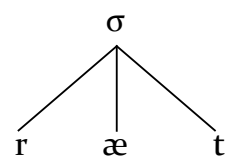

b.

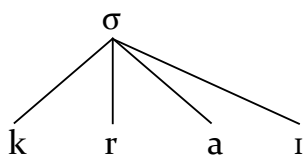

c.

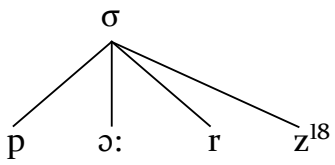

d.

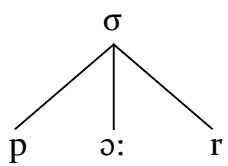

Thus, the rule of $r$-Deletion in (22) can be restated as a formally simple and elegant generalisation in which the concept of the syllable is employed.

${ }^{16}$ Kahn's data are drawn from the Eastern New England dialect, in which the pronunciation of the linking $r$ is obligatory.

${ }^{17}$ I omit the representation of length in (23c) and (23d).

18 I omit the representation of the third person singular form, as well as length here and in (23d). 


\section{Coda \\ $(24) \mathrm{r} \rightarrow \emptyset /$}

The representational hierarchy is further developed by Clements and Keyser $(1983)^{19}$, who introduce the CV-tier in addition to the syllable and the segmental tier. The elements of the CV-tier correspond to timing units: a single $C$ represents a single unit of timing, whereas a double $C$ represents a double timing unit. The need for this development is confirmed, for instance, by the structural representations of affricates versus clusters consisting a stop and a fricative. Clements and Keyser (1983: 17) offer the following analysis of the Polish minimal pair czy, "if" (25a) versus trzy, "three" (25b).

a. czy

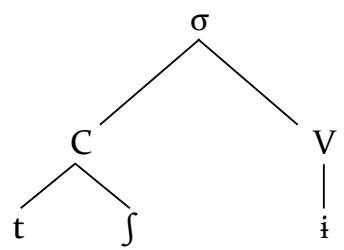

b. trzy

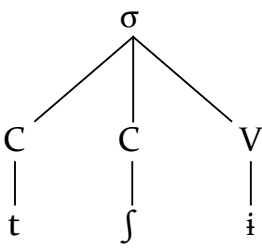

In (25a), a stop and a fricative constitute an affricate, which is formally represented by the fact that they occupy one timing unit at the CV-tier. Conversely, in (25b), [t] and [S] occupy two distinct timing units. The perceptual difference between the words in (25) is accounted for through the introduction of a CV-tier.

The SPE phonology constitutes a non-syllable-based theory. The introduction of the syllable tier (Kahn 1976) and the CV tier (Clements and Keyser 1983) seems to advance the generative theory by giving a remarkable insight into former's linear rules.

19 The development of the syllable-based theory is not part of the SPE framework, yet a sketch of this concept is provided in the present section, for it is connected with Kahn's views regarding the representation of phonological generalisations. 


\subsection{Natural Generative Phonology}

Though partly based on the principles of SPE phonology, Natural Generative Phonology (NGP) differs from the standard theory in defining acceptable linguistic generalisations and phonological rules, as well as the way in which it perceives the interaction of phonology and morphology.

In NGP, there is a distinction between phonetically conditioned rules on the one hand, and morphophonemic rules and via-rules on the other. The rule of flapping in English (wri[t]e wri[r]er), and the rule of syllable-final devoicing in German are P-rules (phonological rules) because they have purely phonetic conditioning, i.e. they must correspond to the physical details of articulation. There are no cases of opacity in P-rules - phonetic motivation is present on the surface.

As an example illustrating the tenets of Natural Generative Phonology, let us turn to Sanford Schane's (1968) analysis of nasalised vowels in French. According to Schane, there are no underlying nasalised vowels, but all surface nasalised vowels are derived from sequences of a vowel plus a nasal consonant. The vowel is nasalised if the nasal consonant is in the same syllable, and the consonant is subsequently deleted.
a) Nasalisation $\mathrm{V} \rightarrow[+$ nasal $] / \ldots$ [+nasal $]\left\{\begin{array}{l}\# \\ C\end{array}\right\}$
b) Nasal Deletion $\left\{\begin{array}{c}\mathrm{C} \\ + \text { nasal }\end{array}\right\} \rightarrow$
$\varnothing /\left\{\begin{array}{c}\mathrm{V} \\ + \text { nasal }\end{array}\right\}$

Thus un bon frere "good brother" is realized as [õ bõ frer], where underlying //bon// becomes [bõ]. If the nasal consonant is followed by a vowel, no nasalisation takes place: un bon ami "good friend" is realised as [oẽbonami].

In NGP, the nasalisation rule could not be formulated as a P-rule. The reason is that there are cases of a vowel plus nasal 
consonant followed by a consonant that do not undergo the rule, e.g. the feminine form bonne "good" in a phrase such as une bonne soeur "good sister" is realised as [bon], even though a consonant follows. Schane excludes the feminine form from undergoing the nasalisation rule by giving it an underlying final vowel //bonə //, so that at the point at which nasalisation applies, the $/ \mathrm{n} /$ is followed by a vowel. But in NGP, such a rule would not be considered as expressing true generalisations about French.

In NGP, a rule expressed in phonetic terms must actually correspond to the physical details of articulation. An alternation is phonetically motivated only if it always takes place when the phonetic motivation is present on the surface. If an alternation fails to take place when the phonetic environment is present (as in [bonsœr]), or takes place when the phonetic condition is not present (as in [bõfrer]), then it cannot be associated with a phonetic environment but must be associated with something else in the language, e.g., a particular morpheme, a syntactic category, etc. and, therefore, this kind of alternation would be called an MP-rule.

The phonological forms of underlying representations are closely related to surface phonetic forms by the Strong Naturalness Condition (Vennemann 1971, 1973) which states that "the underlying forms of nonalternating morphemes are identical to their phonetic representations". For alternating forms (a morpheme with one or more allomorphs), one of the allomorphs is chosen as the underlying form, and the others are derived from it (Hooper 1976: 111).

Adopting the NGP tenets, let us reconsider the example presented in section 1.4, namely, the derivation of the word chlebka [xlepka] "bread" (dimin. gen.sg.). The two rules in question are $e$-Deletion and Regressive Devoicing. Regressive Devoicing would be regarded as a P-rule, as it is phonetically conditioned and exceptionless. The $e$-Deletion rule, however, refers to a morphological condition, as the vowel is deleted only if a vocalic suffix is appended. Thus, it is an MP-rule. 
It seems that NGP and classic Generative Phonology (GP) adopt the same approach to phonetically motivated processes. The difference consists in the derivation of morphophonemic alternations. Alternations which NGP treats as a function of morphological and lexical categories, are described in GP as the result of abstract phonological representations and ordered rules (Hooper 1976: 21).

\subsection{Lexical Phonology}

To study the major tenets of Lexical Phonology, let us focus on the aforementioned alternations, which illustrate the rules of Regressive Devoicing and e-Deletion in Polish (see Chapter 1, section 1.4). The data in (16) show the alternation between the voiced and the voiceless labial in chleba [xleba] "bread" (gen.sg.) chlebka [xlepka] "bread" (dimin. gen.sg.). As stated in section 1.4, all obstruents in Polish are devoiced before a pause or a voiceless consonant, and the vowel $/ / \varepsilon / /$ is deleted if a vocalic ending is appended to the stem. In SPE phonology, the concept of the boundary is employed in order to state this rule. In the Lexical Phonology framework, boundaries are replaced by brackets and components in order to account for the interactions of morphology and phonology. I demonstrate the major principles of this framework, focusing on the derivation of the word chlebka [xlepka] "bread" (dimin. gen.sg.), underlying representation of which is $/ / x l \varepsilon b+\varepsilon k+a / /{ }^{20}$

The rule of $e$-Deletion, stated in (19), is conditioned by the internal structure of words, that is, it requires access to

${ }^{20}$ Following Rubach (1982), I take the diminutive suffix to be //عk//. Later research has shown that this $/ / \varepsilon / /$ is better analysed as a floating melodic segment (Rubach 1986, Kenstowicz and Rubach 1987). I will not pursue this hypothesis since my intention here is to illustrate the tenets of Lexical Phonology rather than to engage in a debate concerning the representation of Polish vowels. 
morphological information. The vocalic ending $a$, appended to the stem chlebek [xlcbck] causes the deletion of the vowel //ع// in the word chlebka [xlcpka]. This rule does not operate across words, which is confirmed by the phrases such as chlebek Adama [xlcbsk adama], "Adam's bread", in which the vowel $/ / \varepsilon / /$ in the $/ /-\varepsilon \mathrm{k} / /$ suffix is preserved. Consequently, the $e$-Deletion rule has to be lexical rather than postlexical. Remember that postlexical rules require access to syntax and are not conditioned by the internal structure of words. The other relevant rule, Regressive Devoicing, operates both within words and across word boundaries, therefore it is postlexical.

(27) a. chlebka $[x l \varepsilon p+k+a]$ "bread" (dimin. gen.sg.)

b. chleb który [xlıp kturi] "bread that"

The interaction of phonological, morphological and syntactic information is illustrated by the derivation of the word chlebka presented in (28). On the first cycle of the lexical component,

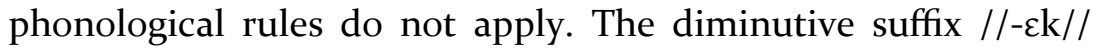
is added on Cycle 2 via a Word-Formation rule (WFR) and the genitive suffix //a// is appended on Cycle 3. At this point, $e$-Deletion can apply. Next, Regressive Devoicing changes //b// into [p]. At the end of each component, the Bracket Erasure Convention (BEC) applies and ensures that the morphological brackets introduced at an earlier level are erased before entering the next level. In Kiparsky's (1982) model, rules do not belong to components, but rather apply whenever the structural description is met. Given this assumption, Regressive Devoicing applies already in the lexical component.

$/ / \mathrm{xl} \varepsilon \mathrm{b} / /$

Lexical component

Cycle $1 \quad$ xleb

Cycle $2+\varepsilon k \quad$ WFR: $-\varepsilon k$ Suffixation 


\begin{tabular}{|c|c|c|}
\hline 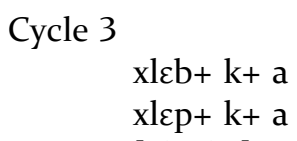 & $+a$ & $\begin{array}{l}\text { WFR: -a Suffixation } \\
\text { e-Deletion } \\
\text { Regressive Devoicing }\end{array}$ \\
\hline
\end{tabular}

The standard model in the Lexical Phonology framework (Kiparsky 1982) can be schematically represented in the following way (Kiparsky 1982 adapted by Booij and Rubach 1987: 2).

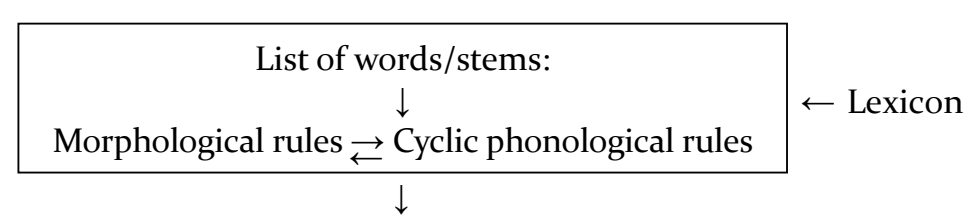

\begin{tabular}{|c|}
\hline Syntactic component \\
$\downarrow$ \\
\hline $\begin{array}{c}\text { Phonological component } \\
\text { (postlexical rules) }\end{array}$ \\
\hline
\end{tabular}

An important feature of Kiparsky's model is the principle of Structure Preservation (SP). In accordance with SP, only distinctive features may be inserted during the lexical phonology. To clarify this point, let us look at the rule of Surface Palatalisation in Polish. Polish consonants are palatalised before [i] and [j], as shown in (30), where $[\mathrm{m}]$ is used as an example.
(30) a. miasto [m'jasto] "city” (nom.sg.)
b. rybami [rib+am'i] "fish" (instr.pl.)
c. tam i tu [tam' i tu] "here and there"

Surface Palatalisation, which changes [m] to [m'], is postlexical, as it works both within words and across word boundaries. The palatalised $[\mathrm{m}]$ is a non-distinctive segment in Polish. Hence, SP blocks the application of Surface Palatalisation in the lexical component. It is only in the postlexical component that the rule can apply. 
In the above example, SP delivers the intended result. Yet, this principle has wider implications. I shall return to them in Chapter 4.

A further contribution to the model of Lexical Phonology is made by Booij and Rubach (1987). The rules operating in the lexical component are divided into two subtypes: cyclic and postcyclic ones. The evidence for the differentiation is given by Rubach (1993: 7).

In German, Final Devoicing (FD) applies at the end of the syllable, as shown in (31), with syllabification being cyclic.
(31) a. Hund [hont] "dog" (sg.)
b. Hunde [hond+a] "dog" (pl.)
c. Hundlein [hont+lain] "dog” (dimin.)

Final Devoicing is a lexical rule. Consequently, in accordance with Kiparsky's model presented in (29), FD applies cyclically. The predictions of this model are cited below (Rubach 1993: 8).
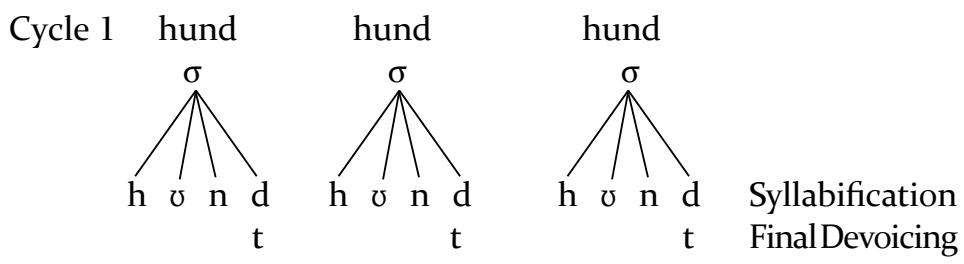

Cycle 2
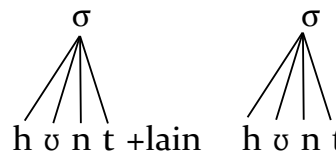

$\mathrm{h} \cup \mathrm{nt}+\partial \quad$ WFRs
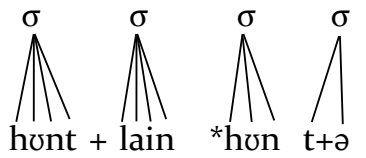

Syllabification

We obtain an incorrect result in the word Hunde *[hont+a] "dog" (pl.). In this model, all morpheme-final obstruents are predicted to be voiceless, since on the root cycle, the morpheme-final consonant 
is also syllable-final. Thus, FD applies and changes [d] to [t] not only in Hund and Hundlein, but also in Hunde.

Thus, FD cannot be cyclic, although it has to be lexical. Rubach (1993) states that FD applies only after the whole word has been derived or, in other words, it has to "wait" until the word has been syllabified. The lexical rules that are permitted to disregard the internal morpheme boundaries are called postcyclic. Let us study the predictions of Booij and Rubach's (1987) model in the process under consideration (Rubach 1993: 8).

(33)

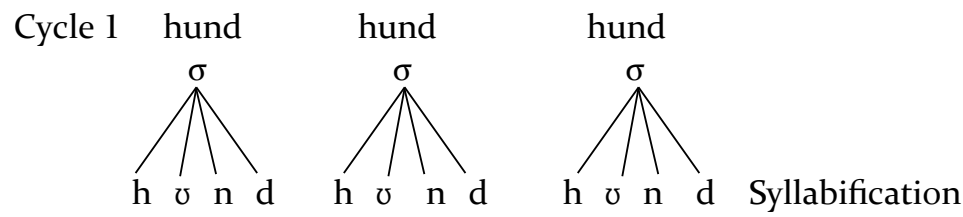

Cycle 2

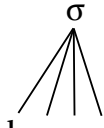

h $v$ n d +lain

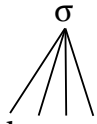

h $v \mathrm{n} \mathrm{d} \mathrm{+ \partial} \mathrm{WFRs}$

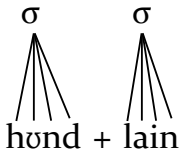

$\mathrm{t}$

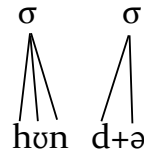

Syllabification

Postcyclic $t$

- $\quad$ Final Devoicing

In this view, FD cannot apply in the word Hunde, since in the postcyclic component, [d] is already in the onset, having been resyllabified on Cycle 2 in the cyclic component.

In sum, the novelty in the model developed by Booij and Rubach (1987) consists in the inclusion of a postcyclic component within the lexical one. Postcyclic lexical rules apply inside morphemes and across morpheme boundaries; they are not conditioned by the internal structure of words. This revised model (Booij and Rubach 1987: 3) is presented in (34). 
(34)

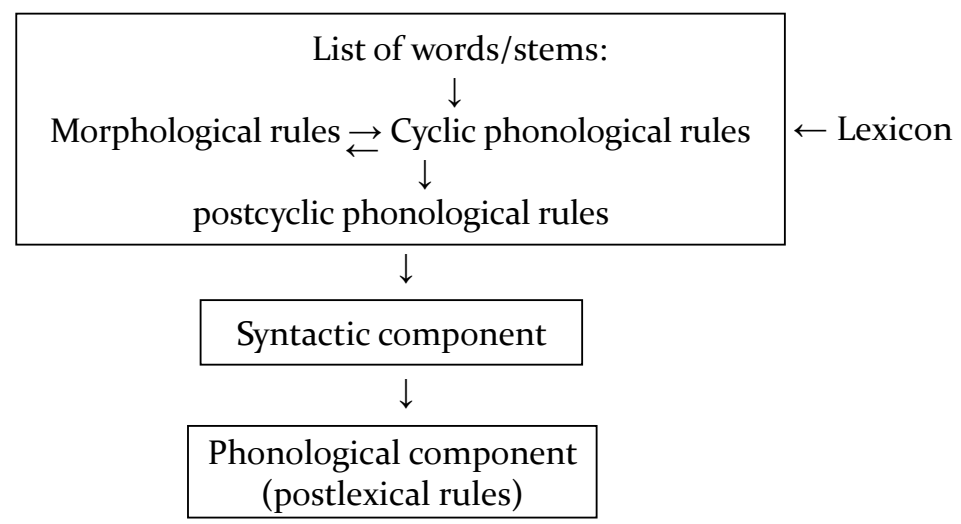

\subsection{Optimality Theory}

An OT grammar (Prince and Smolensky 1993) is an input-output device in which the optimal candidate is selected from a set of other candidates generated by the grammar. In this theory, generalisations are expressed in terms of ranked constraints rather than rules. Candidates are evaluated simultaneously (the principle of parallelism) to select the most harmonic output. The most harmonic, "winning" candidate is the one that incurs the fewest violations of higher-ranked constraints.

To illustrate the principles of OT, let us focus on one of the examples from the preceding sections, namely, the word chlep [xelp] "bread". The input form //xleb// and the output form [xlcp] are in correspondence, that is, each output segment is the "realisation" of an input segment, as presented in (35).

(35) Correspondence diagram of [xlep]

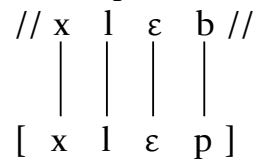


The two types of constraints that take part in the evaluation process are faithfulness and markedness constraints. Faithfulness constraints require that the output should preserve the properties of the input. In this case, one of faithfulness constraints is violated, namely, the IDENT ${ }_{\text {[voIce] }}$ constraint, which requires the input to preserve the feature [voice] in the output. However, constraints are violable, since the optimal candidate is [xlep]. The reason why [xlcp] wins is connected with a higher-ranked markedness constraint which militates against voiced obstruents in word-final position. In Polish, voiced obstruents in word-final position are prohibited, which is expressed by the constraint *VOICED ${ }_{\text {[oвstr] \# }}$. This constraint is violated by the form [xleb] and it is satisfied by $[\mathrm{xl} \varepsilon \mathrm{p}]$.

The two constraints impose conflicting requirements regarding the output forms. The conflict should be resolved by the constraint hierarchy. There are two logical possibilities regarding the hierarchy of the markedness and the faithfulness constraint, as shown in (36). ${ }^{21}$

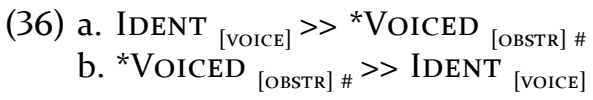

Let us discuss the two potential solutions by illustrating the ranking of the constraints with the help of tableaux. The ranking in (36a) is represented in tableau (37). The candidate which incurs a violation of a constraint is marked with "*”. The exclamation mark "!" indicates a fatal violation of a constraint and, consequently, the elimination of a candidate from further evaluation. The winner is marked with “四".

${ }^{21}$ Here and elsewhere, the constraints are cited from Prince and Smolensky (1993), unless stated otherwise. Some statements of constraints have been simplified. 
(37) $/ / \mathrm{xl} \varepsilon \mathrm{b} / /$

\begin{tabular}{|c|c|c|}
\hline & IDENT $_{\text {[VOICE] }}$ & *VOICED ${ }_{\text {[oBstr] \# }}$ \\
\hline a. $\mathrm{xl} \varepsilon \mathrm{p}$ & *! & \\
\hline b. xl\&b & & * \\
\hline
\end{tabular}

In tableau (37), the faithfulness constraint is ranked above the markedness constraint. Thus, the violation of IDENT ${ }_{\text {[voice] }}$ is fatal for the desired candidate [xlcp] and the obtained result is incorrect.

The other logical possibility is to re-rank the constraints, an operation represented in tableau (38).

(38) $/ / \mathrm{xl} \mathrm{cb} / /$

\begin{tabular}{c|c|c}
\hline & IDENT $_{[\text {OBsTR] } \#}$ & ${ }^{*}$ VOICED $_{[\text {VOICE] }}$ \\
\hline a. xlep & & $*$ \\
\hline b. xleb & $* !$ & $*$ \\
\hline
\end{tabular}

This time, we obtain the correct result, since candidate (38a) is the desired winner. In spite of violating the faithfulness constraint, it constitutes the most harmonic candidate, as *VOICED [овsтR] \# is ranked above IDENT ${ }_{\text {[VOIcE] }}$.

\subsection{Partial conclusions}

This chapter has illustrated the basic mechanisms of the frameworks relevant to the subsequent chapters. The analyses of selected phonological problems have served as examples showing the architecture of each phonological school. The most significant principles of each theory are elaborated on in Chapters 2-4. In particular, biuniqueness and overlapping (Chapter 2), the symmetry of the phonological system (Chapter 3), the levels of phonological representation (Chapter 4 ). 


\section{CHAPTER 2}

\section{BIUNIQUENESS AND OVERLAPPING}

This chapter focuses on the notions of biuniqueness and overlapping, which prove to be crucial in the process of establishing the basic phonological segment. Other issues, such as the formal recognition of the syllable in phonological analysis are also discussed. The status of a flap is analysed in section 2.1 and the status of angma - in section 2.2, with the process of flapping being restricted to the American English variety. Basic generalisations are stated in sections 2.1.1 and 2.2.1. Analyses in the relevant frameworks are presented in the ensuing sections. In some instances, classic analyses are cited, whereas in others I conduct simulations of analyses in accordance with the principles of a given framework. The classic analyses regarding the issues under consideration are, on the one hand, the works of Bloch and Sapir (structuralism) and Borowsky and Rubach (Lexical Phonology) on the other hand. I carry out simulations of analyses in the Kazan School, the Prague School, NGP and OT.

\subsection{The status of flap in American English}

The present section discusses the process of flapping in American English. Basic generalisations are provided in subsection 2.1.1. In the following subsections, the process is analysed from the perspective of selected phonological schools. One of the most important 
issues is overlapping in the structuralist framework. The classic analyses cited in this section are the works of Bloch (1941), Borowsky (1986) and Rubach (1996), which illustrate the relevant principles of structuralism and Lexical Phonology, respectively. In sections 2.1.2, 2.1.3, 2.1.6 and 2.1.8, I conduct analyses according to the principles of Kruszewski's theory of alternations, the Prague School, NGP and Optimality Theory, respectively.

\subsubsection{Basic generalisations}

The alveolar flap [ $[\mathrm{r}$ is one of the variants of coronal stops $t$ and $d$ in American English. It occurs intervocalically, as shown in (la). As a result, the words in (lb) have the same pronunciation in American English. The examples in (1c) show that there is no flapping if the vowel following the voiceless coronal stop $t$ is stressed. Rather, aspiration occurs in that context.

(l) a. bed [bed] - bedding [berın]; mud [məd] - muddy [məri]

b. writer [rarıər] - rider [rairər]

c. satirist ['særırıst] - satirical [sə't ${ }^{\mathrm{h}}$ IrIkəl]

\subsubsection{The Kazan School: Kruszewski's theory of alternations}

Kruszewski's study of alternations constitutes a detailed analysis with powerful theoretical predictions. It is based on the analysis of alternations, divided into divergents and correlatives (see Chapter 1, section 1.1). Several factors need to be considered before a given pair of alternants is assigned to an appropriate category. The factors are of unequal importance and the relations between them are crucial.

As shown by the examples in (lb), $\mathrm{c}$ alternates with $t$ between vowels, if the following vowel is unstressed. First, let us see whether $\mathrm{s}$ and $t$ can be classified as correlatives. Kruszewski presents a list of requirements that alternants should satisfy in order to be labelled as correlatives. The first criterion concerns 
the context of the change, which should be opaque, namely, it cannot be stated in purely phonetic terms. This is not the case in the process under consideration, as the context is stateable solely with regard to the neighbouring phonetic segments and the stress. Next, Kruszewski claims that the alternation may have exceptions, while the process of flapping is exceptionless. The relevance of morphological information constitutes the third characteristics, through which correlatives can be recognised. Again, this requirement is not met, since no access to morphological information is necessary to state the context of the change, which is confirmed by the examples in (2). The flap occurs in monomorphemic words (2a) and in complex words, both morpheme internally (2b) and at morpheme boundaries (2c).

(2) a. utter ['ərər]

b. Saturday ['særərdei]

c. writer ['raisər]

Finally, correlatives are not required to exhibit phonetic similarity. Moreover, the fourth criterion is considered to be imprecise by Kruszewski himself, and as such it is the least important factor in the analysis. Kruszewski upholds a claim regarding the hierarchy of the four factors. He argues that the first two requirements (the opacity of the process and its potential exceptions) are sufficient to identify the relationship between correlatives. They are labelled as more significant than the third criterion (relationships with morphology). Pulling together the results, I conclude that $t$ and $s$ are not correlatives of the first type.

The difference between the two types of correlatives is connected with the third criterion. The second type of correlatives, unlike the first one, is exceptionless within its restricted morphological scope. Thus, the analysed alternants do not belong to this type of correlatives.

In this case, the conclusion that should be drawn is that in Kruszewski's framework the discussed alternations are divergents. These can be recognised on the basis of the classification of four 
factors. First, the context of the alternation is transparent and as such can be stated in purely phonetic terms. As we know, the alternation under analysis complies with this requirement, as it makes reference to the phonetic quality of the neighbouring sounds and to the stress pattern. Secondly, divergents are supposed to be insensitive to morphological boundaries, which is the case in the process under analysis, as illustrated in (2) above. The third requirement, again fulfilled by the alternation, is for the process to be exceptionless. Finally, the fourth factor deals with the phonetic similarity of the alternating sounds. This appears to be problematic, because $[\mathrm{r}]$ is a sonorant, while $[\mathrm{t}]$ and [d] are stops, hence obstruents. However, the significance of the phonetic similarity principle is questionable since no formalism is offered in Kruszewski's framework, so there are no tools (such as distinctive features) to measure the similarity. Besides, it seems that Kruszewski himself does not acknowledge its cardinal importance. On the contrary, he points out that it is not necessary for divergents to satisfy this criterion. Thus, the fourth criterion is not significant, unlike the preceding three ones. Moreover, Kruszewski claims that, due to the close mutual relation between them, only one of the three criteria is enough to determine the divergent status of alternants. This is an insightful observation and a powerful claim. The relation between divergents is generalised through formalisation, as illustrated in (3).

(3) $x$ - the condition of the appearance of a sound $s$ / the context $s-$ a given sound $x_{1}-$ a condition which excludes $s$ and changes it into $s_{1}$ $s_{1}-$ a sound $s$ after a change

The $s$ sound is called original (primary) one, and the $\mathrm{s}_{1}$ sound is secondary. Divergents are a modification (fission) of the primary sound. To sum up the above arguments, I conclude that the alternating sounds under consideration, that is $t$ and $\mathrm{s}$, belong to the category of divergents, and as such they are allophones of a single phoneme, in modern terms. The formalisation is given in (4). 
(4) $x$ - word-final position, preconsonantal position ${ }^{22}$

$s-\mathrm{t}$

$x_{1}$ - intervocalic position, with the unstressed syllable following $s_{1}-\varsigma$

The analysis for $d$ would be parallel, namely, the flap would be analysed as a contextual variant (an allophone) of the $d$ phoneme.

\subsubsection{The Prague School: functionalist structuralism}

Although it is most renowned for the insightful observations concerning the suspension of oppositions, the Prague School of phonology also made a standard distinction between the basic and combinatory variant of a given segment. In modern terminology, we would use the terms phoneme and allophone to discuss these relations. Let us analyse the alternations: $t-\varsigma$ and $d-\varsigma$ with the use of the principles stated by Trubetzkoy.

As Trubetzkoy points out, if two articulatorily and acoustically related sounds never occur in the same environment, they are combinatory variants of the same phoneme. Therefore, it may seem that the flap should be regarded as a variant of a given coronal stop. Yet, let us repeat Trubetzkoy's statement concerning the allophone - phoneme distinction. In his view, if the two sounds cannot be interchanged without altering the meaning or making the word unrecognisable, they are realizations of two different phonemes (see Chapter 1, section 1.2). The change of $t$ and $s$ does not alter the meaning. What seems to be problematic is the statement "making the word unrecognisable". This criterion appears to be imprecise, as it lacks formalisation. Still, one may venture a claim that Trubetzkoy does not refer to the distinctions

22 The analysis of aspiration is beyond the scope of this chapter, which is the reason why I disregard the intervocalic position with the stressed syllable following (the context for the aspirated $t$ to occur). In Kruszewski's framework, only two-way alternations are analysed. Thus, he would presumably analyse the relation between the aspirated and non-aspirated $t$ as a separate alternation. 
of the considered type. Rather, he aims at covering the alternations presented in section 1.2 of Chapter 1, namely, Fisch - Fasch.

To summarise, in the Prague School framework, the alveolar flap should be analysed as a contextual variant of the alveolar plosive. Thus, the result of the analysis is similar to the one in the Kazan School framework.

\subsubsection{Distributional structuralism}

In the phonological frameworks analysed in the preceding sections, $ᄃ$ was considered to be a divergent of $t$ or $d$ (the Kazan School) or their combinatory variant (the Prague School). In both cases, the modern label of an allophone would be used to indicate the status of a flap. In the descriptivist-structuralist framework, however, the discussion regarding the status of a flap poses certain methodological problems due to the biuniqueness principle. Another issue of interest is the problem of phonemic overlapping, connected with the once a phoneme, always a phoneme principle (see Chapter 1, section 1.3).

Bloch (1941: 279) considers two contexts of flapping. ${ }^{23}$ A flap occurs intervocalically after a stressed vowel, as illustrated in (5a), and it follows th (5b). ${ }^{24}$

(5) a. butter ['bərər], betting ['berın], kitty ['kıri]

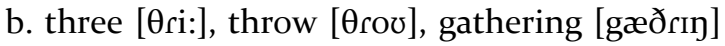

${ }^{23}$ Jones (1967: 96) also provides a distributional analysis of the two contexts in which a flap occurs. He states that in Saturday and beautiful a flap belongs to the $t$-phoneme, whereas in three and brethren-to the $r$-phoneme. In his analysis, the flap in three cannot come from $t$ due to the fact that $t h t$ is a possible sequence in English (earthed, berthed, Smithton). Thus, $t$ and $r$ overlap in the sound $r$.

${ }^{24}$ It is the American variety of English that is analysed in section 2.1. As Bloch (1941: 279-280) claims, in the speech of some Americans, an alveolar flap is the allophone of $r$ followed by dental fricatives. It should be added that in British English this is a more regular process. It is crucial, however, that Bloch observed these two contexts for flapping in one and the same variety, namely, American English. 
What is problematic from the structuralist perspective is the apparent violation of the biuniqueness principle. The segments $t$ and $r$ intersect (overlap) in the alveolar flap. In other words, the flap is the allophone of two phonemes, which is a highly undesirable outcome of the analysis.

Yet, as Bloch argues, the issue under consideration does not necessarily pose a significant problem for the structuralist analysis. The biuniqueness principle requires that phonemic representations should be uniquely recoverable from phonetic data. Actually, this principle is obeyed due to the possibility of allowing partial overlapping of phonemes. Partial overlapping is made distinct from complete overlapping, which is a crucial issue in Bloch's analysis. He defines two types of overlapping in the following way:

The intersection or overlapping of phonemes will be called partial if a given sound $\mathrm{x}$ occurring under one set of phonetic conditions is assigned to phoneme $\mathrm{A}$, while the same $\mathrm{x}$ under a different set of conditions is assigned to phoneme B; it will be called complete if successive occurrences of $\mathrm{x}$ under the same conditions are assigned sometimes to A, sometimes to B (Bloch 1941: 279).

It is the latter case that is unacceptable, as it constitutes a genuine violation of the biuniqueness principle. Partial overlapping, on the other hand, is allowed in structuralism. Flapping is an instance of partial overlapping and there is no uncertainty to which phoneme a flap should belong in each case. If it occurs between vowels, it belongs to $t$, and if it occurs after a dental spirant-to $r$. There is no confusion with regard to establishing the appropriate set of phonemes.

The problem of a flap belonging allophonically to two distinct phonemes seems to be resolved thanks to the principle of partial overlapping. Yet, there is an issue that Bloch does not consider. As pointed out in section 2.1.1, a flap can occur as a variant of both $t$ and $d$. The latter case is disregarded in Bloch's analysis. In fact, he seems to assume that there is no flapping in this context because he gives the examples of words containing $d$ as 
contrasting with the examples in (5a). The relevant examples are quoted in (6).

(6) a. budded ['badid]

b. bedding ['bedin]

c. kiddy ['kidi]

In Bloch's view, there is no flapping in the words in (6). Even if this were true, he seems to encounter a problem with regard to the once a phoneme, always a phoneme principle. In accordance with the structuralist principles, kitty and kiddy constitute a minimal pair. Consequently, both $d$ and $\mathrm{c}$ should be analysed as phonemes.

Actually, the alveolar flap is a contextual variant not only of $t$ but also of $d$. The problems that come to light in connection with this fact have wider theoretical implications. Let us focus on the example in (lb), that is, writer [raisər] and rider [rairər]. A flap replaces both the $t$ and $d$ phonemes, which is an instance of complete overlapping. It is impossible to recover the phonemic representations from phonetic data. In other words, the principle of biuniqueness is violated. Bloch's analysis seems to be flawed from both the methodological and the empirical points of view. The principle of biuniqueness is a core issue that causes analytical problems regarding the status of a flap.

\subsubsection{Early Generative Phonology}

In generative phonology, the analysis of flapping does not seem to be as problematic as in the structuralist account. The methodology of establishing underlying segments is different. Since the phonemic representation is rejected, the principle of biuniqueness does not play a role in the analysis. ${ }^{25}$ Thus, overlapping is not considered to be problematic. Moreover, in generative view,

25 See Chapter 4, section 4.1.4 for the discussion of Voice Assmilation in Russian in Halle's view, where he justifies the rejection of the phonemic representation. 
reference to the postlexical level can be made. Hence, examples such as get Ann [ger 'æn], in which a flap occurs, also need to be accounted for.

In the standard SPE framework, in which the syllable is not recognised as a unit in the analysis, the rule of flapping can be formulated as indicated in (7) (Kahn 1976: 95).

(7) $\mathrm{t} \rightarrow \mathrm{s} /\left[\right.$-cons] _ $(\#(\#))\left[\begin{array}{l}+ \text { syllabic } \\ \text {-stress }\end{array}\right]$

Phonological features are also used in the analysis, as shown in (8).

(8) $\left[\begin{array}{l}\text {-contin } \\ + \text { son }\end{array}\right] \rightarrow[+$ +sonor $] /[$-cons $] \_(\#(\#))\left[\begin{array}{l}+ \text { syllabic } \\ \text {-stress }\end{array}\right]$

Kahn (1976) is the first to incorporate the concept of the syllable in phonological analysis in a formalised way. He states that $t$ becomes a flap if it is tautosyllabic with a following [+syllabic] element (1976: 97). Only non-aspirated $t$ 's are subject to flapping, as word-initial $t$ 's are always syllable-initial. The syllable-initial $t$ 's are aspirated, with the rule of aspiration being ordered before the rule of flapping. ${ }^{26}$ The ordering assures that $t$ in phrases such as buy tomatoes is aspirated. Kahn (1976: 98) postulates the rule of flapping as cited in (9). ${ }^{27}$

(9)

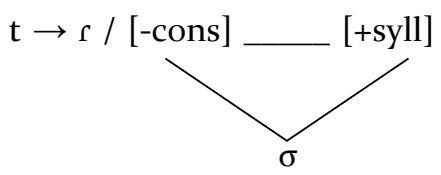

${ }^{26}$ Flapping is intricately connected to the process of aspiration and glottalisation. However, I focus on flapping, as analysis of both aspiration and glottalisation is outside the scope of the present dissertation. For details regarding the interrelation of flapping on the one hand, and glottalisation and aspiration on the other, see Kahn (1976: 98-106).

27 For clarity, I use the standard syllable symbol, although in Kahn's original the $S$ symbol is used. 
The analysis in which the syllable is recognised as a formal unit seems to be more effective than the standard SPE account, as it captures the generalisation in a more elegant way.

\subsubsection{Natural Generative Phonology}

As pointed out in section 1.5, rules in NGP are divided into phonologically-conditioned (P-rules) and morphophonologically-conditioned (MP-rules). MP-rules require access to morphological or syntactic information and they tend to have exceptions. P-rules, on the other hand, do not refer to morphological or syntactic information. However, they may refer to a syllable-conditioned context. P-rules constitute transparent generalisations, without exceptions or opacity. Flapping is therefore labelled a P-rule in NGP framework. Thus, there is no difference between Standard Generative Phonology and Natural Generative Phonology with regard to this process.

\subsubsection{Lexical Phonology}

In this section, I discuss two analyses of flapping conducted within the Lexical Phonology framework. Both of them, in line with Kahn's concepts, recognise the status of the syllable in phonological analysis. In the first analysis, Borowsky (1986) employs resyllabification, whereas in the second analysis, Rubach (1996) uses ambisyllabicity.

\subsubsection{Borowsky's analysis}

Borowsky (1986) supports resyllabification (Selkirk 1982) as the key to analysing flapping, stating that phonetic material is resyllabified from the unstressed to the stressed syllable. She does not account for the ambisyllabicity phenomenon, assuming that it is a purely phonetic process.

The diagram illustrating resyllabification is given in (10). 
(10)
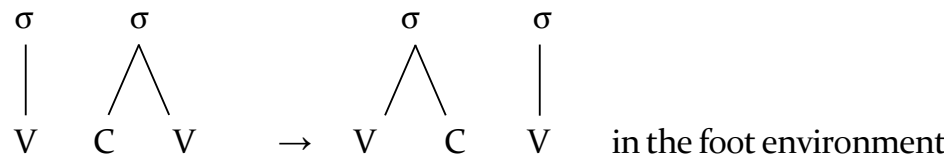

The consonant from the onset of the unstressed syllable is first dissociated and then attached to the coda of the preceding syllable. Flapping occurs in the above context, which explains the difference between atom $[\mathrm{r}]$ and atomic $\left[\mathrm{t}^{\mathrm{h}}\right]$. The representation of resyllabification in the word atom is provided in (11).

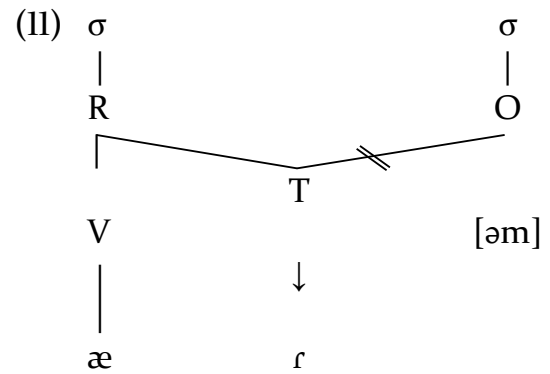

Yet, phrases such as get Ann appear to be problematic in this view, since the word Ann in this example is stressed. Borowsky claims, however, that flapping depends on the final position in the syllable rather than on the preceding vowel being stressed and the following unstressed, the rest being merely phonetics. ${ }^{28}$

${ }^{28}$ Another problem in Borowsky's analysis is how to account for the optional glottalisation of the final obstruent in get. The solution adopted by Borowsky, is to treat both flapping and glottalisation as phonetic implementation rules. The features that are implemented are [+release] and [-release], in order to obtain either $s$ or $t^{2}$.

a) Flap: $t, d \rightarrow c\left({ }_{\sigma} \ldots[\right.$-cons $\left.][+ \text { release }]_{\sigma}\right)$

b) Glott: $\mathrm{p} \mathrm{t} \mathrm{k} \rightarrow \mathrm{p}^{2} \mathrm{t}^{2} \mathrm{k}^{2} /$ [-release]

If a segment is both syllable-final and released, it becomes a flap; if it is, on the other hand, unreleased it is glottalised. Borowsky, however, does not use the feature [+release]. Rather, she interprets this as a factor of phonetic implementation. For details, see Borowsky (1986: 265). 
Resyllabification applies throughout phonology, both in the lexical and postlexical components, that is, whenever its structural description is met. Flapping is restricted from applying in the lexical component by the principle of Structure Preservation, which prohibits the insertion of non-distinctive features in this component. $^{29}$

\subsubsection{Rubach's analysis}

In contrast to Selkirk (1982) and Borowsky (1986), Rubach (1996) argues for ambisyllabicity to be incorporated into phonological analysis, not merely as phonetic spell-out. The concept of ambisyllabicity was introduced by Anderson and Jones (1974) and developed in Kahn's autosegmental framework. The evidence for ambisyllabicity is confirmed by English native speakers' intuitions. Both resyllabification and ambisyllabicity turn an open syllable into a closed one, but ambisyllabicity does not remove the linking of the segment in question to the onset, as indicated in (12) (Rubach 1996: 218).

(12) a. Resyllabification

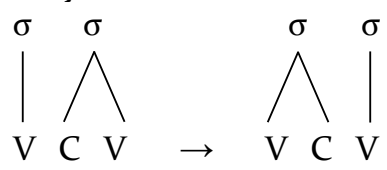

b. Ambisyllabification

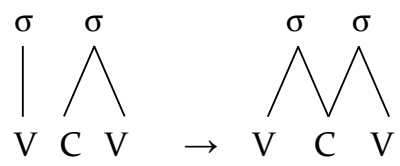

In the case of adopting resyllabification (Myers 1987), it may be assumed that it has two expansions, as shown in (13). The grids

29 For details regarding the Structure Preservation Principle and its consequences for the theory, see Chapter 4 , sections 4.1 .7 and 4.2.7. 
are used to indicate stress, that is, a stressed syllable has two grids (cited from Myers 1987).

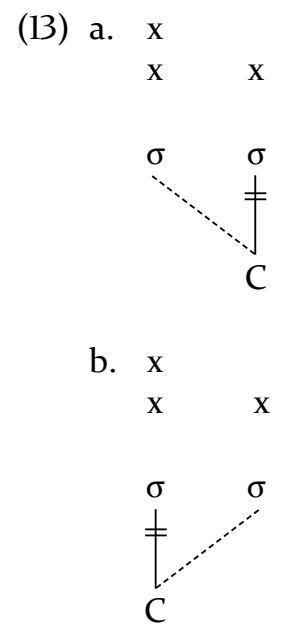

As Rubach points out, both (13a) and (13b) are necessary. The alveolar stop $t$ in atomic must be in the onset as it is aspirated. The rules in (13) are not applicable because the vowel following $t$ is stressed. In contrast, the $t$ in atom precedes an unstressed vowel, so it undergoes (13) and hence is subject to flapping.

There are two types of ambisyllabicity rules, namely, Coda Ambisyllabicity and Onset Ambisyllabicity, which have distinct generalisations. The former applies if the preceding syllable has no coda and the following syllable is unstressed. The onset consonant is linked to the coda of the preceding syllable, as indicated in (14).

(14) Coda Ambisyllabicity<smiles>CCOCC[V]</smiles> 
Due to the fact that in the above rule the following vowel is unstressed, rather than the preceding stressed, ambisyllabicity is possible also in case of both vowels being unstressed, so (14) predicts that the $t$ in, for example, divinity will be ambisyllabic and hence it will turn into a flap. This is the current prediction, so (13) must be rejected in favour of (14).

Flapping occurs also when $t$ and $d$ are ambisyllabic in accordance with Onset Ambisyllabicity (15), as in the phrase about Ann.

(15) Onset Ambisyllabicity

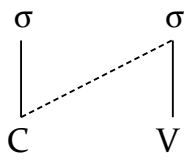

The status of both rules is different. Onset Ambisyllabicity is postlexical as it applies across word boundaries, as in about Ann. Coda Ambisyllabicity cannot apply in such contexts since there is no flap in buy tomatoes. Thus, the latter rule is lexical and postcyclic. ${ }^{30}$

As the evidence for ambisyllabicity, Rubach provides an analysis which seems to be less abstract than resyllabification alone, grasping the intuitions of native speakers at the same time. The segment $r$ appears as a tap ${ }^{31}$ in Received Pronunciation in intervocalic position or after a vowel and before a syllabic consonant if the following syllable is unstressed-in (a) but not in (b) below.

(16) a. tap: courage, very, sorry

b. r: courageous, reduce, red, bright, Henry

c. tap: for example

30 Flapping occurs in non-derived environments, as in city [r], so it cannot be a cyclic rule.

31 "Tap" and "flap" are two names for the same sound. The reason for the different terms is the source of $[\mathrm{r}]$ : from $/ / \mathrm{r} / /$ or from $/ / \mathrm{t} \mathrm{d} / /$, hence tapping and flapping, respectively. 
Ambisyllabicity makes an important distinction between the words in (16a) as opposed to those in (16b), namely, only the words in (16a) have an ambisyllabic $r$. The tap appears in the coda, the presence of $r$ in the onset being irrelevant here.

Rubach gives further evidence for ambisyllabification rather than resyllabification, including dark $l$ and tapping in English. He presents the data cited in (17).

(17) a. clear 1: leap, like, telling, all over

b. dark 1: bell, tell Tom, always

c. clear 1: million

d. dark 1: always

The $l j$ cluster is a possible onset in English, whereas * $/ w$ is not. Therefore, the generalisation is that clear $l$ appears in onsets (and not merely before vowels, dark $l$ being "the elsewhere case"). This is confirmed by the phrases such as tell it or all over, which may have clear $l$. The example is the alternation Bill [1] - Billy [1]. Ambisyllabicity accounts for these facts with its Coda version.

(18)

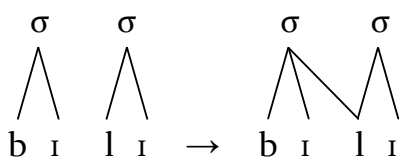

In contrast to the Ambisyllabification analysis, the Resyllabification analysis is problematic because $l$ appears in the coda, which produces an incorrect result. Therefore, the analysis has to have an intermediate representation, as shown in (19).

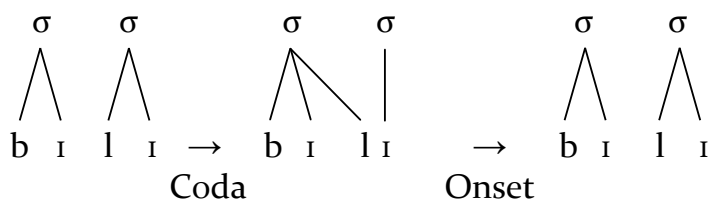

Resyllabification Resyllabification 
This representation seems to be unnecessarily abstract, with the intermediate representation having little justification.

\subsubsection{Lexical Phonology: partial conclusions}

Syllable-conditioning is recognised in both analyses discussed above. The difference consists in applying either the concept of resyllabification (Borowsky) or ambisyllabification (Rubach). It seems that the latter analysis captures he relevant generalisations in a more elegant and effective way, at the same time accounting for the intuitions of native speakers.

\subsubsection{Optimality Theory}

As stated in the preceding sections, post-SPE analyses typically assume that flapping occurs in coda position. Adopting this view seems to be interesting from the perspective of Optimality Theory, which began as a theory of the syllable.

There is cross-linguistic preference for certain syllable types, namely, syllables prefer to begin with a consonant and end in a vowel (Jakobsonian's universal). Thus, if a consonant occurs intervocalically, it forms the onset of the following syllable (20a) rather than the coda of the preceding syllable (20b).
(20) a. VCV $\rightarrow$ V.CV
b. VCV $\rightarrow$ VC.V

In OT, the observation regarding syllable types can be captured in an effective way by formulating the implicational universal for syllable onsets and syllable codas. A well-known observation that all languages allow onsets and none excludes them can be represented by the ranking of two constraints: ONSET and No-CODA, stated in (21).

(21) a. ONSET: Syllables must have an onset.

b. No-CODA: Syllables cannot have a coda. 
The implicational universals for syllable onsets and codas are cited in (22) (Jakobson 1962).

(22) a. If a language has syllables that lack an onset, then it also has syllables that have an onset.

b. If a language has closed syllables, then it also has open syllables.

There are four logical possibilities regarding the types of syllables, as illustrated in (23).

(23)

\begin{tabular}{c|c|c}
\hline Syllable type & ONSET & No-CODA \\
\hline a. CV & & \\
\hline b. CVC & & $*$ \\
\hline c. V & $*$ & $*$ \\
\hline d. VC & $*$ & \\
\hline
\end{tabular}

Typology predicts that CV is the perfect syllable, as single intervocalic consonants are universally syllabified as onsets rather that codas.

Ambisyllabicity poses a problem from the perspective of OT. In accordance with the principles and predictions stated above, an intervocalic consonant in atom should belong solely to the onset of the following syllable. Thus, it is predicted that no flapping should occur in this context, which is counterfactual. In order to account for the rules that apply in the ambisyllabic context, it seems that a constraint "Have a coda" (CODA) should be postulated. This assumption, however, weakens the predictive power of the theory in a highly undesirable way.

\subsubsection{Flapping in American English: partial conclusions}

The analysis of flapping in American English leads to certain conclusions regarding the role of theoretical "artefacts" that play 
a role in establishing the phonological status of a given segment. In particular, the structuralist principle of biuniqueness proves to be problematic, as it causes analytical problems concerning the status of a flap (section 2.1.4). In the remaining frameworks, a flap is analysed as a contextual variant of $t$ or $d$.

\subsection{The status of angma in English}

This section discusses the status of angma in English from the perspective of selected phonological schools. The classic analyses cited in this section are the works of Sapir (1925) and Jones (1967) in the structuralist framework (section 2.2.4), Chomsky and Halle (1968) in the SPE framework (2.2.5), and Borowsky (1986) in the Lexical Phonology framework (2.2.7). In sections 2.2.2, 2.2.3, 2.2.6, I conduct analyses according to the principles of Kruszewski's theory of alternations, the Prague School and NGP, respectively. The analysis in terms of OT is provided in section 2.2.8.

\subsubsection{Basic generalisations}

The status of angma in English has been a controversial issue in a number of phonological frameworks. The problem whether to analyse it as a basic unit (phoneme) or a contextual unit (allophone) is solved in distinctly different ways, depending on the tenets of a given theory.

The distribution of the velar nasal in English is presented in (24). The analysed segment occurs in word-final position of monosyllabic words (24a), in which it can also be followed by a voiceless velar stop, as illustrated in (24b). In disyllabic monomorphemic words, $\eta$ can be followed by a voiced velar stop (24c), while in disyllabic complex words, $g$ is silent $(24 \mathrm{~d})$. There is a small group of complex words, in which both $\eta$ and $g$ are pronounced (24e). These words constitute a grammatical category of the comparative degree. 
(24) a. sing [sin]; long [lon]

b. sink [sink]

c. finger [fingə]

d. singer $[\sin +\partial]$; singing $[\sin +\mathrm{In}]$

e. longer [long+ə]

The distribution of the velar nasal in English is restricted, i.e. it never occurs in word-initial position.

\subsubsection{The Kazan School: Kruszewski's theory of alternations}

Kruszewski's theory constitutes a study of alternations, which means that the analysis of segments that do not alternate is beyond the scope of his theory. As a consequence, words such as sink [sıjk], bank [bæyk] or finger [fingə] are not subject to analysis. Rather, it should be assumed that the velar nasal in these words is of phonemic status.

Therefore, let us focus on the alternations involved in the present analysis, which are repeated in (25).

(25) a. sing [sin] - singer [sin+o]

b. long [lon] - longer [long+ə]

In Kruszewski's view, the analysis of the examples in (25a) is straightforward. The velar nasal occurs as a morphological alternant in both words under consideration and therefore we should postulate its phonemic status. The alternation in (25b) is more complicated. In Kruszewski's theory, the phoneme may correspond to several sounds or even to one sound and a certain feature of another sound. Thus, in Kruszewski's terms, Russian ml' in земля "earth" is a phoneme, as it alternates with $m$ in земский "earthly". This theoretical assumption leads to interesting phonological predictions in the present analysis. The morphological alternants in (25b) are $\eta$ and $\eta g$, which means that both $\eta$ and $\eta g$ have a status of phonemes. 
In Kruszewski's framework, /y/, /g/ and /gg/ are all phonemes. There are no formalised tools that would allow for an analysis in which $\eta$ would be derived from $n$. Kruszewski does not deal with distributional facts, which are crucial in the generative account (see Chapter 2, section 2.2.5). On the other hand, he is not restricted by structuralists principles such as biuniqueness or once a phoneme, always a phoneme (section 2.2.4). Rather, he is preoccupied with the functional account of phonological facts. It is a theory of representations rather than rules. As a result, the functional analysis of angma conducted in his framework strikingly differs from the analyses discussed below.

\subsubsection{The Prague School: functionalist structuralism}

In accordance with the principles of the Prague School framework, sounds that cannot replace each other without changing the meaning of the word obtain phonemic status. Thus, the phonemic status of angma in English should be recognised on the basis of pairs of words such as $\sin [\sin ]-\operatorname{sing}[\sin ]^{32}$

Yet, sometimes the contrast between an alveolar nasal and a velar nasal is suspended, as shown in (26).

(26) a. bank [bænk]; sink [sink]

b. finger [frngə]; hunger [h^ggə]

The concept of the archiphoneme $N$ is a crucial tool in this analysis, as it represents the neutralisation of contrast between $n$ and $\eta$ before a following $k$ or $g$. The archiphoneme $N$ lacks the value for place, since it encompasses the features common to both members of the pair. In other words, $N$ carries the features "nasal" and "stop" but it is unspecified for "place". The representation of the relevant contexts is provided in (27).

32 Vachek (1964) argues that angma may be perceived as one of "peripheral phonemes", having no stable status in the phonological system of Modern English. 
(27) Lexical form: $\{\mathrm{n}+\mathrm{k}\}\{\mathrm{n}+\mathrm{g}\}$

Phonemic form: /N+k/ /N+g/

Phonetic form: $[\mathrm{n}+\mathrm{k}][\mathrm{y}+\mathrm{g}]$

The analysis of words such as longer [lpy+o] (one who longs) as opposed to longer [long+ə] (the comparative degree of the adjective) belongs to morphophonology rather than to phonology. This discipline has a separate status in the Prague School system. Morphophonology deals with morphological conditioning of the alternation, e.g. if a given segment occurs only in a specified morphological class.

Although the Prague School framework deals with representations and not rules, certain insightful generalisations can be deduced from the former. On the basis of the representation in (27), it can observed that $n$ assimilates its place of articulation with the following stop. The archiphoneme proves to be a useful tool for capturing important phonological generalisations.

\subsubsection{Distributional structuralism}

This section discusses the analyses conducted by Sapir (section 2.2.4.1) and Jones (section 2.2.4.2). Partial conclusion are summarised in section 2.2.4.3.

\subsubsection{Sapir's analysis}

According to Sapir (1925), the English nasal stop $\eta$ does not have the same phonemic status as $m$ or $n$, hence it does not stand in correspondence with an oral stop $g$ in the way in which the pairs $b: m$ and $d: n$ do. Native speakers, as he points out, do not perceive $m-n-\eta$ as the same kind of chain as $p-t-k$. Sapir offers a detailed distributional analysis of the latter group of phonemes, pointing to the characteristics that they share.

First of all, $p, t, k$ occur initially, medially, finally, as exemplified in (28a). They may be preceded by $s(28 \mathrm{~b})$ and they may be followed by $r(28 \mathrm{c})$. Next, they may be simultaneously preceded 
by $s$ and followed by $r$ (28d). All the segments under consideration have voiced correspondents, that is, $b, d$ and $g$, respectively. Finally, they are not closely associated with the corresponding spirants, $f, \theta$ and $x$.

(28) a. pay [per], spot [spot], lip [lip] tick [trk], stand [stænd], lost [lpst] cat [kæt], scan [skæn], lock [lok]

b. speak [spi:k], stay [ster], skip [skip]

c. pray [prei], tray [trer], cry [krai]

d. sprain [sprein]; stream [stri:m]; scream [skri:m]

On the other hand, Sapir claims that there is a correspondence between sink and sing, similar to that between ant and and. Furthermore, he notices that $\eta$ has restricted distribution as it cannot appear initially. Sapir accounts for the absence of $g$ in singer (as opposed to finger) by saying that medial elements are treated in terms of their final form (here sing), as in cutter - cut. Besides, he observes that -er has "the reality of a word which occurs as the second element of a compound" as different from -er in the comparative.

Sapir rejects the hypothesis that $\eta$ has the same status as other nasal stops, that is, $m$ and $n$. He emphasizes the limited distribution of angma and points to the intuitions of native speakers, as well as the psychological reality of phonemes:

In spite of what phoneticians tell us about this sound ( $b: m$ as $d: n$ as $g: \eta)$, no naïve English-speaking person can be made to feel in his bones that it belongs to a single series with $m$ and $n$. Psychologically it cannot be grouped with them because, unlike them, it is not a freely movable consonant (there are no words beginning with $\eta$ ) (Sapir 1925: 24).

\subsubsection{Jones's analysis}

According to Jones (1967), a British structuralist, the phoneme is a family of sounds. It is a class of phonetically related sounds, one of which is the principal member, and the remaining ones are allophones, or "conditioned variants". The principal member 
of the phoneme is the one that is produced in isolation or that is intermediate among its subsidiary members. The members of the same phoneme should be related in character, therefore, phonetic similarity also plays a role here. The word is the basis for his analysis, otherwise, as he states, it might be impossible to establish a set of phonemes in a given languages since "variations of sound at word junctions may take so many forms" (1967: 10). Yet, numerous problems arise due to this restriction. One of the examples is 3 as used in the phrase please yourself. Jones wonders whether this sound is the same as the 3 in prestige or just similar to it. As a result of the biuniqueness principle, Jones's conclusion is that if it is the same, then the speaker substitutes /3/ for / $\mathrm{z} /$ used in please; if not - then [3] is a subsidiary member of $/ \mathrm{z} /$. In accordance with the general structuralist theory, a sound cannot belong to two phonemes, yet there are exceptions to this rule. Jones does not support the view that phonemes are ideal sounds as it is impossible to demonstrate that "different uttered sounds are realisations of the same ideal sounds and not realizations of different ideal sounds" (1967: 204).

It is axiomatic for Jones that a given sound belongs to a single phoneme. He addresses the hypothesis that $\eta$ belongs to the $n$-phoneme in ink, but is a separate phoneme in sing. It seems that an argument supporting this hypothesis is of distributional nature. It is always $\eta$ that appears in the context of $k$, and never $n$, which means that they are in complementary distribution. In the case of sing, however, $\eta$ and $n$ are in contrastive distribution, since one can find minimal pairs such as sing and sin. Jones concludes that the whole theory is unworkable. If $\eta$ can belong to $n$ in ink but not in sing, then a logical consequence would be to assume that $m$ should belong to the $n$-phoneme in lamp but not in ham, or, the opposite, $m$ in lamp and $n$ in end-to the $\eta$-phoneme. The same principle holds for $s$ as belonging to $z$ in stand and box since $z$ cannot occur in such situations. He concludes that "it would not be feasible to invent a definition of a phoneme which would allow for such possibilities" (1967: 98). 
Jones admits that certain sounds could be di-phonemic, i.e. assigned to two phonemes depending on the context. He states that this solution cannot be justified on phonetic grounds but is convenient from a linguistic point of view and confirmed by external facts from the history of sounds. Another possibility is to assign the two sounds to one phoneme at random, which produces good results, though no grounds for choice are offered. Finally, it is possible to assume that a given sound constitutes a separate phoneme, independent of the other two phonemes, yet it would entail the addition of an unnecessary letter into broad transcriptions. However, Jones does not allow a di-phonemic analysis of $\eta$. In his view, a velar nasal has a phonemic status.

\subsubsection{Distributional structuralism: partial conclusions}

Jones's analysis of the status of angma is conducted in accordance with the structuralist principles. He does not recognise an allophonic status angma, as it would violate the principle of biuniqueness ${ }^{33}$ and make the phonemic theory unworkable. Sapir, on the other hand, seems to be a forerunner of generativism, as he emphasises the restricted distribution of angma and the predictability of the contexts in which it occurs.

\subsubsection{Early Generative Phonology}

The concept of angma as an underlying segment is not an attractive solution in generative phonology. What is emphasised is the limited distribution of this segment and the alternations in which it occurs, such as: long [lon] - longer [long+a]. The methodology of establishing the basic phonological unit is different from the methodology employed in structuralism. Consequently, the predictions of this framework are also different.

33 Jones himself does not use this term (the same applies to terms such as contrastive and complementary distribution). In practice, however, this idea is present in his work. 
In SPE (Chomsky and Halle 1968: 85), the underlying representation of sing is //siNg// and of mingle $-/ \mathrm{miNgl} / /$, //N// being the archi-segment. This concept resembles the notion of the archiphoneme in the Prague School phonology (section 2.2.3). The rule of Nasal Assimilation, stated informally in (29), assimilates the place of articulation of the nasal and the following segment, changing //N// to $\eta$.

(29)

$$
\left[\begin{array}{l}
+ \text { nas } \\
+ \text { coron }
\end{array}\right] \rightarrow[+ \text { velar }] /-\left[\begin{array}{l}
+ \text { obstr } \\
- \text { cont } \\
+ \text { velar }
\end{array}\right]
$$

In the present analysis, it is the velar place of articulation that is assimilated. Yet, the alveolar nasal $n$ assimilates the place of articulation of other stops, e.g. labials, as illustrated by words such as impossible. In order to account for this fact, the rule in (30) should be postulated.

(30)

$$
\left[\begin{array}{l}
+ \text { nas } \\
+ \text { coron }
\end{array}\right] \rightarrow[+ \text { labial }] /-\left[\begin{array}{l}
+ \text { obstr } \\
- \text { cont } \\
+ \text { lab }
\end{array}\right]
$$

The rules in (29) and (30) were combined to express the generalisation in a more elegant way. The adopted concept was that of $\alpha$-place, which captures the assimilation facts in a more general and unified way, as cited in (31). The nasal segment assumes the place of articulation of the following stop. ${ }^{34}$

${ }^{34}$ Nasal Assimilation applies in words such as Birmingham [ $\left.\mathrm{n}\right]$ and dinghy [n], as well. These instances are rare but they pose a problem from the perspective of the rule in (31), as there is no velar stop following. The SPE analysis is as follows. The underlying representation of these words is //N $+\mathrm{x} / /$. The nasal assimilates to the following velar, as it does in think or finger. Then, $x$ is deleted after a consonant. 
(31)

$$
[+ \text { nas }] \rightarrow[\alpha \text { place }] /-\left(\begin{array}{l}
+ \text { obstr } \\
- \text { cont } \\
\alpha \text { place }
\end{array}\right)
$$

Let us now focus on the issue of $g$-deletion. The voiced velar stop $g$ is deleted in word-final position but remains word-medially: bring [y] but mingle [ng]. The velar stop $g$ is also dropped before certain affixes that carry a \# boundary in SPE phonology, e.g. -ing, er (agentive), -ly: /bring \# Ing/ and /sing\#ər/ vs. /longər/.
(32) a. /sing\#ər/ [sınər]; /briNg \# ing/ [brinın]
b. /loNg+or/ [longa]

In (32b), the \# boundary is erased by a language-specific rule, e.g. through eliminating a lexical category from the surface structure before \# is inserted (as the \# boundary signifies a lexical category). As a result, $g$-deletion does not apply, which motivates a boundary distinction in the SPE framework.

$$
\left[{ }_{\mathrm{A}}\left[{ }_{\mathrm{A}} \text { long }\right]_{\mathrm{A}} \partial \mathrm{r}\right]_{\mathrm{A}} \rightarrow\left[_{\mathrm{A}} \text { long }+\partial \mathrm{r}\right]_{\mathrm{A}}
$$

Thus, the words listed in (34) below (the examples come from Chomsky and Halle 1968: 367) are assigned an internal \# boundary via the convention cited below, as they contain a word belonging to lexical categories: differ $(\mathrm{V})$, ring $(\mathrm{V})$, language $(\mathrm{N})$, establish $(\mathrm{V})$.

The boundary \# is automatically inserted at the beginning and end of every string dominated by a major category, i.e., by one of the lexical categories "noun", "verb", "adjective", or by a category such as "sentence", "noun phrase", "verb phrase", which dominates a lexical category (Chomsky and Halle 1968: 366).

(34) a. differing

b. ringing

c. metalanguage

d. establishment
$\left[_{V} \#\left[{ }_{V} \text { differ\# }\right]_{V} \text { ing }\right]_{V}$

$\left[{ }_{V} \#\left[\left[_{V} \# \text { ring\# }\right]_{V} \text { ing\# }\right]_{V}\right.$

$\left[{ }_{\mathrm{N}} \# \text { meta }\left[{ }_{\mathrm{N}} \# \text { language } \#\right]_{\mathrm{N}} \#\right]_{\mathrm{N}}$

$\left[_{\mathrm{N}} \#\left[{ }_{\mathrm{V}} \# \text { establish } \#\right]_{\mathrm{V}} \text { ment } \#\right]_{\mathrm{N}}$ 
The convention which introduces the \# boundary is responsible for the processes of final $g$-deletion illustrated in (35). ${ }^{35}$

$$
\left[{ }_{V} \#\left[{ }_{V} \# \text { sing } \#\right]_{V} \text { ing } \#\right]_{V}
$$

In sum, the angma cannot be analysed as an underlying segment in SPE phonology. Rather, it is derived from the //N// segment, which assumes the place of articulation of the following stop.

\subsubsection{Natural Generative Phonology}

In the NGP framework, the angma in words such as bank or sink would be regarded as an underlying segment, since they do not have alternations. The NGP principle called the Strong Naturalness Condition (Vennemann after Hooper 1976) requires that "the underlying forms of nonalternating morphemes are identical to their phonetic representations" (Hooper 1976: 111). In accordance with this condition, surface forms should be related to one another in the most direct way. For alternating forms (a morpheme with one or more allomorphs), one of the allomorphs is chosen as an underlying form, and the others are derived from it (Hooper 1976: 111). This approach seems to resemble Kruszewski's assumption according to which the non-alternating forms are beyond the scope of the theory (see Chapter 2, section 2.2.2).

Let us therefore turn to the analysis of the alternations involving $g$-deletion. The relevant examples are repeated in (36).

35 Similarly, the convention which introduces the \# boundary is responsible for other processes apart from $g$-deletion, such as the non-application of the laxing rule before non-dental clusters, so that *wipt is non-existent (see Chomsky and Halle 1968: 369). Yet, in the form kept, the laxing rule operates, which is analysed as the subsequent elimination of the \# boundary by a language-specific rule (the same as in longer) in a subcategory of irregular verbs such as keep, lose and weep. It is represented in the following way:

${ }_{V} \#\left[\left[_{V} \# \text { kep\# }\right]_{V} d \#\right]_{V} \rightarrow\left[_{V} \#\left[_{V} \# \text { kep\# }\right] d \#\right]_{V}$ (see Chomsky and Halle 1968: 369). 
(36) a. long [lpy] - longer [lpy+a] 'one who longs'

b. long [lon] - longer [long +2$]$ 'the comparative degree of long'

As mentioned before, there are two major types of rules in the NGP framework: P-rules and MP-rules. P-rules do not have access to morphological or syntactic information, but they can make use of the notion of the syllable. Even though the context in which $g$ disappears could be connected with syllable structure ${ }^{36}$, this generalisation cannot be subsumed under the notion of a P-rule. The analysis needs to be carried out on the morphophonemic level, as it refers to morphological and syntactic categories, such as "the comparative degree" in (36b).

It seems that an important observation has been lost in the NGP framework, namely, this of a limited distribution of angma, which was significant already in Sapir's account. Like biuniqueness in structuralism, the requirement of "naturalness" in NGP weakens the predictive power of the theory, as it disregards the predictability criterion.

\subsubsection{Lexical Phonology}

This section is based on Borowsky (1986) and, as far as the major syllable-based generalisations are concerned, on Kahn (1976).

English velar nasal $\eta$ is derived by assimilation from an underlying sequence $/ / \mathrm{N}+\mathrm{g} / \mathrm{k} / /$. Its limited distribution, that is, the reason why $g$ does not surface, is caused by English syllabification restrictions. The clusters of $g$ and a nasal are not permitted in English, for instance, the pronunciation of the word gnat is [næt], not [gnæt]. In words such as angma, $g$ cannot be in the onset (as shown in 37b) and it deletes (37a), a generalisation that was discovered by Kahn (1976). The syllable-based representation of the word angma is provided below (Borowsky 1986).

36 This assumption, based on Kahn's (1976) ideas, is presented in the succeeding section, devoted to Borowsky's analysis. 
(37) a.

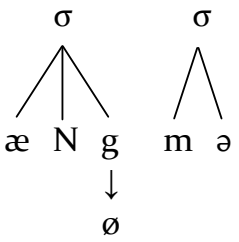

b. ${ }^{*} \sigma$
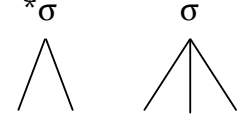

æ $\mathrm{N}$

$\mathrm{g} \mathrm{m} \partial$

Words such as England or angry, on the other hand, do not violate the syllabification pattern. The velar stop can syllabify into the onset, since $g l$ and $g r$-onsets are well-formed, compare gleam [gli:m] and green [gri:n].

Furthermore, the notion of the syllable enables us to explain the gap in the distribution of $\eta$, namely, the fact that there is no angma in initial position. The reason for that lies in the fact that, as already mentioned, $N+g$ is not a possible onset in English. Yet, the word singing [sinın] seems to be a counterexample, since the expected pronunciation is *[singin], with $g$ forming a perfect onset. Still, however, $N+g$ are assumed to be in the coda, rather than in the onset. In Borowsky's account, this is assured by employing resyllabification (see Chapter 2, section 2.1.7.1). As illustrated in (38), first the velar stop forms the onset of the unstressed syllable and subsequently it resyllabifies to the coda of the stressed syllable. Finally, $g$ deletes.

(38)
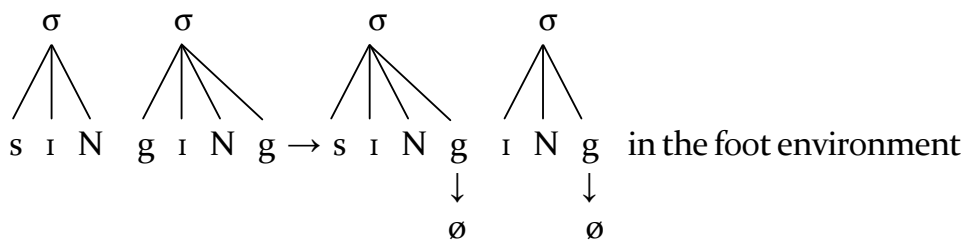

Thus, there is no underlying $\eta$-phoneme in English. Formally, this is rendered by a marking condition (Kiparsky 1985) which prohibits 
marking of velarity to a [+nasal] segment (39a), as opposed to $m$ and $n$, which are marked for, respectively, labiality and coronality (39b-c).

(39) a.

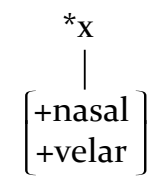

b.

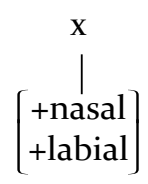

c.

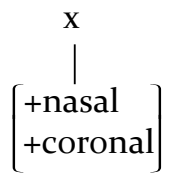

As stated above, the velar nasal is not present in the underlying representation. Rather, it is derived from the placeless nasal archiphoneme. The archiphoneme assumes the place of the following obstruent by the rule of Nasal Assimilation (NA), as represented in (40) (Borowsky 1986).

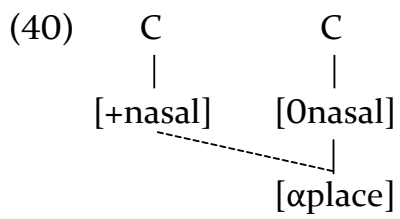

The rule of Nasal Assimilation derives all homorganic clusters, not only velar, but also labial and coronal, as exemplified in $(41) .{ }^{37}$

37 If NA does not apply, the archi-nasal is specified as coronal by the default rule [ ] $\rightarrow+$ cor . Moreover, NA is blocked in words with prespecified nasal segments, such as, Canberra, Camden or melancholia. 
(41) a. pump [p^mp], bomb [bom]

b. lend [lent], sent [sent]

After NA has applied, voiced stops $g$ and $b$ delete if they are tautosyllabic with the preceding nasals.

$\left.(42) \mathrm{g}, \mathrm{b} \rightarrow \varnothing / \mathrm{N}_{-}\right)_{\sigma}$

The examples cited from Borowsky (1986) are presented in (43).

(43) a. $/ / \mathrm{p} \wedge \mathrm{Np} / / \rightarrow[\mathrm{p} \wedge \mathrm{mp}] ; \mathrm{NA}$

b. //bnNb// $\rightarrow$ [bom]; NA; $b$-deletion

c. //siNg// $\rightarrow$ [sin]; NA; $g$-deletion

In Lexical Phonology, rules apply at distinct levels. It is assumed that English has between two and four levels of morphology in the lexicon. In Kiparsky's view (1982), there are three levels in English, while Halle and Mohanan (1985) posit four levels, as stated below.

(44) Level 1: Class 1 derivation, irregular inflection Level 2: Class 2 derivation

Level 3: Compounding

Level 4: Regular inflection

According to Halle and Mohanan, the rules of $g / b$-deletion apply at level 2 but not at level 1. In Borowsky's view, however, rules are not restricted to levels, as predicted by the Strong Domain Hypothesis (see Chapter 4, section 4.1.7). Thus, the processes of $g$-deletion and $b$-deletion are available already at level 1 , but they are blocked because the final consonant is regarded as invisible to both syllabification and deletion. This is subsumed under the notion of extrametricality (EM), accounting for the phonological behaviour of segments at the edges of domains. Extrametricality entails invisibility of one designated segment at the beginning of phonological derivation. Later, it turns off and the segment in question may take part in phonological processes. 
In the processes under consideration, extrametricality plays a significant role. As shown in (45), at the beginning of the derivation, $b$ is extrametrical, and hence-invisible to the phonological rules. In Borowsky's view (1986: 80), NA and deletion can take place only with metrically associated segments (45a). When suffixes are attached, the segment may be syllabified and is not deleted (45b).

(45) a.

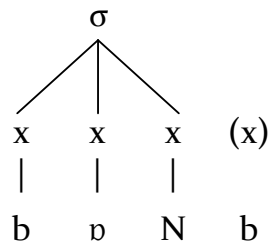

b.
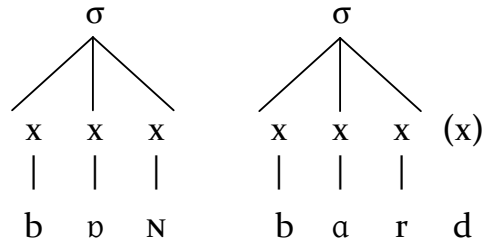

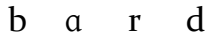

syllabification

NA

$\mathrm{m}$

$g / b$-del

Morpheme internal $g$ and $b$ are not deleted when they can be syllabified into the onset or the rhyme. The final $b$ in bomb is metrically associated at level 2, where both NA and $b$-deletion take place.

Let us now consider the analysis of the words in (46), namely, angma, in which $g$ is syllabified into the rhyme of the first syllable, NA takes place and $g$ deletes, and England, in which $g$ is incorporated into the onset of the second syllable, where it remains (cited from Borowsky 1986: 81). ${ }^{38}$

(46) a. angma

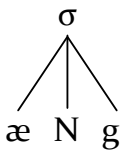

y

ø

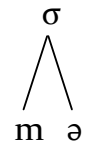

)

( b. England
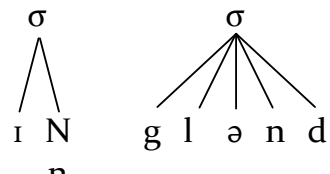

Syll

y

NA

g/b-del

38 Prior to deletion, //N// assimilates to //g//, yielding [ $\mathrm{p}$. 
At level 2, extrametrical consonants are syllabified, then they go through the word cycle (on the unaffixed word), and if they are tautosyllabic, undergo deletion. The derivation of the velar nasal must take place at level 2, as Structure Preservation ${ }^{39}$ does not block it any longer.

Further examples illustrating the assumptions of Borowsky are pairs of words such as long - longing. At level 1 , the final $g$ in long is extrametrical $\left(\operatorname{loN}(\mathrm{g})_{\mathrm{EM}}\right)$. Thus, NA cannot take place, as $g$ is not metrically associated with the syllable node. However, at level 2, $g$ stops being extrametrical and is syllabified, hence is tautosyllabic with $n$. Nasal Assimilation and $g$-deletion can apply on the word cycle before affixation of -ing, since $g$ is never saved by syllabification to the following syllable. The outcome of the analysis is the form [lonin] and not *[longin].

Overall, at level 1, the crucial processes are mute, since the relevant consonants are extrametrical. At level 2, they are no longer extrametrical; therefore they are linked to the syllable node. They undergo a cycle on the word before any affixation takes place. The rules of Nasal Assimilation and $g / b$-deletion can finally apply.

\subsubsection{Optimality Theory}

In Optimality Theory, generative rules are expressed as ranked constraints, by interaction of which candidates are evaluated. The constraints that prove significant in the present analysis are stated below.

(47) a. NA: A nasal and a following obstruent agree in place.

b. $\left.{ }^{*} \mathrm{Ng}\right]_{\sigma}$ : No clusters of a nasal and a velar stop in coda position.

c. MAx: No deletion.

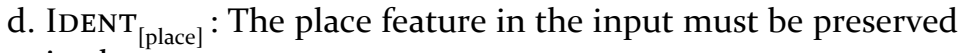
in the output.

39 For the discussion of Structure Preservation, see Chapter 4, sections 4.1.7 and 4.2.7. 
e. STRICT LAYER: Constituents of a given type may embed constituents only of the next lowest unit in the prosodic hierarchy.

f. Contiguity: Segments in the output form a contiguous string.

Constraint (47b) constitutes an instance of Coda Condition, a classic phonological generalisation regarding the strength relations within the syllable. It is in the syllable-final position that lenition processes (e.g. deletion or neutralisation) tend to occur. ${ }^{40}$ The constraint in (47e) goes back to the Strict Layer Hypothesis (Selkirk 1984), concerning the hierarchy of the following prosodic categories: syllable, foot, Phonological Word, Phonological Phrase and Intonational Phrase. In this analysis, STRICT LAYER prohibits joining $g$ to the Phonological Word. The ConTIGUiTY constraint (47f) allows to delete segments at the edges, but prohibits to delete segments in the middle.

Let us consider a preliminary evaluation in terms of OT, as presented in (48). The segments are enumerated for ease of reference. The actual output in (48a) loses, as compared with its contender, candidate (48d). Both candidates violate the MAX constraint, but candidate (48d), the winner, satisfies

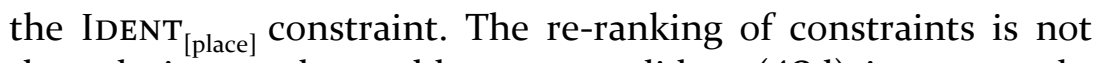
the solution to the problem, as candidate (48d) incurs a subset of the violations of candidate (48a). In other words, there is no imaginable constraint ranking under which candidate (48a) can win.

40 A similar generalisation was made already by Kruszewski (1967 [1880]: 19), who differentiates between sound deletion in particular positions within a word. He observes that there are few examples of deletion in the onset of a word. In the coda, however, all sounds disappear, even those which would never be deleted in other positions. Kruszewski (1967 [1883]: 80) tries to explain this phenomenon with reference to the meaning - the onset is the main carrier of the meaning, which could explain the quicker changes in the middle part of the word and in the coda . 
(48)

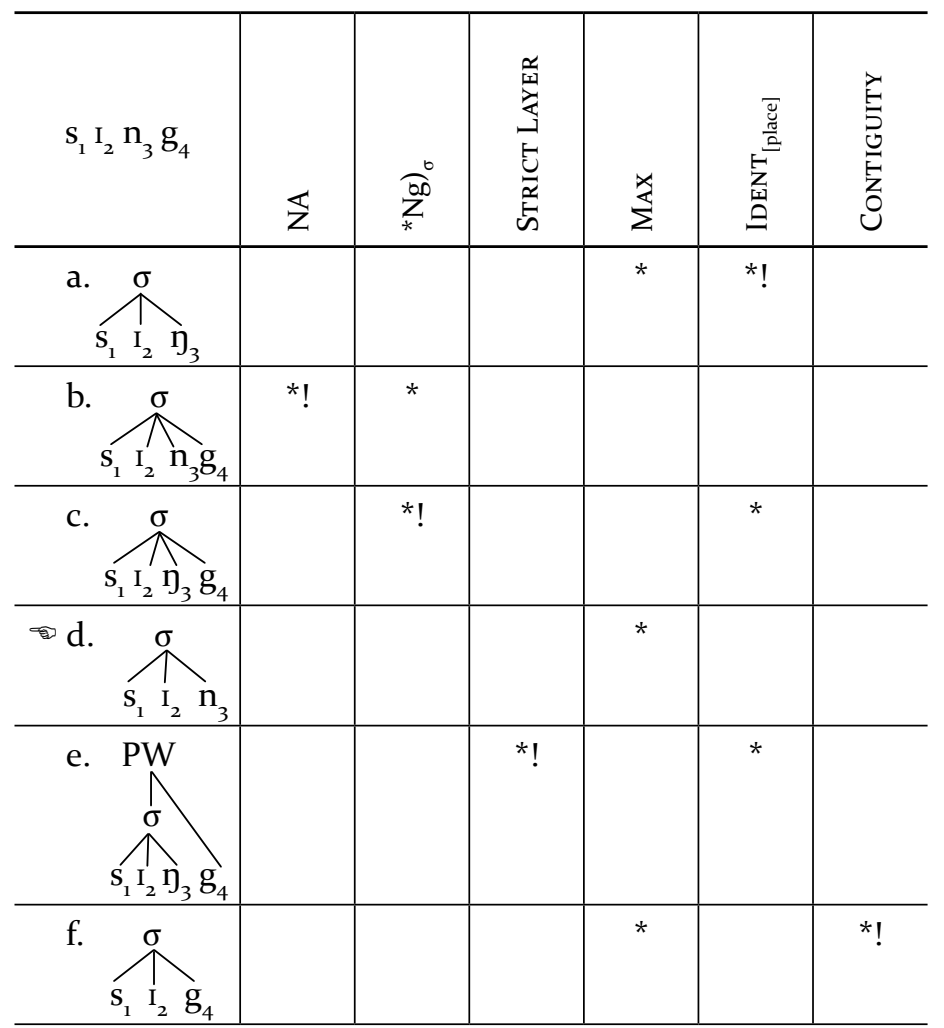

It seems that the analyses of Nasal Assimilation and $g$-deletion pose a problem for Optimality Theory. In a classic generative account, distinct derivational stages need to be employed. First, the coronal nasal assumes the place of articulation of the following stop. Next, the stop deletes. Yet, standard OT does not allow for derivational stages, requiring the evaluation to be parallel. ${ }^{41}$ It seems that the only solution is to accept angma in the

${ }^{41}$ The analysis is not problematic in Derivational Optimality Theory (DOT) (Rubach 1997), in which derivational levels are recognised. In a DOT account, MAx outranks $\left.{ }^{*} \mathrm{Ng}\right)_{\sigma}$ at level 1, deriving the intermediate stage /sing/. At level $\left.2,{ }^{*} \mathrm{Ng}\right)_{\sigma}$ is ranked above MAX, hence the deletion of $g$. 
underlying representation. However, such a decision would entail the loss of a significant generalisation concerning the predictability of contexts in which the velar nasal occurs. This problem is solved by coalescence.

In OT terms, the assimilation process under consideration is understood as coalescence (fusion). The obstruent in the input leaves its place of articulation to the nasal. The obstruent itself is not deleted, since it has correspondents in the output. MAX is not violated by our desired candidate with two indices. A new, low-ranked UNIFORMITY constraint prohibits fusion.

(49) UNIFORMity: No element of the output should have multiple correspondents in the input.

A revised evaluation is conducted in (50).

(50)

\begin{tabular}{|c|c|c|c|c|c|c|c|}
\hline $\mathrm{s}_{1} \mathrm{I}_{2} \mathrm{n}_{3} \mathrm{~g}_{4}$ & $\overleftrightarrow{Z}$ & $\overbrace{*}^{0}$ & 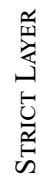 & $\sum_{\Sigma}^{x}$ & 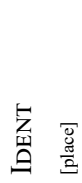 & 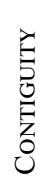 & 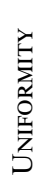 \\
\hline a. & & & & & $*$ & & $*$ \\
\hline b. & $* !$ & $*$ & & & & & \\
\hline $\begin{array}{cccc}c . & \sigma \\
\mathrm{s}_{1} & \mathrm{I}_{2} & \mathrm{y}_{3} & \mathrm{~g}\end{array}$ & & $* !$ & & & $*$ & & \\
\hline d. & & & & $* !$ & & & \\
\hline
\end{tabular}




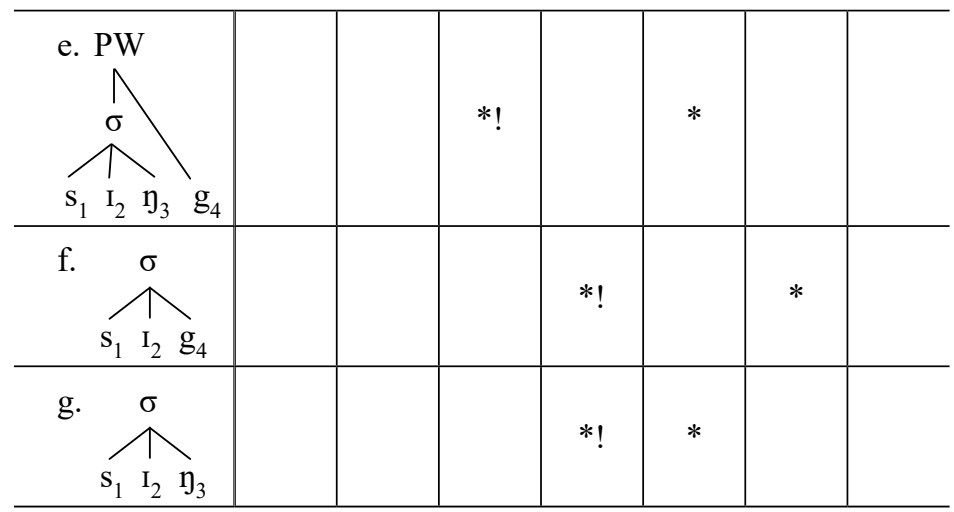

The requirement for parallelism forces OT to reanalyse Nasal Assimilation as coalescence. Otherwise, it is not possible to account for NA and $g$-deletion at one level.

In order to avoid underlying angma in English, Optimality Theory is forced to interpret Nasal Assimilation as coalescence. This approach differs from the preceding generative accounts, constituting the liability, an "artefact" of OT.

\subsection{Partial conclusions}

In Chapter 2, I have discussed the status of a flap and angma in English from the perspectives of selected frameworks. The core issues that have come to light are the structuralist principles of biuniqueness and overlapping (sections 2.1.4 and 2.2.4). The morphology-phonology interface is another significant factor that plays a role in the establishment of the basic phonological unit. In particular, it proves to be crucial in Kruszewski's theory of alternations and in the NGP framework (sections 2.1.2, 2.2.2, and 2.1.6, 2.2.6.). Finally, it is the notion of syllable-conditioned rules that provides elegant accounts of the two processes under consideration (sections 2.1.7 and 2.2.7). 


\section{CHAPTER 3}

\section{SYMMETRY OF A PHONOLOGICAL SYSTEM}

This chapter deals with nasal assimilation and selected aspects of nasal gliding in Polish, with the focus on the establishment of the basic phonological unit and the discussion of the methodological principles of each framework. One of the crucial issues that surfaces in this discussion is the structuralist ideal of the symmetry of phonological system. Other notions, such as biuniqueness and the Structure Preservation principle also prove to be significant. The presentation is organised as follows. Section 3.1 introduces the issue, presenting a list of the relevant classes of data. In the succeeding sections, the problem is analysed from the perspective of selected phonological theories, from the Kazan School to the Optimality Theory. In sections 3.2 and 3.3, I conduct the analyses in accordance with the principles of Kruszewski's theory and the Prague School framework. Leszek Biedrzycki's classic structuralist account is discussed in section 3.4. This approach is confronted with Rubach's generative analysis in section 3.5. In section 3.6, I analyse the processes by adopting the principles of Natural Generative Phonology. Section 3.7 presents Rubach's analysis in the Lexical Phonology framework. The OT perspective is characterised in section 3.8. Partial conclusions are summarised in section 3.9. 


\subsection{Basic generalisations: Nasal Assimilation and Nasal Gliding}

Polish nasal consonants assimilate the place of articulation of the following stop or affricate; the process is widely known as nasal assimilation and is illustrated in (1).

(1) a. bilabial

[mb]: rąbać "hew", gnębić "oppress"

[mp]: romb "rhombus", kompot "stewed fruit"

b. dental

[nd]: indyk "turkey", tędy "this way"

[nt]: kąt "corner", prezydent "president"

c. alveolar

[n̄č]: tęcza "rainbow" (nom. sg.), męczyć "to bother"

d. alveolo-palatal

[ndz]: (kiedy) indziej "some other time", będzie "be" ( ${ }^{\text {rd }}$ p.sg.fut.) [nt6]: chęć "will", ciąć "cut"

e. velar

[ng]: potęga "power"

[yk]: ręka "hand"; klękać "to knee”

f. alternations

ręka [nk] "hand" (nom.sg.) - ręce [nts] "hand" (dat.sg.)

wstęga [yg] "ribbon" (nom.sg.) - wstędze [ndz] "ribbon" (dat.sg.)

The process of nasal assimilation applies across morpheme boundaries, as illustrated by the words such as klać [klõn+t6], "to swear/ curse", or przeklęty [pšE+klen+t+i] , "cursed". The behaviour of words that are not completely nativised may be irregular, namely, assimilation need not take place, especially in careful speech, as indicated in (2).

(2) a. bank [nk] "bank"

b. hungarystyka [ng] "Hungarian studies"

c. angina [ng] "tonsillitis"

d. tango [ng] "tango"

e. sankcja [nk] "sanction" 
As mentioned above, the process of nasal assimilation takes place before stops and affricates. If a fricative follows, a nasal segment and a preceding vowel form a nasal glide (or "nasal vowel" in traditional terms). The process is called nasal gliding, and it is restricted to dental [n] and prepalatal nasal [n], as presented

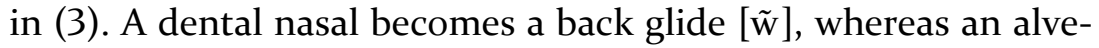

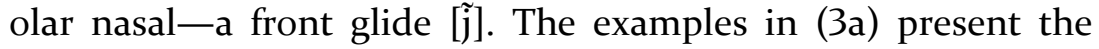
non-alternating instances of $[\tilde{w}]$, whereas the ones in (3b) and (3c) show instances of alternating forms employing, respectively, front and back glides.

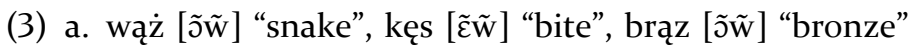

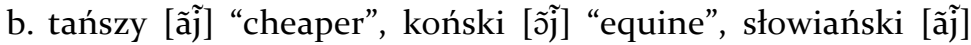
"Slavic", młyński [ĩj] "mill” (Adj.)

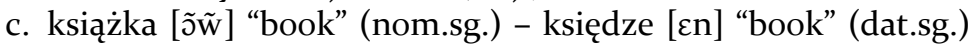
- księga [عj] "book" (nom.sg.)

Moreover, nasal glides occur in word-final position. The context is morphologically restricted to specific inflectional endings, such as the ones listed in (4).

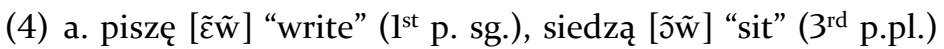

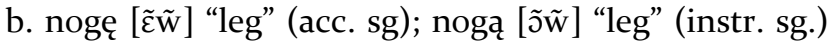

c. jagnię $[\tilde{\varepsilon} \tilde{\mathrm{w}}]$ "lamb” (nom.sg.neuter)

\subsection{The Kazan School: Kruszewski's theory of alternations}

This section deals with analyses of Nasal Assimilation and Nasal Gliding from the perspective of the principles of Kruszewski's theory of alternations. Kruszewski's theory constitutes a study of alternations, that is a study of sounds replacing each other under definable conditions. Depending on the type of alternations, members of a given pair of sounds can be classified as belonging to the same or different phonemes. Kruszewski distinguishes between 
two major classes of alternations, one of which is further divided into two subtypes.

Let us focus on the change from $n$ to $\eta$ in Polish, namely-on the aspect of Nasal Assimilation relevant for the present discussion. Divergents are recognised on the basis of the classification of four factors. First, the context of the alternation is transparent and as such can be stated in purely phonetic terms. As we know, this is not the case of Nasal Gliding because of words such as Irenka [nk], "Irene" (dimin.), where the assimilation does not take place. Consequently, we cannot conclude that the assimilation takes place before $k$ and $g$. Second, divergents are supposed to be insensitive to morphological boundaries. Again, the process under analysis does not conform to this requirement, as confirmed by the pair: i ręka [nk], "and a hand" - Irenka [nk] "Irene" (dimin.), where morphology is crucial in recognising the context of the change. The third requirement, also not satisfied by Nasal Assimilation, is for the process to be exceptionless. Finally, the fourth factor deals with the phonetic similarity of the alternating sounds. It seems that $n$ and $\eta$ may be classified as similar and the alternation as such fulfils the fourth requirement. Yet, this criterion is too imprecise to play a significant role in the analysis, which is stated by Kruszewski himself, who argues that it is not necessary for divergents to satisfy this criterion. Thus, the fourth factor is not compelling, unlike the preceding three ones. To summarise, the alternating sounds that take part in Nasal Assimilation do not belong to the category of divergents, and as such do not constitute the same phoneme.

Let us examine the alternations that appear as a result of Nasal Assimilation in order to discover which type of correlatives they represent. It turns out that one of the conditions studied above is still valid in our present discussion, namely, the one requiring alternations to be exceptionless. This requirement holds true not only for divergents, but also for one of the subtypes of correlatives. The second type of correlatives, unlike the first one, is exceptionless within its restricted morphological scope. Yet, it seems not 
possible to treat the analysed alternations as representatives of this category, for a precise morphological context of the alternations is not definable. To see what is at stake, let us compare the word piosenka, "song", with the word anglistyka, "English studies", in their separate morphological forms.

(5) a. piosenka [nk]

b. piosenki [nk]

c. piosence

d. piosenkę [nk]

e. piosenką [nk]

f. piosence

g. piosenko [nk] anglistyka [ $\mathrm{ng}$ ]

anglistyki [yg]

anglistyce [ng]

anglistykę [ng]

anglistyką [ng]

anglistyce [ng]

anglistyko [ng] (nom.sg)

(gen.sg)

(dat.sg)

(acc.sg)

(instr.sg)

(loc.sg)

(voc.sg)

The data in (5) show that the application of Nasal Assimilation is not determined by specific grammatical cases. Both piosenka and anglistyka are in the same case (nominative singular) but still they differ with regard to Nasal Assimilation. Another potential solution would be to claim that the assimilation does not apply in diminutive forms such as Irenka, "Irene" (dimin.), but this statement is again incomplete because of words such as rumianku, "camomile" (gen.sg), which is not in the diminutive form and yet the alternation does not take place. To recapitulate, the possibility that $n$ and $\eta$ belong to the second category of alternations is ruled out.

Thus, the conclusion that should be drawn is that in Kruszewski's framework, the alternations presented are correlatives of the first type. Let us see whether this indeed is the case. The first requirement for a given pair of alternants to be classified as correlatives concerns the context of the change, which is supposed to be opaque, that is, unstateable in purely phonetic terms. This is the case with the $n-\eta$ alternation, as it is not fully transparent. The context is difficult to establish due to the second criterion, that is, the existence of exceptions. Therefore, it may be concluded that the context is both phonetically and morphologically sensitive, which constitutes the third characteristics of this subtype of 
correlatives. The fourth criterion-phonetic similarity-seems to be violated, since $n$ and $\eta$ are related. Yet, this criterion is far from being decisive due to its vagueness. In sum, in Kruszewski's view, $\eta$ and $n$ are correlatives of the first type, that is, they are separate phonological units. In modern terms, it can be stated that $\eta$ is a phoneme and not just a contextual allophone of $n$.

What remains to be clarified is the status of the segments that participate in Nasal Gliding. Let us focus on a representative sample of examples in (6).

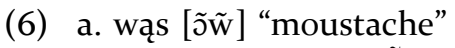

b. koń [n] - koński [j] "equine"

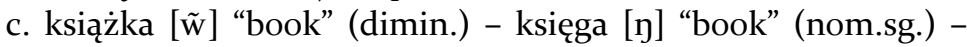
księdze [n] "book" (dat.sg.)

With regard to the example in (6a), it should assumed that in Kruszewski's framework nasal vowels would constitute unitary phonemes. Besides, his theory deals with alternations exclusively and therefore the example given in (6a) lies outside the scope of his study.

The alternation of $n$ and $\tilde{j}$ presented in (6b) is embraced by Kruszewski's theory. Let us demonstrate the mechanisms through which it is classified as belonging to one of the three types mentioned above. The context of the change is transparent $-\mu$ changes to $\tilde{j}$ before fricatives. The rule is not morphologically sensitive and it does not have exceptions. The degree to which the two alternants are phonetically related is difficult to establish using Kruszewski's theory. It seems, however, that these two sounds would not satisfy the fourth criterion, namely, this one requiring phonetic similarity of alternants. Yet, the fourth requirement is actually analytically redundant, with the remaining three being decisive. I conclude that the two alternants discussed are labelled as divergents and belong to the same phoneme.

The alternation given in (6c) poses a certain theoretical problem from the point of view of Kruszewski's study. Kruszewski does not analyse three-way alternations. Rather, he focuses on two-way 
relationships. It is Baudouin de Courtenay who emphasises the psychological reality of the phoneme that may encompass several members. Even though Kruszewski's analyses are extremely insightful and logical, they are not detailed as far as phonemic investigation is concerned. It must be admitted that the interrelation between such three-way alternants is unclear.

Another problematic issue concerns the word książka, which

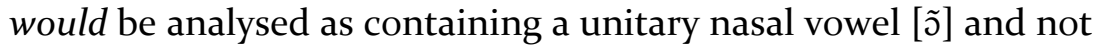
a diphthong. Kruszewski claims that it is crucial to differentiate between a letter, a sound, and an articulation. In his works, the phoneme appears in the sense of a morphological alternant, i.e. it may correspond to several sounds or even to a single sound and a certain feature of another sound (Kuryłowicz 1967). Kruszewski argues that the anthropophonetic (phonetic) unit is not always identical with the phonetic (phonological) unit, that is, the former always comprises one sound, while the latter does not necessarily consist of only one sound. ${ }^{42}$ By the same token, we can include książka in the analysis because it shows alternations (6c), unlike $o$ in wąs (6a).

The contexts in which $n$ and o appear are phonetically transparent. The alveolar nasal appears before alveolars and the nasal vowel-before fricatives. The case of $\eta$ is more problematic, as discussed in the preceding paragraph. As its divergent relation to $n$ has already been established, let us focus on the $w$-õ alternation. Apart from the context being transparent, the alternation does not require access to morphological information. Furthermore, it is exceptionless. Phonetic relatedness, which is the final criterion of establishing the correlative relationship, once again proves to be unclear. On the basis of Kruszewski's examples, it may be assumed that the two alternating segments are not related. Yet, the importance of this criterion is minor, and therefore it does

${ }^{42}$ See Chapter 2, section 2.2.2, in which Kruszewski's example from Russian is presented. The word земля, "earth" (nom.sg.) is analysed as z'-e-m'-l'-a, but $m l$ ' is a phoneme because it alternates with $m$ in, e.g. земский, "earth's, earthly". 
not affect the results of the analysis. These observations lead to the conclusion that $o$ and $n$ are divergents-they belong to the same phoneme.

As Kruszewski's theory deals mainly with alternations, there is one more logical possibility that he would investigate, namely the alternation between $\eta$ and $\tilde{o}$ as is shown by the pair: ksiegga$k s i q z \dot{z} k a$. In this relation, $\eta$ and o would be classified as the first category of correlatives, i.e. as segments that belong to distinct phonemes. The reason for this would be the difficulty of establishing the context in which $\eta$ appears (as in the case of Nasal Assimilation). The context is not fully transparent but at the same time not restricted to selected morphological categories. It should also be stated that in Kruszewski's theory, Polish nasal vowels constitute basic phonological units, which is different from the analyses in subsequent frameworks.

Kruszewski's theory of alternations generates interesting results from both the structural and the generative perspectives. ${ }^{43}$ The outcome of the analysis of Nasal Assimilation is the statement that the $\eta$ segment is a regular phoneme in Polish, which is parallel to the structuralists analysis. However, the analysis of Nasal Gliding brings a result that is parallel to the generative account, rather than the structuralist account. The segments $\tilde{j}$ and $\tilde{w}$ are classified as members of the $n$ and $n$ phonemes, respectively. Strikingly, the analysis of the alternation between $n$ and $\tilde{w}$ resembles the generative account of the process. In Kruszewski's theory, it is impossible to treat $\tilde{w}$ and $\eta$ as members of the same phoneme, as is the case in structuralism.

\subsection{The Prague School: functionalist structuralism}

The aim of phonological analysis within the Prague School framework is to establish a system of oppositions operating in a given

43 These two perspectives are presented in sections 3.4 and 3.5, respectively. 
language. Jakobson and Trubetzkoy developed this system, with Trubetzkoy's analysis constituting a more detailed study and Jakobson's being more relevant for generative phonology. Some of the contrasts, however, may be suspended on the surface, which is formalised by the notion of an archiphoneme. This essential tool represents the lack of contrast in the position of neutralisation, carrying only the features that are present in both members of the opposition. The archiphonemes, represented with capital symbols, constitute independent units in the phoneme inventory.

Let us now investigate the rules of Nasal Assimilation and Nasal Gliding in accordance with the principles of the Prague School phonology. Bilabial and dental nasal consonants in Polish produce a surface contrast whenever they appear in a prevocalic position, as illustrated in (7).

(7) a. tomy [m] "tomes"

b. tony $[\mathrm{n}]$ "tones"

However, this contrast is suspended before obstruents. The multilateral contrast of the place of articulation is no longer present on the surface, since the nasal and the following obstruent have to be homorganic, as shown in (8).

(8) a. labial: romb [romp] "rhombus"

b. alveolar: indyk [indik] "turkey", kąt [kənt] "corner"

c. postalveolar: męczyć [menčitte] "bother"

d. alveolo-palatal: chęć [xєnţ] "will"

e. velar: potęga [potznga] "power"

The archiphoneme is a tool used to represent the neutralisation of contrast in this position, and in the analysed process, it is unspecified for place features. This placeless nasal is symbolised by a capital $N$. We arrive at the representation given in (9).

44 Please note that the double underlining means that the nasal is postalveolar. This is the case here because [č $]$ is postalveolar. 
$\begin{array}{lllll}\text { (9) Lexical form } & \{n+i\} & \{n+b\} & \{n+t\} & \{n+g\} \\ \text { Phonemic form } & \{n+i\} & \{N+b\} & \{N+t\} & \{N+g\} \\ \text { Phonetic form } & \{n+i\} & \{m+b\} & \{n+t\} & \{n+g\}\end{array}$

The $n-\eta$ alternation is problematic because of words such as Irenka or rumianku, in which the assimilation does not take place, and thus the cluster is not homorganic. The formulation of the archiphoneme presented in (9) seems to require modification since it is evident that $n$ and $\eta$ may be contrastive on the surface in this position, i.e. before an obstruent. In order to account for the facts, we have to employ the concept of morphoneme that encompasses the whole class of alternating phonemes, such as the $n-\eta$ alternation in the process under consideration. Consequently, the system captures the differences between the alternation and the lack of alternation, as illustrated in (10). The example in (10a) constitutes an archiphoneme $N$, while the one in (10b) is simply /n/.

(10) a. ręka, "hand"

$\begin{array}{ll}\text { Lexical form } & \{\mathrm{n}+\mathrm{k}\} \\ \text { Phonemic form } & \{\mathrm{N}+\mathrm{k}\} \\ \text { Phonetic form } & \{\mathrm{n}+\mathrm{k}\}\end{array}$

b. Irenka, "Irene" (dimin.)

$\begin{array}{ll}\text { Lexical form } & \{\mathrm{n}+\mathrm{k}\} \\ \text { Phonemic form } & \{\mathrm{n}+\mathrm{k}\} \\ \text { Phonetic form } & \{\mathrm{n}+\mathrm{k}\}\end{array}$

The Prague School phonology is not preoccupied with the statement of rules. Rather, it is focused on representations, for the establishment of which alternations are indispensable. Morphophonemic segments are not distinguished from ordinary phonetic segments.

Let us now turn our attention to the problem of Nasal Gliding. The relevant examples are repeated in (11).

(11) a. koń [koj] "horse" - koński [k̃̃̃jsk'i] "equine"; $n \rightarrow \tilde{j}$

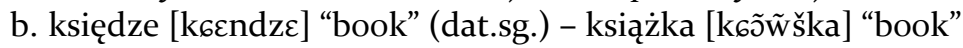
(nom.sg.); $\mathrm{n} \rightarrow \tilde{\mathrm{w}}$ 
As has already been said, nasal stops become nasal glides before fricatives. However, the members of the two pairs under analysis are not contrastive in Polish. Thus, the contrast regarding the feature [continuant] is not suspended before fricatives. Although the phonetic value of continuancy in a nasal is externally conditioned by the following fricative, the concept of the archiphoneme is not put forward in the case of these alternations. The representation is as in (12) below.

$\begin{array}{cl}\text { (12) a. koń-koński } & {[\mathrm{n} \rightarrow \tilde{\mathrm{j}}]} \\ \text { Lexical form } & \{\mathrm{n}+\mathrm{s}\} \\ \text { Phonemic form } & \{\mathrm{n}+\mathrm{s}\} \\ \text { Phonetic form } & \{\tilde{\mathrm{j}}+\mathrm{s}\} \\ \text { b. księdze-książka } & {[\mathrm{n} \rightarrow \tilde{\mathrm{w}}]} \\ \text { Lexical form } & \{\mathrm{n}+\check{s}\} \\ \text { Phonemic form } & \mathrm{n}+\check{s}\} \\ \text { Phonetic form } & \{\tilde{\mathrm{w}}+\check{\mathrm{s}}\}\end{array}$

Trubetzkoy's phonological theory is focused on illustrating the details of representations. Phonological rules can be indirectly deduced from the relations embraced by a given representation, but they are not stated in a straightforward fashion. In other words, the rules are built into the alternations. As a result, we are offered a systematic analysis of alternations, but no generalisation regarding basic phonological segments. Therefore, to a certain extent, Kruszewski's theory of alternations seems to be more insightful. Although his main interest concerns alternations as well, he attempts to make certain theoretical predictions regarding the status of phonological segments. Neither Trubetzkoy nor Kruszewski emphasise the significance of the psychological reality of the phoneme, but in Kruszewski's work this notion can be reached indirectly, which is not the case in Trubetzkoy's theory. 


\subsection{Distributional structuralism}

Biedrzycki's $(1963,1978)$ interpretation of Polish nasal vowels is one of the classic analyses carried out in the structuralist framework. He conducts his analysis in the phonemic framework, adopting Jones's definition of the phoneme understood as a family of sounds (see Chapter 2, section 2.2.4.2).

For the purpose of this study, I focus only on selected aspects of the nasal assimilation process, in particular, on its relation with the identity of the $\eta$ segment in Polish phonology. Crucial for the structuralist debate are examples such as those in (13).

(13) a. i ręka [irønka] "and a hand"

b. Irenka [irenka] "Irene" (dimin.)

In structuralism, phonology is treated as an autonomous module, that is, it crucially has no relation to morphology or syntax. Consequently, the presence of a morpheme boundary in the latter word (13b), Iren $+k(a)$, as well as its absence in the former one (13a), ręk(a), are not relevant from the phonological analysis' point of view. Thus, the examples in (13) constitute a minimal pair. As one minimal pair is enough to establish the phonological status of a given segment, $\eta$ has a phonemic status in Biedrzycki's view. Once the phonemic status of $/ \mathrm{y} /$ has been established, this segment cannot be analysed as an allophone of another phoneme, for instance, of $/ / \mathrm{n} / /$. This is prohibited by the principle of biuniqueness (Bloch 1941), which requires that a given sequence of phones should be represented by a unique sequence of phonemes, and that a given sequence of phonemes should be represented by a unique sequence of phones.

Biedrzycki provides further examples of minimal pairs that seem to confirm the phonemic status of $\eta$, though they are of different nature. 


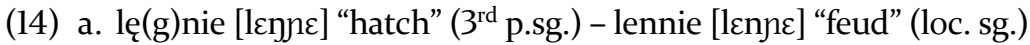

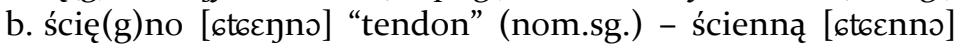
"wall" (attrib.)

As illustrated in (14), the velar stop $g$ can be deleted, the process being restricted to casual speech. The pairs of words in (14) are in fact minimal pairs, but their phonological analysis is more complex. To see what is of interest, let us look at the contexts in which $\eta$ occurs in Polish. Biedrzycki challenges the statement that $\eta$ occurs only before $k$ and $g$. The evidence confirming this view is given in (15).

(15) a. before nasals: osią(g)nięcia [ñ] “achievements”, pielę(g)niarka [yn] "nurse"

b. before $l, w$ : cią(g)le zapominam [yl] "continually forgetting", cią(g)ły niepokój [yw] "constant anxiety";

c. before $t, d$ : instyn(k)t samozachowawczy [nt] "self-preservation instinct", pun(k)tualny [nt] "punctual"

On the basis of the above examples, it can be concluded that there are optional segments in pronunciation between consonants $k$ and $g$. Since they can be deleted, we are left with the instances of $\eta$ that are not followed by a velar consonant. By the same token, this process applies to the words in (14) and, consequently, the contrast between $n$ and $\eta$, which is visible on the surface, becomes distinctive.

A further argument confirming the phonemic status of $\eta$ is of general nature, namely, structural symmetry of the phonemic system in Polish. This is a strong argument in structuralism, dealing with the elegance of the pattern that is formed by consonants. The $\eta$ phoneme fills the gap in the system of stops and nasals, as indicated in (16).

(16) a. p t $\mathrm{k}^{\mathrm{\prime}} \mathrm{k}$

b. b d g $\mathrm{g}$

c. $\mathrm{m} \quad \mathrm{n} \quad \mathrm{n} \quad \mathrm{y}$ 
Let us now focus on Nasal Gliding, a process whose analysis preserves the insight of Biedrzycki's research regarding the status of $/ \mathrm{y} /$.

Biedrzycki analyses nasal vowels as bi-phonemic diphthongs and focuses on the symmetry of the pattern that is formed by back nasal glides $(\mathrm{V} \tilde{\mathrm{w}})$ and front palatal glides [Vj] , as illustrated in (17).

(17) a. chiński [ĩj] "Chinese" - insekt [ĩw] "insect"

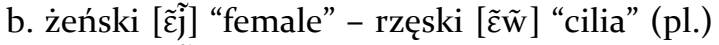

c. tańsza [ã̃] "cheaper" - plansza [ã $\tilde{w}]$ "board"

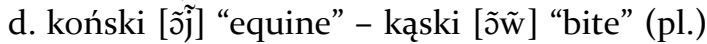

e. duński [ũ̃] "Danish" - munsztuk [ũw̃] "bit"

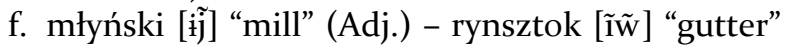

Biedrzycki argues that, due to the systematic nature of this pattern, the decision concerning the phonemic identity of one of the glides should be also implemented for the other glide. The nasalised vowels transcribed in (17) are uncontroversially analysed as belonging to the respective vowel phonemes. The front palatal glide $\tilde{j}$ is analysed as a member of the palatal nasal phoneme $n$. What remains to be clarified is the status of the back glide $\tilde{w}$. The assumption is that a symmetrical pattern entails an identical status. Consequently, if the palatal glide $\tilde{j}$ belongs to the same phonemic family as the palatal nasal stop $n$, the velar glide $\tilde{w}$ should belong to the same phonemic family as the velar nasal stop $\eta$. Distributional arguments are invoked to confirm the thesis that $\tilde{w}$ and $\eta$ never appear in the same context, meaning that they are mutually exclusive. The same holds true for $\tilde{j}$ and $n$. The analysis is presented in (18).

(18)

\begin{tabular}{c|l|l|l}
\hline \multicolumn{2}{c|}{ Vn } & \multicolumn{2}{c}{ Vn } \\
\hline \multicolumn{1}{c|}{ on } & \multicolumn{1}{c}{$\tilde{\mathrm{j}} \tilde{\mathrm{j}}$} & \multicolumn{1}{c}{ on } & \multicolumn{1}{c}{$\tilde{\mathrm{w}}$} \\
\hline $\begin{array}{l}\text { kądziel } \\
\text { "distaff” }\end{array}$ & $\begin{array}{l}\text { koński } \\
\text { "equine" }\end{array}$ & $\begin{array}{l}\text { kąkol “corn } \\
\text { cockle” }\end{array}$ & $\begin{array}{l}\text { kąski “bite” } \\
\text { (nom.pl.) }\end{array}$ \\
\hline
\end{tabular}


Let us now follow up on the issue mentioned by Biedrzycki concerning the alternative solution that he adopted prior to this analysis. The solution was to recognise the phonemic status of $\tilde{w}$, which is supported by the koński-kqqski minimal pair. In accordance with the principle once a phoneme, always a phoneme, we conclude that one minimal pair is enough to establish the phonemic status of the alternating segments, irrespectively of their functional load.

Although the result obtained obeys one of the major structural principles, there are problems that come to light in connection with such an analysis. Compared with Biedrzycki's analysis of Nasal Gliding presented above, it is evident that important generalisations would be lost. There are crucial arguments in the structuralist framework that favour choosing $\eta$ as the principal variant of the phoneme. The elegance of the system plays a pivotal role in the analysis. Thus, the choice of $\eta$ has wider implications regarding the symmetries within the consonantal and the vocalic systems.

Furthermore, from the generative perspective, recognising the phonemic status of $\tilde{w}$ entails serious theoretical problems. A single rule of Nasal Gliding would be artificially split in two. To see what is of interest, let us reconsider the analysis repeated in (19).

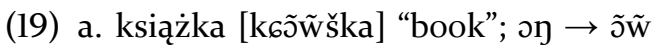

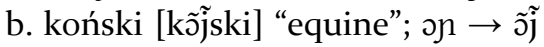

The generalisation in (19a) produces a phonemic change, since both $\eta$ and $\tilde{w}$ have this status. On the other hand, the generalisation in (19b) is an instance of a subphonemic change, since only $n$ has the status of a phoneme, $\tilde{j}$ being merely an allophone. The obtained result is similar to the analysis of Voice Assimilation (VA) in Russian (see Chapter 4, section 4.1.4). It seems that an important theoretical generalisation would be lost, unless the principle saying once a phoneme, always a phoneme is abandoned. In fact, this principle is not obeyed in Biedrzycki's analysis for the sake of stronger structural arguments presented above. After combining the results, it can be concluded that the choice of 
$\eta$ as the principal variant of the phoneme is more justified than the choice of $\tilde{w}$. The arguments are grounded in the solid structural principles, due to which some of the solutions are preferred, while others are predicted to be incorrect.

In the structuralist framework, the symmetry of the phonemic system seems to be more important than the symmetry of phonological generalisations. Consequently, certain observations are disregarded, while other are employed as evidence supporting the thesis. This decision is based on the theoretical validity of a given fact. For instance, the pronunciation of the word instytut, "institute", can vary phonostylistically from the version with a nasal glide [ĩ $\tilde{w} s t i t u t]$ to the version with a nasal stop [institut]. This fact is disregarded in structuralism, whereas in generative phonology it serves an important, though auxiliary, function. On the other hand, purely phonostylistic arguments regarding the deletion of $g$ in certain context, illustrated in (14) and (15), are crucial in recognising the phonological status of $\eta$. In the latter case, surface contrasts of purely allophonic nature are more important than predictability. The pressure of the system exerts powerful impact on phonological decisions, whereas the types of generalisations are of minor importance and the generative concept of rule ordering has no significance whatsoever.

\subsection{Early Generative Phonology}

This section presents generative accounts of Nasal Assimilation and Nasal Gliding. I begin by sketching out the relevant methodological principles that changed the perspective of the analyses as compared to structuralism, focusing on these principles that are relevant with regard to the two processes discussed in the present chapter. Next, Rubach's (1982) account of the processes under consideration is presented.

One of the major methodological differences between structuralist and generative phonology is the approach to morphology 
and syntax. In the structuralist view, phonology is an autonomous module, in particular, different from morphophonology. Generativism, in contrast, allows morphological and syntactic information to influence phonological analysis. Furthermore, biuniqueness does not exist as a principle in generative phonology, while predictability plays a pivotal role in the analysis. These two assumptions have decisive impact on the phonological identity of the segments under analysis. Since phonology in generativism is closely related to other branches of linguistics, namely, morphology and syntax, the concept of boundaries becomes one of the central issues. Basic phonological segments, described in terms of matrices of features, are "psychologically real". This significant assumption, stated by Chomsky (1957) harks back to the works of Baudouin de Courtenay (1895) and Sapir (1925); yet it was rejected in structuralist phonology. Finally, one of the central tenets of generative phonology is derivation of surface variants from the underlying representation, whereas the aim of structuralism is to establish the relationship of the forms that create surface contrasts. In the course of the derivation, abstract rule ordering is allowed.

Rubach (1982) analyses Nasal Gliding using a tri-morphemic word książka, "booklet", as an example.

(20) a. książ- "book"

b. //عk// the diminutive suffix (compare genitive plural: książek)

c. /a/ the inflectional morpheme

With regard to Nasal Gliding, it is the first morpheme that constitutes the focus of the analysis, as it appears in several distinct forms presented in (21).

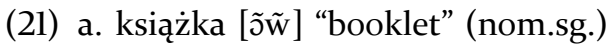

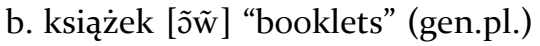

c. ksiąg [ojk] "book” (gen.pl.)

d. księga [عj] "book" (nom.sg.)

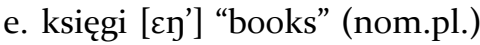

f. księdze [عndz] "book” (dat.sg.) 
The aim of a generative analysis is to account for the range of facts presented above by establishing the underlying form, from which the remaining forms are derived. Predictability rules out the possibility of choosing palatalised $\eta$ ' and $\tilde{w}$ as underlying forms. The former appears before a velar that has been palatalised by a front high vowel $i$, while the latter - before fricatives. We are left with two candidates: //y// and //n//. Rubach points out that due to phonetic similarity of $\tilde{w}$ and $\eta$ one might try to derive the former from the latter. However, this hypothesis entails a controversial assumption. One would have to postulate the rule of $\eta$ changing into $n$ before alveolars, as shown by the form in (2lf). Yet, as Rubach argues, such a rule is uncommon in sound patterns, in contrast to the rule changing $n$ to $\eta$ before velars. Phonostylistics offers another piece of evidence concerning the choice of the underlying segment. We can observe variation of $n$ and $\tilde{w}$ before fricatives in a post-vocalic position in the case of borrowings, cited in (22).

(22) a. instytut [in] or [ĩw] "institute"

b. cenzus $[\varepsilon n]$ or $[\tilde{\varepsilon} \tilde{w}]$ "qualifications"

c. lansować [an] or [ãw w] "promote"

d. kunszt [un] or [ũ̃w] "art"

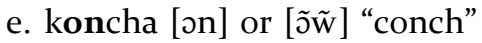

The only logical way to account for these facts is to postulate a phonostylistic rule that changes $n$ into $\tilde{w}$ in a post-vocalic position and before a fricative.

$$
\text { (23) } \mathrm{n} \rightarrow \tilde{\mathrm{w}} / \mathrm{V}-\left[\begin{array}{l}
\text { +obstr } \\
+ \text { contin }
\end{array}\right]
$$

The same rule of gliding applies to the examples in (21). Rubach provides the derivation that is cited in (24), with the underlying representation of ksiażk $k a$ being $/ / k 60 n g+\varepsilon k+a / /$. 
(24) $/ /$ k6ong $+\varepsilon k+a / /$

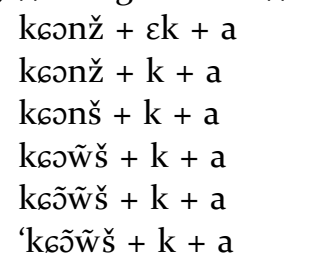

$\mathrm{g} \rightarrow$ ž palatalisation

e-deletion

Devoicing rule

Gliding

$\mathrm{V}$-nasalisation in the context of $\tilde{\mathrm{w}}$

Stress Assignment

Although predictability alone is sometimes not sufficient to establish the underlying form, it is considered to be one of the fundamental criteria in generative phonology. In problematic cases, additional arguments are raised, such as references to fast speech phenomena. Although the role of phonostylistic arguments is auxiliary, their significance it not to be underestimated, as pointed out by Rubach (1982: 166): "phonostylistic rules are often simply reflexes of corresponding obligatory rules with the notable difference that their domain of application is broader".

On the basis of Rubach's (1982) analysis of Nasal Assimilation, it can be concluded that the status of $\eta$ is different in generative phonology, as compared with the structuralist view. The basic observation is that the dental nasal $n$ assimilates the place of articulation of the following velar stop: $k$ or $g$. However, the rule stated in such a straightforward fashion has numerous exceptions, examples of which are provided in (25). At first glance, it might seem that the rule does not apply in diminutive forms, as presented in (25a). The examples in (25b), however, contradict this assumption because they are not diminutives and yet have [n] rather than [y].

(25) a. [nk]: Irenka "Irene" (dimin. nom.sg.); roślinka "plant" (dimin. nom.sg.), piosenka "song" (dimin. nom.sg.)

b. [nk]: ratunku "help" (voc.sg.), gatunku "kind" (gen.sg.), rumianku "camomile" (gen.sg.)

The common feature of the words in (25) is the presence of $e$ separating $n$ from the velar stop in the underlying representation, 
which is confirmed by their alternations in (26), where the rule of $e$-deletion does not take place. ${ }^{45}$

(26) a. [nєk]: Irenek "Irene" (gen.pl.); roślinek "plant" (gen.pl.); piosenek "song" (gen.pl.)

b. [nek]: ratunek "help" (nom.sg.); gatunek "kind" (nom.sg.); rumianek "camomile" (nom.sg.)

The explanation offered by generative phonology is that the words containing the underlying $e$ in the above position do not undergo Nasal Assimilation ${ }^{46}$, hence, the concept of rule ordering. Nasal Assimilation is ordered before $e$-deletion, which blocks its application in the words cited in (27). Rubach's analyses of Irenka and i ręka are presented below.

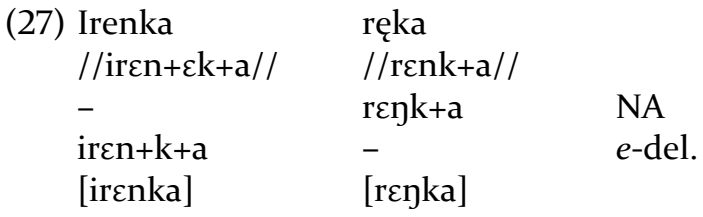

According to the above analysis, $\eta$ is not an underlying segment in Polish. The predictability criterion and rule ordering ensure the correct results. Biedrzycki's examples cited in (15), such as pielę(g)niarka, "nurse", or instyn(k)t, "instinct", are not an issue in the generative approach. Due to their purely allophonic, phonostylistic status, they do not pose an analytical problem. First,

45 The vowel $[\varepsilon]$ is actually a "yer" but I do not pursue the details of this analysis, as it is beyond the scope of the present dissertation. See, for example, Rubach (1986).

46 Some foreign words may not conform to the pattern, that is, assimilation is only optional (see 2). Moreover, as Rubach (1982) argues, the rule of Nasal Assimilation is stress-sensitive. Assimilation is optional (phonostylisitic) if the preceding vowel is unstressed. Otherwise, assimilation is obligatory, as in the following examples: bankowość [nk] [nk] "banking", anglistyka [ng] [ng] "English studies"; bank [nk] "bank", ring [nk] "ring." This generalisation applies to borrowings exclusively. In native words, assimilation is exceptionless. 
Nasal Assimilation applies before a velar stop, which appears on the surface in the standard variety of pronunciation. Next, the nasal stop that caused assimilation can be dropped in fast speech, the process being an optional, surface phenomenon. The context for $g$-deletion and $k$-deletion is inter-consonantal. The interaction of phonological rules is illustrated in (28).

(28) //instinkt//

$\begin{array}{ll}\tilde{\text { Ĩwstinkt }} & \text { NG } \\ \tilde{1} \tilde{w} \text { stinkt } & \text { NA } \\ \tilde{\text { îwstint }} & k \text {-del. }\end{array}$

Rubach's (1982) statement of Nasal Assimilation is quoted in (29).

(29)

$$
[+ \text { nas }] \rightarrow\left[\begin{array}{l}
\alpha \text { anter } \\
\beta \text { coron } \\
\gamma \text { high }
\end{array}\right]\left(\begin{array}{l}
\mathrm{V} \\
++ \text { stress } \\
- \text { high } \\
+ \text { low }
\end{array}\right]-\left(\begin{array}{l}
+ \text { obstr } \\
- \text { cont } \\
\alpha \text { anter } \\
\beta \text { coron } \\
\gamma \text { high }
\end{array}\right)
$$

Due to the differences in methodology, as compared with the preceding frameworks, generative phonology offers a novel account of Nasal Assimilation and Nasal Gliding. The velar nasal $\eta$ is not an underlying segment. Rather, it is derived from the alveolar nasal $/ / \mathrm{n} / /$. The back nasal glide $\tilde{w}$ is also derived from the alveolar nasal $/ / \mathrm{n} / /$. Such predictions are possible because of the rejection of the biuniqueness principle and a different approach towards the morphology-phonology interface. Finally, the concept of "psychological reality" plays a role in the analysis. The segments $\eta$ and $\tilde{w}$ cannot be treated as members of the same "phoneme", since this relationship does not seem to be psychologically real. Rather, the variation of $n$ and $\tilde{w}$, illustrated in (22), confirms the intuitions of native speakers concerning the relatedness of these sounds. 


\subsection{Natural Generative Phonology}

The major aim of Natural Generative Phonology is to constrain the predictions of the SPE framework, which is regarded as too powerful. One of the theoretical tools thanks to which the desired result may be obtained is the division of rules into phonologically conditioned and morphologically conditioned (see Chapter 1, section 1.5). The context of phonologically-conditioned rules (P-rules) is phonetically transparent, with exclusively phonological features and boundaries being used. Phonological boundaries include a syllable boundary and a pause boundary. P-rules do not have exceptions and they are supposed to be universally natural. Morphophonemic rules (MP-rules), on the other hand, require access to non-phonetic information of either morphological or syntactic character. MP-rules frequently have exceptions and are not regarded as natural.

Apart from restricting the scope of phonological rules as such, two further conditions that change the derivation procedure are introduced. The No Ordering Condition prohibits extrinsic rule-ordering. A given rule can apply each time its structural description is met. The Strong Naturalness Condition requires lexical representations of non-alternating forms to be identical to their phonetic representations. The aim of these two conditions is for phonology to express only the generalisations that are surface-true and transparent.

Before I address the major topics of this section, that is, the analyses of Nasal Assimilation and Nasal Gliding, I shall focus on the article by Schane (1971) entitled "The Phoneme Revisited". After pointing to basic assumptions that he adopts, I will show how they combine with the approach towards Nasal Assimilation and Nasal Gliding.

Along the lines that resemble these of Natural Generative Phonology, Schane postulates reintroducing the concept of the phoneme within the generative framework. The phoneme is supposed to embrace the knowledge of a native speaker regarding 
relevant surface contrasts. The evidence that he gives concerns French nasal vowels, which are not considered to be underlying, according to the principles of generative theory. Schane claims, however, that the distinction between oral and nasalised vowels is more significant in French (it is "what makes French French") than, for instance, the distinction between long and short vowels preceding continuants. In classical phonemics, French nasalised vowels would have the status of the phoneme.

In order to state the conditions under which the phoneme (but, crucially, not phonemic representation) may enter generative phonology, Schane investigates types of morphophonemic rules. First of all, a morphophonemic rule "converts one underlying segment to another, where both can occur in the same environment" (1971: 512), which is exemplified by English Velar Softening. This rule changes $k$ to $s$ in alternations such as eclectic $[\mathrm{k}]$ - eclecticism [s], although there are words in which the alternation does not take place, for example, bolshevik [k] - bolshevikism [k]. Secondly, an MP-rule is involved in the analysis if a derived feature (underlyingly non-distinctive) becomes contrastive on the surface due to the loss of the conditioning factor. This is the case of the nasalisation of the aforementioned French vowels. Finally, Schane investigates the rules in which morphological conditioning leads to a derived feature becoming contrastive on the surface. The example here is the $\eta$ - $\eta g$ alternation in English, in particular, the contrast between longer [ $\mathrm{n}]$, "one who longs", vs. longer [ng], "more long". There is no underlying $\eta$ in English. It is assumed that the underlying form is $/ / \mathrm{ng} / /$. $G$-deletion takes place after Nasal Assimilation has applied. The contrast under consideration is connected with a specific suffix, that is, the agentive $-e r$ in this case. The deletion of $g$ takes place before this suffix.

In his attempt to reintroduce the phoneme, Schane argues that "only those phonetic differences resulting from morphophonemic rules are phonemic" (1971: 514). Thus, it is not the case that each phonetic contrast visible on the surface has phonemic 
status. Processes such as aspiration or flapping in English do not yield phonemic results. ${ }^{47}$

I begin my account of Nasal Assimilation and Nasal Gliding by adopting the principles of Natural Generative Phonology. Then, I investigate the significance of Schane's suggestion with regard to these two processes.

From the point of view of NGP, the rule of Nasal Assimilation seems to be a good candidate for a P-rule. This process is phonetically natural due to its assimilatory characteristics and phonetic grounding, that is, the relations with the vocal tract. Phonological features that appear in the structural description of the rule have intrinsic phonetic content. Yet, the $n-\eta$ alternation appears to be rather problematic. It is necessary to account for the non-application of Nasal Assimilation in the words analysed in the preceding section and repeated in (30).

(30) a. [nk]: Irenka "Irene" (dimin. nom.sg.); roślinka "plant" (dimin. nom.sg.), piosenka "song" (dimin. nom.sg.)

b. [nk]: ratunku "help" (voc.sg.), gatunku "kind" (gen.sg.), rumianku "camomile" (gen.sg.)

These words constitute exceptions in the NGP framework because the fact NA is interrelated with the rule of $e$-deletion is irrelevant. Let us repeat the derivation discussed in the preceding section to show the crucial rule-ordering involved in the process.
(31) Irenka
ręka
//iren+ek+a//
$/ / \mathrm{renk}+\mathrm{a} / /$
$-$
renk+a
NA
iren $+\mathrm{k}+\mathrm{a}$
$-$
e-del.

In NGP, however, rule ordering is prohibited. By the No Ordering Condition, rules are allowed to apply at random, each time their structural description is met. Nasal Assimilation cannot be ordered

${ }^{47}$ For the discussion of flapping, see Chapter 2, section 2.1. 
before $e$-deletion and then forced not to apply. Consequently, it is not possible to treat NA as a single process. Rather, it belongs to MP-rules, which actually means that it is outside the scope of phonological analysis. The analysis of the process in the NGP framework is presented in (32).

$$
\{\mathrm{n}\} \rightarrow\left\{\begin{array}{l}
\left.\mathrm{n}]_{\text {_ }} \text { velar stops }\right]_{\text {diminutive, genitive, vocative }} \\
\left.\mathrm{n}]_{\text {_ }} \text { velar stops }\right]_{\text {elsewhere }}
\end{array}\right\}
$$

As confirmed by the examples in (30), Nasal Assimilation does not take place if $n$ precedes a velar stop in words belonging to various morphological categories, such as diminutive, vocative and genitive. Thus, the rule of NA is split into two generalisations: phonological and morphophonological.

Yet, even the rule presented in (32) constitutes too powerful a statement in the NGP framework. Apart from problematic words such as Irenka or rumianku (30), instances of Nasal Assimilation in bank "bank" and potęga "power" pose a theoretical controversy as well. In line with the Strong Naturalness Condition, underlying representations of non-alternating forms should be the same as their phonetic representation. The word bank does not have alternating forms in which the alveolar nasal would surface. Given that, it must be concluded that $\eta$ is an underlying segment, in all the instances, in which it appears.

One could venture a claim that the Strong Naturalness Condition considerably weakens the predictive power of the theory. Predictability, one of the major generative criteria, has no impact on the analysis in the NGP framework. Actually, the significant generalisations which are made in the classic Generative Phonology are lost.

By the same token, namely, the application of the Strong Naturalness Condition, the words in (33a), which in classic Generative Phonology were analysed as exhibiting Nasal Gliding, 
are labelled as containing an underlying back glide $\tilde{w}$. The words in (33a) do not have alternating forms in which the alveolar nasal $n$ would surface. However, the status of the back glide in the words in (33b) and (33c) is different, since they exhibit alternations.

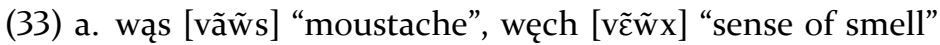

b. koń [kon] "horse" - koński [kว̃jski] "equine"

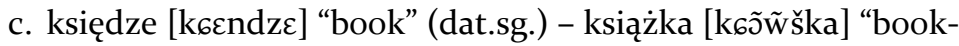
let" (nom.sg.)

Let us therefore focus on the alternations involved in the analysis, namely, $n \rightarrow \tilde{j}$ and $n \rightarrow \tilde{w}$. The rule of Nasal Gliding is exceptionless and it does not require access to morphological information. Therefore, its context can be stated in purely phonological terms. Given that, both changes have the status of P-rules in the NGP framework.

Let us now examine the implications of Schane's theory with regard to the above analysis. I apply his assumptions concerning the reintroduction of the phoneme in order to investigate the outcomes of the two rules in question.

The analysis of Nasal Gliding does not change after incorporating Schane's assumptions into the NGP theory. Since Schane argues that "only those phonetic differences resulting from morphophonemic rules are phonemic" (1971: 514), it can be concluded that no phonemes are involved in the interpretation of Nasal Gliding. According to the analysis that I postulated above, Nasal Gliding is not a P-rule, and as such it does not enter the scope of phonemic analysis.

The scope of interest of Natural Generative Phonology is considerably restricted, as compared to the standard view. The reason for this seems to be the division of rules into P-rules and MP-rules, but Anderson (1986) argues that this division is rather a consequence of adopting other grammatical conditions that require rules to express true generalisations about the surface contrasts. The aim is to limit the number of potential abstract 
solutions and to offer stronger claims about language instead. Yet, the problem with NGP is the fact that attention is focused only on these types of processes which are completely regular and frequently of an allophonic status. For instance, the $\eta$ segment needs to be posited as underlying in Polish. The reason lies in the principle of eliminating morphological information from the scope of phonological rules, which resembles one of the central tenets of structuralism, called no level mixing. A strong argument against Natural Generative Phonology is raised by Anderson (1986), who undermines its scientific status:

A program of this sort is effectively impossible to falsify, since it consists not in a potentially verifiable claim about the object of linguistic study but in an externally imposed limitation on the object of such study. [...] Now a consistent advocate of the "natural generative" theory may well be happy with the result that certain domains are legislated out of consideration, just as a confirmed intuitionist may be convinced of the result that much of classical and modern mathematics is literally meaningless (Anderson 1986: 341).

\subsection{Lexical Phonology}

In Lexical Phonology, rules are divided into lexical and postlexical, depending on their relation to morphology and phonology. Lexical rules apply only within words, while postlexical rules apply within words or across word boundaries. Since morphological information is necessary to determine the context of Nasal Gliding, we conclude that the rule belongs to the lexical component. The development of the Lexical Phonology framework by Booij and Rubach (1987) makes further observations regarding differences between rules in the lexical component. As a result, the theory is refined by introducing the concepts of cyclic and postcyclic rules. Both of them apply inside words only but postcyclic rules are not conditioned by the internal structure of words, applying inside morphemes and across morpheme boundaries (see Chapter 1, section 1.6). 
Nasal Gliding is therefore a postcyclic rule, as pointed out by Ewa Czaykowska-Higgins (1988). The rule applies within the domain of a word, yet its internal structure is irrelevant. Nasal Assimilation is also a postcyclic lexical rule, as it does not operate across word boundaries and morphological information is not part of the statement. ${ }^{48}$

Yet, we have to take into account Structure Preservation (Kiparsky 1985), which is one of main principles of Lexical Phonology. Structure Preservation does not allow non-distinctive features to be introduced in the lexical component. Only distinctive features may be inserted within the lexical phonology component, while the features of allophonic status are to appear in the postlexical component.

If we apply the principle of Structure Preservation to the problem under consideration, the derivational picture presented in section 3.5. does not seem appropriate. Both Nasal Assimilation and Nasal Gliding produce non-distinctive segments, namely $\eta$ and $\tilde{w} / \tilde{j}$. Yet, there is nothing in their theoretical description that would allow us to place these rules in the postlexical component. It seems that the analysis that employs SP produces undesirable results. A potential solution would be to label $\tilde{w}, \tilde{j}$ and $\eta$ as distinctive segments in Polish. The problem is that such an assumption would violate the fundamental generative principles, such as predictability. Actually, this would mean losing some of the generalisations that were admitted already in the structural view discussed in section 3.4. The status of $\eta$ would be the same, but the features of nasal glides would have to be given a distinctive status, which is not the case in Biedrzycki's analysis.

Considering the problems that have come to light in connection with Structure Preservation, I conclude that this principle delivers a result that seems to be flawed from the generative point of view. The major line of criticism is that, like the structuralist principle

48 Rather, it is rule ordering that plays a role in the generative analysis, as discussed in section 3.5. 
of biuniqueness, it restricts the scope of the possible theoretical assumptions. Thus, SP seems to be a particularly undesired invention within the generative framework, making it impossible to capture a single generalisation and obtain an insightful solution to the analysed problems.

\subsection{Optimality Theory}

The Optimality Theory framework captures transparent cases of Nasal Assimilation effectively through the interaction of relevant faithfulness and markedness constraints. The following constraints prove to be significant in the analysis (Iwan 2015: 169):

(34) a. NA: A nasal and a following plosive or affricate must agree in place.

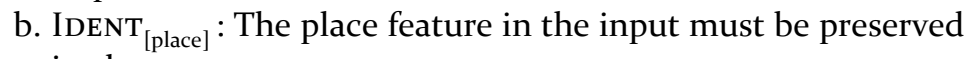
in the output.

c. IDENT ${ }_{[\text {place(plosive) }}$ : Correspondent plosives must have the same place of articulation.

Constraint (34c) is called for in order to avoid the undesirable result of the evaluation of the word ręka "hand" given in (35).

(35) $/ / \mathrm{r} \varepsilon n k+a / /$ (failed evaluation)

\begin{tabular}{c|c|c}
\hline & NA & IDENT $_{\text {[place] }}$ \\
\hline a. renka & & $*$ \\
\hline b. renka & $* !$ & \\
\hline c. renta & & $*$ \\
\hline
\end{tabular}

If only the generic constraint IDENT [place] $_{\text {was }}$ used, candidates (35a) and (35c) would tie, as both of them satisfy the NA constraint,

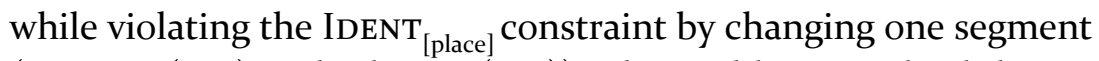
$(/ / \mathrm{n} / /$ in $(35 \mathrm{a})$ and $/ / \mathrm{k} / /$ in $(35 \mathrm{c}))$. The problem is solved due to 
the introduction of a more specific faithfulness constraint, that is IDENT $_{\text {[place(plosive)] }}$, which should crucially outrank the generic one. The final evaluation is presented in tableau (36).

(36) $/ / \mathrm{renk}+\mathrm{a} / /$

\begin{tabular}{c|c:c|c}
\hline & NA & IDENT $_{\text {[place(plosive) }}$ & IDENT $_{\text {[place] }}$ \\
\hline a. rejka & & & $*$ \\
\hline b. renka & $* !$ & $* !$ & \\
\hline c. renta & & & $*$ \\
\hline
\end{tabular}

The use of the more specific IDENT constraint resolves the prob-

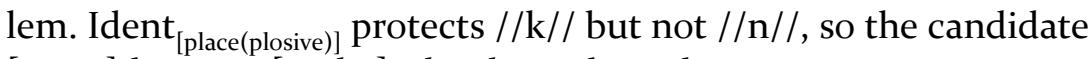
[renta] loses to [renka], the desired result.

However, in the case of opaque instances of NA, i.e. the non-application of the process due to its being ordered before $e$-deletion (see (25) and (26) above), OT encounters a major analytical problem. As the process interacts with $e$-deletion (Yerdeletion), some new constraints become relevant (for details, see Iwan (2015) and Yearley (1995)).

(37) a. *E/Y: no moraless vowels. *YER: no moraless vowels. ${ }^{49}$ b. MAX-V: do not delete a vowel

Constraint (37a) militates against yers in surface forms, with yers interpreted as vowels without representation on the moraic tier, while vowel deletion is prohibited by constraint (37b). As Iwan (2015: 171) points out, it is not possible to determine the mutual ranking of the constraints responsible for NA and $e$-deletion. One

${ }^{49}$ Iwan (2015) uses the symbols of two capital letters //E// and //Y// for the palatalising (front) and nonpalatalising (back) yers, respectively. Hence, her formulation of the relevant constraint is as follows: "* $\mathrm{E} / \mathrm{Y}$ : no moraless vowels." I do not pursue the details of yer interpretation, as it is beyond the scope of the present study. Therefore, an abridged version of the constraint is used. 
of the possible rankings is given in tableau (38) (adapted from Iwan 2015: 171), with Irenka, "Irene" (dimin. nom.sg.) as a representative form.

(38) //iren+\&k+a// (failed evaluation)

\begin{tabular}{r|c|c:c|c}
\hline & ${ }^{*}$ YER & MAX-V & NA & IDENT $_{\text {[place] }}$ \\
\hline a. irenka & & $*$ & $* !$ & \\
\hline b. irenka & & $*$ & & $*$ \\
\hline c. irencka & $* !$ & & & \\
\hline
\end{tabular}

The actual output in (38a) loses, as compared with its contender, candidate (38b). Both candidates violate the MAX-V constraint, but candidate (38b), the undesired winner, satisfies the higher-ranked NA constraint. The re-ranking of NA and IDENT[place] is not possible, as it is independently motivated by the assimilation in the words such as ręka (see (36) above).

It seems that the analysis of Nasal Assimilation poses a problem for standard OT, which does not allow for derivational stages, requiring the evaluation to be parallel. However, as discussed by Iwan (2015), the analysis is not problematic for Derivational Optimality Theory, in which MAX-V and NA outrank *YER and IDENT[place] at level 1 , whereas *YER and IDENT[place] outrank MAX-V and NA at level 2.

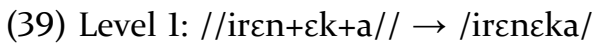

\begin{tabular}{c|c|c|c|c}
\hline & MAX-V & NA & $*$ YER & IDENT $_{\text {[place] }}$ \\
\hline a. irenka & $* !$ & $*$ & & \\
\hline b. irenka & $* !$ & & & $*$ \\
\hline$*$ c. irencka & & & $*$ & \\
\hline
\end{tabular}

At level 1 the output is /irencka/, which becomes the input to level 2. 


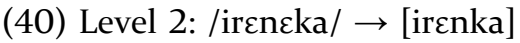

\begin{tabular}{r|c|c|c|c}
\hline & ${ }^{*}$ YER & IDENT $_{\text {[place] }}$ & MAX-V & NA \\
\hline a. irenka & & & $*$ & $*$ \\
\hline b. irejka & & $* !$ & $*$ & \\
\hline c. irencka & $* !$ & & & \\
\hline
\end{tabular}

At level 2 the desired candidate (40a) wins, as it satisfies the Ident $_{\text {[place] }}$ constraint, which now outranks MAX-V and NA.

In the OT framework, Nasal Gliding is the outcome of the interaction of faithfulness constraints and well-formedness (markedness) constraints. Following Dziczek-Karlikowska (2012), constraints relevant in the evaluation of the word wąs [võws], "moustache" (Tableau (42)) are specified in (41).

(41) a. NG: A nasal and a following obstruent agree in [ \pm contin].

b. IDENT [-ConTIN]: The feature [-contin] in the input must be preserved in the output.

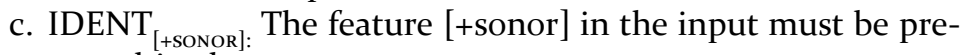
served in the output.

d. IDENT $_{[+\mathrm{NAs}]:}$ The feature [+nas] in the input must be preserved in the output

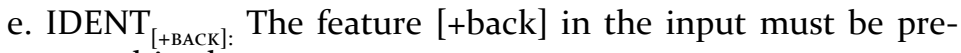
served in the output.

The requirement for a nasal to undergo the process is expressed by the constraint NG (NASAL GLIDING). However, a faithfulness constraint IDENT [-CONTIN] militates against the change of the underlying [-continuant] feature. Further faithfulness constraints eliminate, respectively, the potential candidates with: [s] (4lc), [w] (4ld) and [j] (4le). ${ }^{50}$ The evaluation of the exemplary word is given in $(42)^{51}$.

50 Moreover, the constraint IDENT $_{[+\mathrm{LAB}]}$, ranked higher than NG, would account for the non-application of Nasal Gliding in the words with $m$ (e.g. zemsta "revenge"), the process being restricted to $n$ and $n$. For further discussion 
(42) //vons//

\begin{tabular}{|c|c|c|c|c|c|}
\hline & 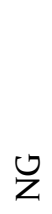 & 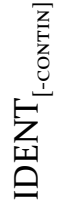 & 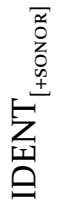 & 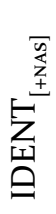 & 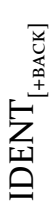 \\
\hline a. vons & *! & & & & \\
\hline b. võ $\tilde{w} s$ & & * & & & \\
\hline c. võws & & * & & *! & \\
\hline d. võjs & & * & & & $* !$ \\
\hline e. voss & & * & $* !$ & * & \\
\hline
\end{tabular}

\subsection{Partial conclusions}

I have discussed the predictions of selected phonological frameworks as regards the basic phonological segments involved in the processes of Nasal Assimilation and Nasal Gliding in Polish.

Kruszewski's theory of alternations (section 3.2) seems to lack certain restrictions imposed by structuralism later on. Kruszewski does not employ the major structural principles used for establishing the phonemic system, namely, once a phoneme, always a phoneme and biuniqueness. He is not preoccupied with the

of this ranking, as well as the OT perspective on the ensuant process of Vowel Nasalisation, see Dziczek-Karlikowska (2012).

51 The evaluation of the word such as e.g. książka, "book", would be problematic in the parallel paradigm of OT, due to the interaction between gliding and palatalisation. As specified in (24), the underlying form of the word is // $k$ cong $+\varepsilon k+a / /$. The nasal $[n]$ changes into $[w]$ before a fricative $[\check{z}]$. Yet, the fricative as such results from palatalisation, the trigger of which (the vowel $[\varepsilon]$ ) subsequently disappears. The analysis would not be problematic, though, in Derivational Optimality Theory, which recognizes derivational levels and the minimal re-ranking of constraints between them. 
notion of the elegant overall structure. On the one hand, such an attitude means that Kruszewski simply did not develop the theory of the phoneme as such, focusing on alternations only. On the other hand, however, thanks to this attitude, his theory lacks certain restrictions of the structural view, offering superior predictive power instead.

The concept of the archiphoneme in the Prague School framework (section 3.3) entails insightful predictions regarding both processes under consideration. Despite the fact that it is a theory of representations, the rules seem to be indirectly encoded in the system. To a certain extent, the outcome of the analysis resembles some generative solutions, in particular, the $\alpha$-place convention.

In the structuralist account (section 3.4), phonetic and distributional facts, together with the importance of the symmetry of a phonological system, constitute the most significant arguments of the analysis. The pressure exerted by the Polish consonantal system is one of the major arguments for granting $\eta$ the status of a phoneme. The study is focused on phonemics, whose major principle is to cover phonetic and phonological data in a given language without reference to grammar. Thus, morphophonology is considered to be a separate field of studies and, by the same token, generative phonology would basically be regarded as an alternative technique of the morphophonological description.

The differences between the structuralist and the generative methodological principles lead to strikingly distinct analyses of Nasal Assimilation and Nasal Gliding in the generative framework (sections 3.5, 3.7 and 3.8). Generative phonology makes use of morphological and syntactic information, including the tool of boundaries. In the Lexical Phonology framework rules are organised in components and given distinctive status. The predictability criterion is emphasised in establishing the underlying form. Biuniqueness is rejected as an argument, as establishing the taxonomy of surface contrasts is no longer the ultimate aim of phonological analysis. Consequently, $\eta$ cannot appear as the underlying form in Polish. Yet, Kiparsky's requirement according 
to which lexical rules should be structure-preserving is problematic from the generative point of view, since the results it generates seem to be flawed and not insightful. Constructing a symmetrical phonological system is not as significant as it is in structuralism. Thus, the argument that $\eta$ fills in the gap in the consonantal system in Polish is no longer decisive. The standard OT framework accounts for the transparent cases of the discussed processes in an elegant manner. Yet, it encounters analytical problems in the opaque contexts, in which the DOT framework turns out to be successful.

From the generative point of view, the analysis in the NGP framework (section 3.6) produces undesirable results. Significant generalisations, interrelated with the predictability criterion, are lost due to severe restrictions imposed on the phonology-morphology interface. Further considerable loss can be blamed on the NGP principles: the No Ordering Condition and the Strong Naturalness Condition. 


\section{CHAPTER 4}

\section{LEVELS OF PHONOLOGICAL REPRESENTATION}

This chapter deals with the issue of distinct levels of phonological representation. Section 4.1 focuses on the phonemic representation, the problem of overlapping in the structuralist framework and the methodological assumptions due to which overlapping ceased to be a problem in generative phonology. Moreover, the interrelation of morphology and phonology is discussed, as it influences the process of establishing the basic phonological unit in the frameworks such as Kruszewski's theory of alternations or Natural Generative Phonology. Thus, the first section deals also with the problem of distinct levels of phonological and morphophonological representations (divergents and correlatives, P-rules and MP-rules). The basis for the discussion is the process of Voice Assimilation. Section 4.2 focuses on the morphology-phonology interface by presenting the notion of a juncture phoneme. The basis for the discussion is the problem of German ch. It is shown how it is accounted for in selected phonological frameworks. The adopted solutions give an overview of the concepts that have been crucial in the process of establishing the basic phonological unit in the history of phonology. Hence, the notions of a juncture phoneme, phonological boundaries and brackets are shown as crucial in the judgement concerning the problem of one phoneme-or two phonemes. 


\subsection{Phonemic representation}

The presentation begins with a review of the assimilation facts in Russian (section 4.1.1)..$^{52}$ In section 4.1.2, I conduct the analysis in accordance with the principles of the Kazan School. The Prague School interpretation of Voice Assimilation is discussed in section 4.1.3. Section 4.1.4 presents the classic analysis carried out by Halle (1959), in which the structuralist and the generative theoretical assumptions are compared. In section 4.1.5 Schane's proposal of a modified concept of the phoneme is analysed. Section 4.1.6 focuses on the interpretation of the process in the Natural Generative Phonology framework. In section 4.1.7, I conduct the analysis in the Lexical Phonology framework and in section 4.1.8, in the Optimality Theory framework. Partial conclusions are presented in section 4.1.9.

\subsubsection{Voice Assimilation: basic generalisations}

Obstruent clusters in Russian agree in voicing both inside words and across word boundaries, as illustrated in (la) and (lb). ${ }^{53}$ The same process can be noticed in complex words with prefixes such as od and $z$, as presented in (lc) and (ld).

(1) a. zvezda [zd] "star" (nom.sg.) - zvezd [st] "star" (gen.pl.)

b. budet dokazano [d] "it will be proved"; budet tiše [t] "it will be quieter"

52 Voice Assimilation exists in Polish as well. The reason why I choose Russian as the basis for the discussion is the fact that this language is actually analysed in classic works in the history of phonology, in particular, Halle (1959).

53 The only exception to the rule is the context in which $v$ occurs. Although it regarded as an obstruent, this segment does not trigger Voice Assimilation. However, one of possible analyses of the labial fricative is to assume that underlyingly it is a glide //w// (see for example Hayes 1984; for further discussion and other references, see Mołczanow 2008). Due to the controversies involved in the analysis of $v$, I will not focus on its exceptional behaviour. This behaviour would be problematic in all the discussed frameworks. 
c. ot-kryt' [t] "to open"; ot-dyhat' [d] "to rest"

d. s-torgovat' [t] "to bid"; s-davat' [d] "to deliver"

The examples on which I base the analyses in the succeeding sections come from Halle (1959) and are presented below.

(2) a. mok li [mok li] "was he getting wet?"

b. mok by [mog bi] "were he getting wet"

c. žeč li [žદč li] "should one burn?"

d. žeč by [žcdž bi] "were one to burn"

As confirmed by the words in (2a) and (2c), Voice Assimilation does not occur before sonorants. Before voiced obstruents, the segments $k$ and $\check{c}$ become $g$ and $d \check{z}$, respectively.

The rule of Final Devoicing (FD) is also active in Russian. As can be seen in the examples provided below (3b), Voice Assimilation may be fed by FD, that is, after devoicing has applied, the assimilation takes place.

(3) a. noga [g] "leg” (nom.sg.) - nog [k] "leg” (gen.pl.)

b. zvezda [zd] "star" (nom.sg.) - zvezd [st] "star" (gen.pl.)

However, there are certain contexts in which Final Devoicing (4a) does not apply (4b).

(4) a. vrag naroda [k-n] "the enemy of the people/nation"

b. nad narodom $[\mathrm{d}-\mathrm{n}]$ "above the nation"

The generalisation is as follows. Final Devoicing takes place before words that begin with a sonorant, unless the word is a preposition. Hence, the difference between the words in (4a) and (4b). ${ }^{54}$

54 Prepositions in Russian may be analysed as belonging to the same phonological word (PWd) as the following word. Therefore, it is possible to state that FD occurs at the end of the phonological word, which explains the behaviour of the preposition in (4b). 


\subsubsection{The Kazan School: Kruszewski's theory of alternations}

Kruszewski made a distinction between two major categories of phonological alternations: divergents and correlatives, the latter one being further divided into two subtypes. Divergents are characterised as closely related (phonetically) and the cause of this alternation as such is based on phonetic grounds. Moreover, the contexts in which an alternation takes place are visible and can be well defined, and the alternation itself is exceptionless. Divergents are modifications (fission) of one and the same sound, and not two or three distinct sounds. In modern terms, divergents would be regarded as allophones of one phoneme.

For the purpose of this study, I base the analysis on the examples presented in the preceding section and repeated in (5).

(5) a. mok li [mok li] - "was he getting wet?"

b. mok by [mog bi] - "were he getting wet"

c. žeč li [žzč li] - "should one burn?"

d. žeč by [žzdž bỉ] - "were one to burn"

Let us now examine the facts of VA in Russian in accordance with the methodological principles of Kruszewski's theory of alternations. Firstly, I will focus on correlatives. The first requirement for given alternants to be classified as correlatives is the opacity of the context in which they occur. This criterion is not met, since Voice Assimilation in Russian can be stated solely with regard to the neighbouring phonetic segments. Second, the alternation of correlatives may have exceptions. Voice Assimilation, however, is exceptionless. ${ }^{55}$ The third characteristic feature of correlatives is the relevance of morphological information for the statement of the context. Yet, this requirement is not met, since no access to morphological information is necessary to state the context of the change. Finally, correlatives are not required to be phonetically similar. However, the analysed alternants are very similar, which

55 The peculiar behaviour of $v$ is disregarded, see Chapter 4, section 4.1.1. 
would not be typical of correlatives. Yet, this criterion is imprecise and hence - the least important. In fact, Kruszewski argues that only the first two requirements are sufficient to identify the relationship between correlatives. In sum, I conclude that both $k-g$ and $\check{c}-d \check{z}$ are not correlatives of the first type.

The difference between two types of correlatives is connected with the criterion regarding potential exceptions. The second type of correlatives, unlike the first one, is exceptionless within a limited morphological scope. The analysed alternants do not belong to this type of correlatives, as voice assimilation in Russian is not restricted to specific grammatical categories, such as, e.g., "plural" or "diminutive".

Further, let us check whether the alternants under consideration belong to the category of divergents. There are four factors that need to be considered before labelling a given pair of alternants as divergents. First, the context of the alternation should be transparent and stateable in purely phonetic terms. Voice Assimilation in Russian fulfils this requirement, as it makes reference only to the phonetic quality of the neighbouring sounds. Next, divergents are insensitive to morphological boundaries, which is the case in the process under analysis. The third requirement, again met by the alternation, is for the process to be exceptionless. The fourth factor requires phonetic similarity of the alternating sounds. Kruszewski does not state the principles of this criterion in formal terms. Yet, given his examples, we may draw certain conclusions concerning the process at stake. In Kruszewski's view, there are various degrees of sounds' affinity in the linguistic system: $k^{\prime}$ is a closer relative of $k$, while $c$-a further relative. The latter one could not be a divergent of $k$, which seems to hold true for our examples cited in (5) above. However, it is difficult to take this principle into account, as no formalism is offered in this framework, and Kruszewski himself claims that it is not necessary for divergents to satisfy this criterion.

The relationship between divergents is formalised, as illustrated in (6). The sound $s$ is called primary, and the sound $s_{1}$ is secondary. 
(6) $x$ - the condition of the appearance of a sound $s$ / the context

$s$ - a given sound

$x_{1}$ - a condition which excludes $s$ and changes it into $s_{1}$

$s_{1}$ - sound $s$ after a change

The representation of Voice Assimilation in Russian is provided in (7). The analysis of the $k-g$ alternation (7a) is parallel to the analysis of the $\check{c}-d \check{z}$ alternation (7b).

(7) a. $x$ - before a sonorant, before a voiceless obstruent, before a stop $s-\mathrm{k}$

$x_{1}$ - before a voiced obstruent

$s_{1}-\mathrm{g}$

b. $x$ - before a sonorant, before a voiceless obstruent, before a stop

$s-\check{c}$

$x_{1}$ - before a voiced obstruent

$s_{1}-\mathrm{dzz}$

To recapitulate the above arguments, I conclude that the alternating sounds that take part in Voice Assimilation belong to the category of divergents. Divergents are a modification (fission) of the primary sound. In modern terms, they are allophones of the same phoneme, namely, $g$ is a contextual variant of $k$ and $d z ̌$ is a contextual variant of $\check{c}$.

\subsubsection{The Prague School: functionalist structuralism}

Anderson (1986: 110-112) addresses the point of Voice Assimilation in Russian from the perspective of Trubetzkoy's framework. The basis of his analysis are Halle's examples, repeated in (8).

(8) a. mok li [mok li] - "was he getting wet?"

b. mok by [mog bi] - "were he getting wet"

c. žeč li [žeč li] - "should one burn?"

d. žeč by [žદdž bi] - "were one to burn" 
Anderson provides the representations of potential combinations of obstruents and/or sonorants at morpheme boundaries, as cited in (9).

(9) Lexical form: $\{\mathrm{t}+\mathrm{l}\}\{\mathrm{t}+\mathrm{b}\}\{\mathrm{d}+\mathrm{l}\}\{\mathrm{d}+\mathrm{b}\}\{\check{c}+\mathrm{l}\}\{\check{c}+\mathrm{b}\}$

Phonemic form: / $\mathrm{t}+\mathrm{l} / / \mathrm{T}+\mathrm{b} / / \mathrm{d}+\mathrm{l} / / \mathrm{T}+\mathrm{b} / / \check{c}+\mathrm{l} / / \check{\mathrm{c}}+\mathrm{b} /$

Phonetic form: $[t+1][d+b][d+1][d+b][\check{c}+1][d \check{z}+b]$

The crucial tool in this analysis is the concept of an archiphoneme /T/, which represents the neutralisation of the contrast between / $t /$ and /d/ before a following obstruent, hence its lack of value for voicing. Anderson defines neutralisation as "the correlation of voicing in obstruents suspended in preobstruent position" and points to the general nature of this statement. The two classes of obstruents are not made distinct, and, therefore, the basic generalisation is not lost, which is a major disadvantage of the structuralist analysis, as pointed out by Halle (1959). ${ }^{56}$ The second statement (in Anderson's view-equally general as the first one) that must be posited is the rule that distributes the noncontrastive feature of voicing both to the archiphoneme / $\mathrm{T} /$ and to the phonemes such as //č// in the context of a voiced obstruent following.

Anderson argues that although in Trubetzkoy's framework we need two distinct statements, the generalisation itself is not split, as it is in the structuralist account (see Chapter 4, section 4.1.4). The two required statements are supposed to have "distinct logical roles", the first one dealing with the lack of a certain contrast, and the second one - with surface pronunciation rules. Moreover, he points to the fact that both statements are independently motivated and indispensable in the system. The only potential objection could concern their reference to the same environment.

Yet, Anderson concludes that Halle's postulate of having "a uniform rule of variation [...] stated in a single, general way" (1986: 112) is not obeyed in the phonology of the Prague School.

${ }^{56}$ Halle's analysis is presented in the following section. 
On the other hand, however, one should bear in mind that the idea of stating phonological rules in formal terms was not a crucial issue for Trubetzkoy. Rather, the Prague School focused on the representations, with the archiphoneme being a central tool in the process of listing phonological alternations.

\subsubsection{Distributional structuralism vs. generativism: Halle's analysis}

Halle's classic analysis developed in The Sound Pattern of Russian (1959) constitutes the first generative account of the assimilation facts in Russian. The analysis abandons the phonemic representation.

Voicing is distinctive in Russian for all obstruents except $c$, $\check{c}$ and $x$, but if they precede a voiced obstruent, they become voiced. At the end of a word, they are voiceless unless the next word begins with a voiced obstruent, as illustrated in (10).

(10) a. mok li [mok li] - "was he getting wet?"

b. mok by [mog bi] - "were he getting wet"

c. žeč li [žcč li] - "should one burn?"

d. žeč by [žcdž bi] - "were one to burn"

The structural principle of biuniqueness (Bloch 1941) requires that a given sequence of phones should be represented by a unique sequence of phonemes and that a given sequence of phonemes should be represented by a unique sequence of phones, or in other words: phonemic representations should be uniquely recoverable from phonetic data alone.

In Russian, $d \check{z}$ does not appear in contrastive distribution. In the case of non-native words, such as jihad, the initial cluster is pronounced separately, as a stop and fricative and not as an affricate. The segment under analysis occurs solely in complementary distribution with $\check{c}$, as a result of Voice Assimilations discussed in this section. Consequently, it does not have a phonemic status; rather, $d \check{z}$ is an allophone of $\check{c}$. However, it cannot be postulated 
that the change from $k$ to $g$ is an allophonic change, because $g$ is a phoneme in Russian, as could be concluded on the basis of a minimal pair, such as: kora [k] "bark" - gora [g] "mountain". On the basis of the above-mentioned observations and the methodological principles, the structuralist phonemic representation should be as follows: /mok li/, /mog bi/, /ž̌č li/ and /žzč bi/.

Since, however, $d \check{z}$ is not a phoneme in Russian, the change from $\check{c}$ to $d \check{z}$ is an allophonic change. Therefore, a single rule (Voice Assimilation) produces both a phonemic change (here: for $k$ that changes into $g$ ) and a subphonemic change (for $\check{c}$ that becomes $d \check{z}$ ). Yet, if the phonemic representation and the principle of biuniqueness are rejected, the representation is uniform for all segments: /mok li/, /mok bi/, /žč̌ li/, /žદč bi/. Thus, the structuralist analysis enforces a division of a single generalisation, whereas in the generative framework it is possible to account for the assimilation facts in a unified way. The morphophonemic representation and the rules in (11) prove to be sufficient to explain the process of VA.

$$
\text { (11) } \begin{aligned}
{[\text { +obstr }] } & \rightarrow[\text { +voiced }] / \longrightarrow\left[\begin{array}{l}
\text { +obstr } \\
\text { +voiced }
\end{array}\right] \\
{[\text { +obstr }] } & \rightarrow[\text {-voiced }] / \longrightarrow\left[\begin{array}{l}
\text { +obstr } \\
\text {-voiced }
\end{array}\right]
\end{aligned}
$$

As assimilation involves both values of the feature [voice], the rule of VA can be stated with the use of the $\alpha$-convention.

$$
\text { (12) }[+ \text { obstr }] \rightarrow[\alpha \text { voice }] / \_\quad\left[\begin{array}{l}
+ \text { obstr } \\
\alpha \text { voice }
\end{array}\right]
$$

\subsubsection{Schane: The Phoneme Revisited}

The debate concerning "the phoneme" continued in the days of generative phonology. Schane in "The Phoneme Revisited" (1971) adopts the view that the phoneme is a useful tool required in 
phonological analysis. It is only the idea of a separate phonemic level of representation that should be abandoned. He argues that rules have two functions (effects), that is, morphophonemic and phonetic. Morphophonemic rules can change one underlying segment into another (for instance, Final Devoicing in Polish) or an underlyingly non-distinctive feature into a contrastive one on the surface. ${ }^{57}$ The crucial claim is that this distinction allows us to state when a given change is phonemic. As Schane points out: "only those phonetic differences resulting from morphophonemic rules are phonemic" (1971: 514).

Schane addresses the issue of VA in Russian as presented by Halle, stating that in this case, the same rule may have two different effects (phonetic and morphophonemic) for different segments. For $\check{c}$ the function is purely phonetic ( $d \check{z}$ being always recoverable while appearing on the surface level), while for $k$ the effect is morphophonemic (conversion of "one underlying segment into another, where both originally occur in the same environment"). Schane claims that his view is not flawed in the way in which the structural analysis of VA was shown to be, for he does not posit an autonomous phonemic level of representation. Rather, the phoneme is to be deduced from the surface representation and the function of rules. Schane states that Halle rejects the phonemic level in order to have a single rule of VA in the phonological framework; otherwise the rule would have to be divided in two. The conclusion is that his proposal combines the two options that were mutually exclusive before:

The phoneme was the offspring of structuralism, the pride and joy of post-Bloomfieldian linguistics. Since then the child has been abandoned. Yet, some of us may have felt guilty about disinheriting the child. As generativists, if we acknowledged him, then it was an illegitimate child. Perhaps we can now recognize the little bastard for what he really is (Schane 1971: 520).

57 This is illustrated by the problem with angma in English; see Chapter 2 , section 2.2. 
It seems that Schane's proposal concerning novel, "generative" understanding of the phoneme escapes Halle's vital objections aimed at structuralism and its phonemic level of representation. Yet, what remains to be clarified, is the raison d'être of the concept of the phoneme without its formal level of representation. One might conclude that it is not an indispensable tool for phonological analyses, as morphophonology by itself gives an account of all the data under consideration.

\subsubsection{Natural Generative Phonology}

The major distinction that is made in the NGP framework is between phonetically conditioned (P-rules), whose environments are specified in purely phonetic terms. That is, they are specified in terms of phonological features (which have intrinsic phonetic content) and phonological boundaries (which have phonetic manifestation), such as the syllable boundary and the pause boundary. The word and the morpheme boundaries are considered nonphonetic, as they are conditioned by syntactic and semantic information. All P-rules are natural and exceptionless (for instance, aspiration in English). P-rules correspond to Kruszewski's divergents. Morphophonemic rules (MP-rules) are rules whose environments are described in morphosyntactic or lexical terms, so they refer to morphological or syntactic categories, such as plural, past, noun, verb (wife-wives, house-hou[z]es in English) (Hooper 1976: 15). MP-rules take part in the sound-meaning correspondence of a language and are therefore language-specific. They may be phonologically quite arbitrary and are likely to have exceptions. MP-rules correspond to Kruszewski's two types of correlatives.

Let us consider the facts of Russian VA from the point of view of the NGP framework. This process, being assimilatory in nature and as such associated with the physical properties of a vocal tract, may seem a good candidate for the label of a P-rule. 
(13) $[$ +obstruent $] \rightarrow[\alpha$ voice $] /-\left[\begin{array}{c}\text { obstr } \\ \alpha \text { voice }\end{array}\right]$

Phonological features involved in the assimilation have intrinsic phonetic content and the rule itself might be called "natural". Morpheme and word boundaries are not restrictive, that is, they are not required in the statement of the rule.

Thus, in the NGP framework, the rule of VA would be a P-rule. The outcome of the analysis is therefore the same as in the standard generative view.

\subsubsection{Lexical Phonology}

In this section, I conduct the analysis of Voice Assimilation in Russian in accordance with the principles of Lexical Phonology. First, I adopt the tenets of Kiparsky (1982, 1984, 1985), developed by Borowsky (1986). Next, Booij and Rubach's (1987) model of Lexical Phonology is considered, the focus being the status of phonological rules as belonging to specific components. Finally, the predictions of both views are compared.

In Kiparsky's (1982, 1984, 1985) view, adopted and slightly modified by Borowsky (1986), rules are organised into a single block and apply freely whenever their context (structural description) is met. They are not restricted to particular components. Rather, their application may be blocked by the principles of the theory. ${ }^{58}$ In this view, lexical and postlexical rules are not considered to exhibit systematic differences. Their application is crucially governed by the Strong Domain Hypothesis (Kiparsky 1984), cited in (14).

58 As Borowsky admits, this approach is different from Kiparsky's earlier views, as well as from the views of Mohanan and Mohanan (1984), Rubach (1984), Halle and Mohanan (1985), according to whom rules are organised with respect to morphological components. 
(14) The Strong Domain Hypothesis

(i) All rules are available at the earliest level of the phonology.

(ii) Rules may cease to apply, but may not begin to apply at a later level by stipulation.

In general, rules do not belong to domains, forming a single block available in the course of the derivation. Yet, a given rule can be restricted to the earliest phonological level. Borowsky offers a modification of Kiparsky's tenet by adding the principle cited below.

(15) Principle of Domain Assignment

All rules which are marked for a particular domain of application apply at level 1 only. ${ }^{59}$

The Strong Domain Hypothesis and the principle of Structure Preservation (discussed in section 4.2.7) influence the application of rules throughout the derivation.

Borowsky adopts Selkirk's (1982) concepts regarding the levels of morphology involved in the explanation of phonological processes, level 1 being the domain of the Root category processes, and level 2-the domain of the Word category processes. Moreover, Borowsky assumes the existence of a cycle on the unaffixed form entering level 2.

Let us now consider VA in Russian from the general perspective of Lexical Phonology. The analysis involves Halle's examples, repeated in (16).

(16) a. mok by [mog bi] "were he getting wet"

b. žeč by [žcdž bi] "were one to burn"

No rule applies on the first cycle of the lexical component. The suffix $-b i$ is added on Cycle 2 via a Word-Formation rule (WFR).

59 These rules are marked by a diacritic feature [+L] (lexical) and they apple only at level 1 . 
Next, VA takes place, changing $k$ into $g$, and $\check{c}$ into $d \check{z}$. At the end of each component, Bracket Erasure Condition (BEC) applies and ensures that the morphological brackets introduced at this level are erased before entering the next level. A preliminary derivation (without the discussion of components) is offered in (17).
(17) $/ / \mathrm{mok} / /$
//žzč//
Cycle 1 mok
žzč
Cycle 2
+ bi WFR: -bi Suffixation

$\begin{array}{ll}\operatorname{mogbi} & \text { žcdžbi } \\ {[\operatorname{mogbi}]} & {[\check{z} \varepsilon d z ̌ b i]}\end{array}$

The above derivation seems to capture the generalisation that was postulated by Halle (1959), namely, that Voice Assimilation is a unitary process changing voiceless obstruents into voiced ones, irrespectively of the phonemic status of a given obstruent. The lexical framework seems to be able to express that generalisation without splitting the rule into two sub-rules of distinct status, which constituted a firm objection towards the structuralist representation.

Let us now revise and expand this preliminary analysis by adopting the abovementioned principles introduced by Kiparsky. The two principles that are going to prove significant are The Strong Domain Hypothesis and Structure Preservation (SP). According to SP, non-distinctive features cannot be introduced by the rules in the lexical component. Only distinctive features may be inserted within the lexical phonology component.

If we apply the principle of SP to the problem discussed, the derivational picture presented in (17) does not seem appropriate. Voicing is distinctive for $k$ (changing this segment into $g$ ) but non-distinctive for $\check{c}$ (changing this segment into $d \check{z}$ ). Thus, in the lexical component, the same rule of VA seems to exhibit contradictory features in light of SP. For the segment $k$, it fulfils the conditions imposed on lexical rules, hence it belongs to the 
lexical component. For the other segment in question, however, the conditions for a given rule to be classified as lexical are not obeyed ( $d \check{z}$ is a non-distinctive segment in Russian). Consequently, the rule of VA for $\check{c}$ is forced to move to the postlexical component, and the derivation requires modification, as presented in (18) below.

(18)

\section{$/ / \mathrm{mok} / / \quad / / \check{z} \varepsilon \check{c} / /$}

Lexical component

Cycle $1 \quad$ mok $\quad$ žč̌

Cycle 2

/mog

$\begin{array}{lll}/ \text { mogbi/ } & / \text { žcčbi/ } & \\ - & {[\check{z ̌ c d z ̌ b i] ~}} & \text { VA } \\ {[\text { mogbi] }} & {[\check{z ̌ c d z ̌ b i] ~}} & \end{array}$

+ bi WFR: -bi Suffixation blocked by SP VA /žzčbí/

Postlexical component

For the purpose of this study, I assume that the enclitic bi constitutes part of the phonological word. Therefore, VA can be analysed within the lexical component in the case of words such as mokbi [mogbi]. Actually, the phonological status of enclitics, as well as the status of prepositions and prefixes, is a controversial and complex issue, which is beyond the scope of this work. Let us therefore focus on straightforward examples presented below, illustrating the artificial split of VA in the framework under consideration.

(19) a. afganskij [vg] "Afghan"

b. rot bolnoj [db] "sore mouth"

c. noč belaja [džb] "white night" 
The derivation is as follows.

$\begin{array}{lll}\text { (20) //afganskij// } & \text { //rot \# bolnoj// } & \text { //noč \# belaja // } \\ \text { //afgan// } & \text { //rot// } & \text { //noč// }\end{array}$

Lexical component

Cycle 2

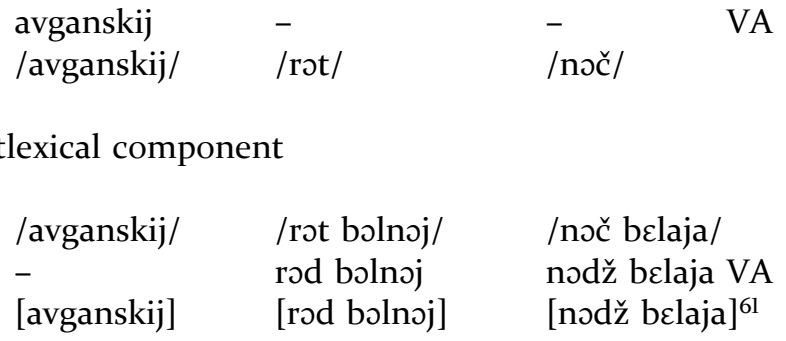

In line with The Strong Domain Hypothesis, Voice Assimilation is not restricted to a given component. Rather, it applies whenever its structural description is met. What seems to be problematic is the prediction regarding the analysis of $d \check{z}$, which splits VA much like in classic structuralist framework, criticized by Halle (1959). All instances of $\check{c} \rightarrow d \check{z}$ would be forced to move to the postlexical component, even if this alternation occurred word-internally. On the other hand, $k \rightarrow g$ would be analysed in both components (lexical and postlexical), depending on the context in which the change occurs (within words or across word boundaries, respectively).

Pulling together the results, I conclude that the Strong Domain Hypothesis and the principle of Structure Preservation make a prediction that seems to be flawed from the methodological point of view. It functions similarly to the structural principle of

${ }^{60}$ Actually, -skij is two different suffixes: -sk for Adjectivization and -ij for the nom.sg., but I am not focusing on these facts here.

${ }^{61}$ Surface Palatalisation palatalises consonants before front vowels, so $k \rightarrow k^{\prime}$ in avganskij and $\mathrm{b} \rightarrow \mathrm{b}^{\prime}$ in belaja. 
biuniqueness, which artificially split one rule into two types of change: phonemic and allophonic (see Chapter 4, section 4.1.4), and thus it fails to capture the single generalisation of Voice Assimilation.

Let us now study Voice Assimilation within the Lexical Phonology framework, but adopting the model of Booij and Rubach (1987). The significant novelty involved in this view consist in recognising the postcyclic component (see Chapter 1, section 1.6). Moreover, according to Booij and Rubach, rules belong to components. Unlike in the previous model, The Strong Domain Hypothesis and the Structure Preservation Principle play no role in the analysis.

As remarked earlier, Voice Assimilation in Russian applies within words and across word boundaries. The rule does not require access to morphological information and it does not have exceptions. Thus, it is assumed to apply in the postlexical component. In Kiparsky's view, VA also applies in this component. Yet, the crucial difference is the prediction that VA applies only postlexically.

What remains to be clarified is the question whether the changes in the methodological principles have application in our analysis. Let us therefore reconsider the examples presented above. The derivations of mokby and żečby ${ }^{62}$ are carried out in (21).

$$
/ / \mathrm{mok} / / \quad / / \text { žč̌// }
$$

Lexical component

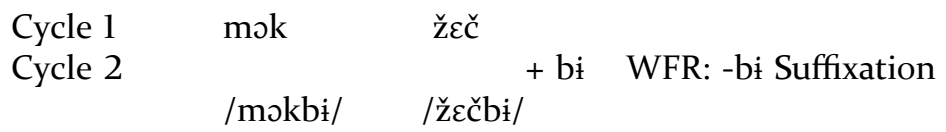

${ }^{62}$ For the purpose of this study, I assume that in this case VA occurs word-internally. In other words, enclitics are not analysed as separate phonological words. 
Postlexical component

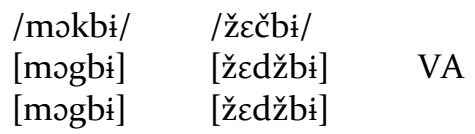

Voice Assimilation applies solely in the postlexical component, irrespectively of the phonological status of the sounds involved in the process.

The examples provided in (20) are now reanalysed as follows.

$$
\begin{array}{lll}
\text { //afganskij// //rot \# bolnoj// } & \text { //noč \# belaja // } \\
\text { //afgan// } & \text { //rot// } & \text { //noč// }
\end{array}
$$

Lexical component

$$
\begin{aligned}
& \text { Cycle } 1 \text { afgan not ň } \\
& \text { Cycle } 2 \\
& \begin{array}{lll}
\text { afganskij } & - & - \\
\text { /afganskij/ } & \text { /rot/ } & \text { /nočl }
\end{array} \\
& \text { Postlexical component } \\
& \begin{array}{lll}
\text { /afganskij/ } & \text { /rot bolnəj/ } & \text { /noč belaja/ } \\
\text { avganskij } & \text { rod bolnəj } & \text { nodž belaja VA } \\
\text { [avganskij] } & \text { [rod bolnəj] } & \text { [nodž belaja] }
\end{array}
\end{aligned}
$$

Again, Voice Assimilation occurs uniquely in the postcyclic component. As a result, the rule is not split into two distinct processes which would apply in distinct components. Overall, the model of Booij and Rubach (1987) succeeds in capturing the fact that Russian VA is a single generalisation.

\subsubsection{Optimality Theory}

In terms of Optimality Theory, Voice Assimilation results from the interaction of faithfulness constraints and well-formedness (markedness) constraints. The requirement for obstruent clusters 
to agree in the feature [voice] is expressed by the constraint AGREE $_{[ \pm V O I C E}$.

(23) AgREE $_{\text {obstruent [tvolce }]}$ : Obstruent clusters agree in voice.

However, a faithfulness constraint IDENT ${ }_{[\mathrm{VoI}, \mathrm{I}}$ militates against the change of the underlying [ \pm voice] features.

(24) IDENT $_{[ \pm \text {VoIcE] }}$ : The value of [ \pm voice] feature in the input must be preserved in the output.

Let us reconsider the examples presented above, namely, //mokbi// and //žcčbi//. The tableau (25) illustrates the constraint interaction involved in the analysis of the former example.

(25) $/ / \mathrm{mokbi} / /$

\begin{tabular}{c|c|c}
\hline & AGREE $_{\text {OBSTRUENT [ }[\text { VOICE] }}$ & IDENT $_{[ \pm \text {VOICE] }]}$ \\
\hline a. mogbi & & $*$ \\
\hline b. mokbi & $* !$ & \\
\hline
\end{tabular}

The optimal candidate (25a) violates the lower-ranked constraint IDENT $_{\text {[VoIce] }}$. Its contender, candidate (25b), incurs a violation of AGREE $_{\text {obstruent [ }[ \pm \text { VoIce] }}$. Since this constraint is higher-ranked, the candidate with Voice Assimilation is the winner.

The analysis of //žzčbít/ is conducted in tableau (26).

(26) $/ /$ žzčbí//

\begin{tabular}{|c|c|c|}
\hline & AGREE $_{\text {OBSTRUENT [ }}$ VOICE] & $\operatorname{IDENT}_{[ \pm \mathrm{VOICE}]}$ \\
\hline a. žcdžbi & & * \\
\hline b. žč̌bi & $* !$ & \\
\hline
\end{tabular}

The constraint interaction is parallel to the analysis in (25). Candidate (26a), which does not violate the higher-ranked the 
AgreE constraint, is the winner. Candidate (26b) satisfies the faithfulness constraint but violates the AGREE constraint.

Overall, Optimality Theory offers a unified account of VA in Russian, without the artificial split of the generalisation into the traditional phonemic and allophonic processes.

What remains to be explained is the issue of directionality, inherent in the OT model. The traditional generative SPE-style rule, presented in (27), entails the direction of the change (in this case: assimilation). In OT, however, the structural change $(\mathrm{A} \rightarrow \mathrm{B})$ and the structural description (the context; here:_C) have been decoupled. Instead, a given sound combination is prohibited, in this case: *AC.

$$
\mathrm{A} \rightarrow \mathrm{B} /{ }_{-} \mathrm{C}
$$

In the process of VA, the prohibited combination is a cluster of obstruents which do not share the same [voice] value. Yet, it cannot be stated whether they should share the feature [+voice] or [-voice]. This is problematic from the point of view of this analysis, as shown in tableaux (28a) and (28b).

(28) a. //mokbi//

\begin{tabular}{c|c|c}
\hline & AGREE $_{\text {OBSTRUENT [ } \pm \text { VOICE] }}$ & IDENT $_{[ \pm \text {VOICE] }}$ \\
\hline a. mogbi & & $*$ \\
\hline b. mokpi & & \\
\hline c. mokbi & $* !$ & \\
\hline
\end{tabular}

b. //žzčbì //

\begin{tabular}{|c|c|c|}
\hline & AGREE $_{\text {Obstruent [ }}$ (EOICE] & $\operatorname{IDENT}_{[ \pm \mathrm{VOICE}]}$ \\
\hline a. žcdžbi & & $*$ \\
\hline b. žč̌pi & & \\
\hline c. žદčbi & *! & \\
\hline
\end{tabular}


In classic generative terms, the process of Voice Assimilation in Russian is regressive. Yet, as stated above, in Optimality Theory, it is not possible to predict the direction of the change. As a consequence, not only mogbi and $\check{z} \varepsilon d z ̌ b i$, but also the new candidates introduced in (28): [mokpi] and [žč̌pi], satisfy the AGREE constraint. The result of the analysis is a tie. It may seem that a modification of the IDENT constraint could solve this problem, namely, we could postulate a more specific constraint: IDENT ${ }_{[+\mathrm{voICE}]}$, as illustrated below. The generic IDENT constraint can split into IDENT $_{[+ \text {voIce] }}$ and IDENT [-voIcE]

(29) a. //mokbí//

\begin{tabular}{|c|c|c|c|}
\hline & AGREE $_{\text {OBSTRUENT [ }}$ VVoice] & IDENT $_{[+ \text {VOICE }]}$ & IDENT $_{\text {[-vOICE] }}$ \\
\hline a. mogbi & & & * \\
\hline b. mokpi & & $* !$ & \\
\hline c. mokbi & $* !$ & & \\
\hline
\end{tabular}

b. //žzčbì //

\begin{tabular}{|c|c|c|c|}
\hline & AGREE $_{\text {OBSTRUENT [ }}$ VOICE] & $\operatorname{IDENT}_{[+\mathrm{VOICE}]}$ & IDENT $_{[\text {-VOICE] }}$ \\
\hline a. žcdžbi & & & * \\
\hline b. žč̌pi & & $* !$ & \\
\hline c. žعčbi & $* !$ & & \\
\hline
\end{tabular}

Both candidates that proved problematic in the previous analysis, that is, [mokpi] and [žcčpi], incur a violation of the higher-ranked IDENT $_{\text {[+VoIce] }}$ constraint. The division of the generic IDENT constraint into IDENT [+voICE] and IDENT [-voIcE] seems to have solved the problem and the evaluations yield the desired results.

The problem is that Voice Assimilation in Russian entails both voicing and devoicing, which is evidenced by words such as gorodek [d] "town" (nom.sg.) vs. gorodka [t] "town" (gen.sg.) 
In gorodka, the underlying $/ / \mathrm{d} / /$ is devoiced in the context of the following voiceless obstruent. Tableau (30) illustrates the consequences of adopting the constraint ranking presented in $(29){ }^{63}$

(30) //gorodoka//

\begin{tabular}{|c|c|c|c|}
\hline & AGREE $_{\text {OBSTRUENT [ }[ \pm \text { VOICE }]}$ & IDENT $_{[+ \text {VOICE }]}$ & IDENT $_{[\text {-voICE] }}$ \\
\hline a. gorotka & & $* !$ & \\
\hline * b. gorodga & & & * \\
\hline c. gorodka & *! & & \\
\hline
\end{tabular}

As shown in (30), the constraint ranking adopted earlier leads to the undesirable results when the trigger of assimilation in the feature [-voice]. In sum, the directionality problem results in a ranking paradox, which needs to be resolved through repair techniques.

Directionality effects in OT are typically obtained by invoking positional faithfulness (Beckman 1995, Beckman 1997, Casali 1997). In this theory, faithfulness can be made sensitive to positions of special privilege, including the onset. The relevant constraint here is the one mandating the preservation of the value of [voice] in the onset.

(31) IdENT $_{[\text {IVoIce])Onset }}$ : The value $[ \pm$ voice] in the input must be preserved in the output in the onset position.

The analysis works on the condition that the syllabification of mokbi is [mok.bi].

${ }^{63}$ I disregard the analysis of an underling yer in the word gorodka, as it lies outside the scope of the present study. Rather, I focus on the assimilation facts, but I ignore the vowel reduction process known as Akanie. 
(32) $/ / \mathrm{mokbi} / /$

\begin{tabular}{|c|c|c|c|}
\hline & AGREE $_{\text {ObStRUEnt [ }[ \pm \text { VOICE] }}$ & $\operatorname{IDENT}_{[ \pm \text {VOICE] }) \text { ONSET }}$ & IDENT $_{[ \pm \text {VOICE }]}$ \\
\hline a. mog.bi & & & * \\
\hline b. mok.pi & & *! & \\
\hline c. mok.bi & $* !$ & & \\
\hline
\end{tabular}

However, Russian maximizes onsets, so the syllabification in (32) is not the default pattern. The preferred syllabification has both obstruents in the onset, but then we face the ranking paradox problem again, since IDENT [士VOICE])ONSET does not differentiate between [mo.gbi], the desired winner, and [mo.kpi], the wrong output.

(33) $/ / \mathrm{mokbi} / /$

\begin{tabular}{|c|c|c|c|}
\hline & AGREE $_{\text {OBSTRUENT [ }}$ (EOICE] & $\operatorname{IDENT}_{[ \pm \text {VOICE] }] \text { ONSET }}$ & $\operatorname{IDENT}_{[ \pm \text {VOICE }]}$ \\
\hline a. mo.gbi & & * & * \\
\hline b. mo.kpi & & * & * \\
\hline c. mo.kbi & *! & & \\
\hline
\end{tabular}

Evidently, IDENT [士VOICE])ONSET cannot deliver the correct result.

The problem in (33) is resolved if we assume with Petrova et al. (2006) that positional faithfulness can be made sensitive to the presonorant position.

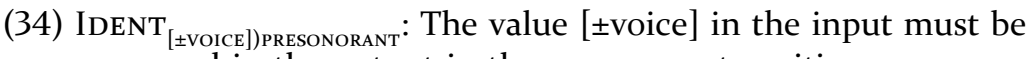
preserved in the output in the presonorant position.

Returning to //mokbi//, see that //b// is before a sonorant (here: before a vowel), whereas $/ / \mathrm{k} / /$ is not. Consequently, //b//, unlike $/ / \mathrm{k} / /$, is protected by IDENT [IVOICE])PRESONORANT , so the candidate [mo. kpi] loses to [mo.gbi], the desired result. The final evaluation is presented in (35). 
(35) $/ / \mathrm{mokbij} / /$

\begin{tabular}{c|c|c|c}
\hline & AGREE $_{\text {OBSTRUENT [ } \pm \text { VOICE] }}$ & IDENT $_{[ \pm \text {VOICE] }) \text { PRESONORANT }}$ & IDENT $_{[ \pm \text {VOICE] }}$ \\
\hline a. mo.gbi & & & $*$ \\
\hline b. mo.kpi & $* !$ & $* !$ & $*$ \\
\hline c. mo.kbi & & & \\
\hline
\end{tabular}

To recapitulate, Optimality Theory captures the generalisation concerning Voice Assimilation in a unified way. There is no distinction of processes with regard to the phonological status of the sounds in question (the alternation of $k-g$ versus $\check{c}-d \check{z}$ ). What proves to be problematic is the directionality issue, which is solved by positing a positional faithfulness constraint - IDENT ${ }_{[ \pm V O I C E]) \text { PRESONORANT }}$.

\subsubsection{Voice Assimilation: partial conclusions}

Using the example of Russian VA as analysed in selected frameworks, I have illustrated the recurring problems which accompany the process of establishing the basic phonological unit. As I tried to argue, the differences frequently stem from distinct priorities and basic concepts ("artefacts") of a given theory. Having different perspectives, phonological theories provide different insights, and bear different liabilities.

The major point of debate in this section is the conflict between grasping the generalisation concerning the phonemic representation on the one hand, and the generalisation concerning the unitary character of a phonological rule, on the other. In Kruszewski's theory of alternations (section 4.1.2) and in the Prague School framework (section 4.1.3), the generalisation is represented in a unitary way. In structuralism, however, the generalisation is split in two because of the biuniqueness principle, which is a major difference between structuralism and generativism (section 4.1.4). There is no difference between the standard Generative Phonology and Natural Generative Phonology regarding the analysis of Voice 
Assimilation in Russian (Section 4.1.6). Lexical Phonology offers a unitary account of Voice Assimilation, if we abandon the principle of Structure Preservation and adopt the concept of rules as belonging to components (section 4.1.7). In Optimality Theory, the generalisation is grasped in a unitary way, but the theory faces a different problem, namely directionality and the constraint paradox (section 4.1.8).

\subsection{Morphophonological representation}

This section deals with the morphophonological interface by analysing the problem of German ch. Section 4.2.1 introduces the issues under consideration by presenting a list of relevant classes of data. In the succeeding sections, the problem is analysed from the perspective of selected theories. I carry out the analyses according to the principles of the Kazan School and the Prague School in sections 4.2.2 and 4.2.3, respectively. The most important interpretations undertaken within the structuralist framework are discussed in section 4.2.4. In section 4.2.5, I provide a generative (SPE) account, whereas in section 4.2.6, I adopt the theses of Natural Generative Phonology. Section 4.2.7 offers two solutions within the Lexical Phonology framework, while section 4.2.8 focuses on Optimality Theory. The conclusions are summarised in section 4.2.9.

\subsubsection{The problem of German ch: basic generalisations}

One of the recurring problems in the phonology of German is the alternation of a velar fricative $x$ and a palatal fricative ç. The distribution of these two segments is almost complementary: $x$ is a [+back] velar fricative that occurs after [+back] vowels, while ç is a [-back] palatal fricative that occurs elsewhere, namely after [-back] vowels, after consonants and word-initially, as exemplified in (36) below. 
(36) a. hoch $[\mathrm{x}]$ "high"

b. mich $[c ̧]$ "me"

c. Milch [ç] "milk"

d. Chemie [ç] "chemistry"

Yet, the distribution of the velar and the palatal fricative is not fully complementary, as can be concluded on the basis of several well-known minimal pairs presented in (37).

(37) a. Kuchen $[\mathrm{x}]$ "cake" - Kuhchen [ç] "cow" (dimin.)

b. tauchen $[\mathrm{x}]$ "dive" - Tauchen [ç] "rope" (dimin.)

c. pfauchen $[\mathrm{x}]$ "hiss" - Pfauchen [ç] "peacock" (dimin.)

The words in the left column are pronounced with the back vowel $u^{64}$ and a velar fricative $x$ following. The words in the right column are also pronounced with a back vowel $u$, but the fricative is palatal ç.

\subsubsection{The Kazan School: Kruszewski's theory of alternations}

Let us focus on the problem of German fricatives from the point of view of Kruszewski's theory. If we centred on the data given in (36) alone, the theoretical solution would probably be straightforward. The success of the evaluation rests crucially on the fact that the context of the change can be stated in phonetic terms. The palatal fricative $c$ is taken as the primary sound $(s)$, and the velar fricative $x$ is the secondary sound $s_{l}$. The context of the change from $c$ to $x$ is the back vowel, to which $c$ assimilates, with $c$ being the elsewhere case. ${ }^{65}$ This solution may be represented as follows.

${ }^{64}$ In (37b) and (37c), the back vowel $u$ is part of a diphthong.

65 What seems to be problematic, however, is Kruszewski's condition that classifies divergents as "closely related phonetically", since he does not state the formal principles of this "close relationship." One might think that the only change allowed in the "divergent" alternation is a minimal phonetic change (as between $k$ and $k$ '). Yet, Baudouin de Courtenay in his elaboration 
(38) $x$ - the position after non-back vowels, after consonants and word-initially

$s-c ̧$

$x_{1}$ - the position after a back vowel

$s_{1}-\mathrm{x}$

Yet, a well-known group of words cited in (37) emerges as a problem in Kruszewski's framework. First of all, the Kuchen-Kuhchen alternation constitutes an exception to the account of the facts illustrated in (38), for in the latter word of the pair, we do not get the intended result, as shown in (39b).

(39) a. Kuchen [u:x] "cake"

$x_{1}$ - the position after a back vowel

$s_{1}-\mathrm{x}$

b. Kuhchen [u:ç] "cow" (dimin.)

$x_{1}$ - the position after a back vowel

$s_{1}-c ̧$ (the undesired result)

As stated earlier, the alternation of divergents is supposed to be exceptionless. For this reason alone, the preliminary analysis in (38) needs modification. What is more, the problematic pairs of words listed in (37) seem to constitute an excellent example of another category of alternations specified by Kruszewski, namely, correlatives of the second type.

In Kruszewski's view, correlatives of the second type form an alternation that is only morphological and not phonetic, yet, within its morphological scope, it is exceptionless. His example is the Umlaut phenomenon in German (see Chapter 1, section 1.1). The problematic instance of the palatal fricative ç, that is, the

on Kruszewski's theory gives further examples of divergents, with one of them being the alternation of vowels in Polish pairs of words such as:

rodu, "family, house" (gen.sg.) - ród, "family, house" (nom.sg.)

grobu, "grave" (gen.sg.) - grób, "grave" (nom.sg.)

The $o$ - ó vowels in this alternation are classified as "divergents" (Baudouin de Courtenay 1974 [1888]: 120). 
non-application of the process of Fricative Assimilation (FA), appears only in the diminutive suffix -chen, and as such, is exceptionless within its restricted scope.

The analysis of German dorsal fricatives poses a methodological problem for Kruszewski's theory of alternations. The observations regarding the regular behaviour of the dorsal fricatives in German lead us to the conclusion that we are dealing with divergents-two allophones of the same ç phoneme. Yet, the alternations including the diminutive suffix -chen seem to be correlatives of the second type, hence-two different phonemes.

\subsubsection{The Prague School: functionalist structuralism}

As shown in Chapter 1, section 1.2, in the Prague School framework, there are three major principles involved in the establishment of the phonological status of a given sound (Trubetzkoy (1971 [1939]: 46-49):

(Rule I) Two sounds of a given language are merely optional phonetic variants of a single phoneme if they occur in exactly the same environment and are interchangeable without a change in the lexical meaning of a word. (Rule II) If two sounds occur in exactly the same position and cannot be interchanged without a change in the meaning of the words or without rendering the word unrecognisable, the two sounds are phonetic realisations of two different phonemes. (Rule III) If two sounds of a given language, related acoustically or articulatorily, never occur in the same environment, they are to be considered combinatory variants of the same phoneme (Trubetzkoy 1971 [1939]: 46-49).

If we focused solely on the words in (36), we would conclude that the alternation of $\mathrm{x}$ and ç fulfils the third criterion. Consequently, the sounds would be regarded as combinatory variants of the same phoneme. However, the alternations in (37) constitute counterexamples to this analysis. Pairs of words such as Kuchen [x] "cake" and Kuhchen [ç] "cow" (dimin.) appear to fulfil the second 
principle stated above. They cannot be interchanged without affecting the meaning of the word (later, in structuralist terms they would be labelled as occurring in contrastive distribution).

Therefore, the alternation under consideration poses a problem for the Prague School framework. It seems that both $x$ and $c ̧$ would be regarded as phonemes in German, although in the vast majority of contexts, they occur in complementary distribution, the only exception being the diminutive suffix.

\subsubsection{Distributional structuralism}

In the standard structuralist account, both $x$ and $c$ should be regarded as separate phonemes. Words such as Kuchen-Kuhchen constitute a minimal pair, differing solely with regard to the velar vs. the palatal fricative, respectively. One minimal pair is sufficient to establish the phonemic status of a given sound (see Chapter 1, section 1.3). In accordance with the principle of once a phoneme, always a phoneme, the phonemic status of $x$ should be recognised, even if its occurrence is predictable in other contexts, as illustrated in (36). Thus, the status of $x$ never changes. Once $x$ has obtained a phonemic status, it cannot be reinterpreted as an allophone of $c$ in a different context, as this would violate the biuniqueness principle. With phonology being an autonomous module, the morphological status of the diminutive suffix -chen in Kuhchen should not influence the analysis.

However, such an analysis was considered undesirable already by some structuralists. As Anderson (1986) points out, Bloomfield's phonological analyses do not obey the principle of biuniqueness. One of the examples is Bloomfield's analysis of Kuchen [ku:xən], "cake"-Kuhchen [ku:çən], "cow" (dimin.) alternation in German. He states that the diminutive suffix -chen functions as a separate word, and therefore the word Kuh-chen is a phonological compound with a boundary. The $x$ phoneme occurs after $a$, $o$ and $u$ of the same word, ç being the elsewhere case. The generalisation is stated, yet it is impossible to recover the phonemic representation 
from the phonetic one, which would be in accordance with the biuniqueness condition.

Moulton (1947) presents a different analysis of German ch in the structuralist framework. He states that voiceless spirants $c$ and $x$ occur in complementary distribution, $x$ after central and back vowels and semivowels as in (40a), whereas ç after front vowels and consonants as in (40b). ${ }^{66}$

(40) a. Bach [bax] "brook"; nach [na:x] "towards"; hoch [ho:x] "high"; Buch [bu:x] "book"

b. mich [mıç] "me"; Pech [pєç] "tough luck"; nächst [ne:çst] "next"; Milch [mılç] "milk"

The ç segment appears also in words with more than one syllable: initially before vowels, where it shows its palatal allophone, as in China [çi:na], "China”.

The exception, when ç appears also after central or back vowels and semivowels, is visible in the latter word in the following alternation: Kuchen [ku:xən], "cake" versus Kuhchen [ku:çən], "cow" (dimin.).

In order to account for this fact, Moulton posits a segmental phoneme of open juncture, symbolised by a plus sign, thanks to which the number of phonemes in German decreases, since sounds that are non-phonemic in monosyllabic utterances can also be analysed as non-phonemic in complex words. In the alternation at stake, $x$ is interpreted as occurring after central and back vowels and $c$-after other segmental phonemes (including $/+/$ ). The $/+/$ phoneme has its allophones: at the beginning and at the end of an utterance, it appears as "a pause of indeterminate duration" (1947: 220), whereas within an utterance- "as a pause of brief duration or in, free variation, as zero" (having no phonetic manifestation)

66 The transcription of German examples in this chapter has been adapted and largely based on Duden Aussprache Woerterbuch (Mangold, ed. 2005). Some conventions applied in the original sources, however, have been retained, in particular the transcription of [ən] instead of [n]. 
(1947: 220). The /+/ phoneme is assumed to occur wherever we find a pause of any duration, and in addition:

1) "aspirated $p, t, k$ (aspirated after $/+/$ ) but unaspirated after all other phonemes;

2) glottal stop (vowels show an allophone with a glottal stop after $/+/$, but an allophone without a glottal stop after all other phonemes);

3) the sound ç following (phonetically) a central or back vowel or semivowel ( $x$ shows the allophone $x$ after central and back vowels and semivowels, but $c$ after all other phonemes including /+/" (Moulton 1947: 223-224)

The examples illustrating the above contexts are provided below.

(41) a. Ich antworte Terrasse [?x ?antvortə $+\mathrm{t}^{\mathrm{h}}$ Erasə] "I answer 'terrace" vs.

Ich antwortete Rasse [?x Rantvortəterasə] "I answered 'race"”

b. i. Arbeit ersuchen [arbait + ใعe्रzu:xən] "to request work" vs. Arbeiter suchen [arbaite zu:xən] "(to) look for workers" ii. ein [+ ?ain] ,one' vs. kein [kain] "none" iii. ereilen [عe+?ailən] "to come over someone" vs. erteilen [Eetailən] "to give/teach someone"

c. Kuhchen [ku: + çən] "cow" (dimin.) vs. Kuchen [ku:xən] "cake"

In accordance with the structuralist principles, the examples of minimal pairs in (41) should be sufficient to posit a phonemic status of aspiration (4la), a glottal stop (4lb) and ç (4lc). However, Moulton argues that positing the $/+/$ phoneme is better as far as the economy of inventory is concerned. We add only one phoneme $(/+/)$, whereas glottalised vowels, aspirated consonants and $c$ are recognised as allophones of "pure" vowels ${ }^{67}$, unaspirated consonants and $x$, respectively. Moulton himself admits that the

67 It is argued that "vowels show an allophone with a glottal stop after $/+/$, but without a glottal stop after all other segmental phonemes" (Moulton 1947: 213-214). 
phonemic analysis of aspirated stops, $?$ and $c$ would have the advantage of "keeping our analysis on familiar ground" (1947: 223). Its disadvantage, however, is the necessity of accepting the phonemic status of sounds which in monosyllabic words would not be regarded as phonemes.

Naturally, Moulton is aware of the coincidence of the a juncture phoneme and morphological or syntactic boundaries. The question is whether syntactic and morphological boundaries should be a part of phonemic analysis. Moulton resolves this matter by adhering to the fundamental principle of the autonomy of linguistic modules, namely, no level-mixing is allowed, additionally pointing to the fact that open junctures do not always coincide with syntactic or morphological boundaries (Moulton 1947: 224).

Leopold (1948) objects to some of Moulton's conclusions by presenting further minimal pairs in which $x$-ç are meaningfully distinctive.

(42) Tauchen [ç] "rope" (dimin.) - Tauchen [x] "diving" Pfauchen [ç] "peacock" (dimin.) - Fauchen [x] "spitting" (of cats)

He adds that there is no observable sign of open juncture (zero) before ç, and therefore Moulton's analysis is circular:

To say that $x$ shows the allophone $c$ after open juncture in its zero form means that there is no observable sign of open juncture. It amounts to saying that we must assume open juncture when $x$ shows the allophone ç (Leopold 1948: 179).

Leopold concludes that there are two analytical possibilities, that is, either to accept $x$ and $c$ as separate phonemes or to include morphological boundaries (word-formation rules) into phonology (as Trubetzkoy (1935) does). The latter view is also predicted by Haugen, as he states that "there appears to be no good way of entirely isolating phonemic and morphological analysis" (Haugen 1951: 220). 
Jones (1967) states that $x$ and $c$ are different phonemes in German. However, he makes an interesting reference to the notion of the syllable, arguing that it would be possible to treat them as belonging to one phoneme if the division into syllables were offered, as well as the morphological information regarding affixation. ${ }^{68}$ His argument is as follows:

North Germans appear to have a particularly definite feeling for word-division, and they seem to feel various prefixes and suffixes as word-like entities. In particular, they seem to take it for granted, for instance, that the $x$ of rauchen terminates the syllable and that the ç of Frauchen begins a syllable; in other words, they appear to have a clear perception of the morphological structure of words. If, therefore, we consider the suffix -chen to be a word, our case for regarding $x$ and $c$ as members of a single phoneme is all but complete (Jones 1967: 69)

Jones names certain counterexamples, i.e. Wacholder "juniper" and a proper name Wachau, in which (in his view) $x$ begins a syllable. He concludes that, although we might exclude proper names, it is "not justifiable to ignore a reasonably common word in order to be able to establish a convenient phonemic system" (1967: 69).

Based on the results, it seems that the $x$-ç alternation poses a problem for the structuralist framework. Recognising the phonemic status of ç seems to be a logical, though undesirable, consequence of the theoretical principles. Moulton's view is particularly interesting, as he makes use of the concept of a juncture phoneme in order to avoid a seemingly straightforward analysis of this alternation.

The principle of no-level-mixing is a priority in the structuralist framework. Due to the independence of levels, there is no access to morphological or syntactic information in the phonological component. Moulton posits a juncture phoneme, the economy of inventory being a solid argument.

${ }^{68}$ He admits that Bloomfield was the first to suggest analysing [x] and [ç] as members of one phoneme. 
A juncture phoneme coincides with morphological and syntactic boundaries. Yet, in accordance with the structuralist principles, it is better to translate straightforward morphosyntactic generalisations into phonological terms, rather than to state them with direct reference to syntax and morphology. Thus, a juncture phoneme seems to be the "artefact" of the theory. Its existence is necessitated by other principles of the theory. It is a new segment in the inventory, whereas morphological and syntactic units are required independently. The alternative solution would be to accept the morphophonological component in the phonological analysis. Positing $/+/$ is not particularly explanatory. Rather, it seems to be a circular argument: "ç occurs in the position following +; while + occurs in the position preceding $c^{\prime \prime}$.

\subsubsection{Early Generative Phonology}

Let us now address the problem of the Kuchen-Kuhchen pair in German by adopting the SPE tool of phonological boundaries. As originally suggested by Bloomfield (see Chapter 4, section 4.2.4), the latter word might be analysed as consisting of two phonological words. Thus, in SPE terms, -chen in the word Kuhchen would be analysed as an affix that carries a \# boundary (43a). The word Kuchen, on the other hand, would be analysed as a monomorphemic word, as shown below (43b).
(43) a. Kuhchen $\rightarrow\left[\left[_{N} \#\left[\left[_{N} \# \text { Kuh\# }\right]_{N} \text { chen\# }\right]_{N}\right.\right.$
b. Kuchen $\rightarrow\left[_{N} \# \text { Kuchen\# }\right]_{N}$

The \# boundary before -chen prevents the rule of Fricative Assimilation (44) from applying in (43a).

$(44) c ̧ \rightarrow \mathrm{x} / \mathrm{V}$

$$
\text { [+back] }
$$

Further examples of well-known minimal pairs containing the dorsal and the palatal fricative are listed in (45). 
(45) a. tauchen [x] "dive" - Tauchen [ç] "rope" (dimin.)

b. pfauchen $[\mathrm{x}]$ "hiss" - Pfauchen [ç] "peacock" (dimin.)

The analyses of tauchen and pfauchen would be in line with the analysis of Kuhchen, since both words contain the same diminutive suffix. However, tauchen and pfauchen differ from Kuchen in their morphological status, as they are bi-morphemic, -en being the infinitival suffix in both cases (as in Rauch $(\mathrm{N})$ - rauchen (V) "smoke"). These forms would be accounted in the same way as it was done for the word longer (see Chapter 2, section 2.2.5), namely, the \# boundary is erased by a language-specific rule through eliminating a lexical category from the surface representation.

(46) a. $\left[_{V}\left[\left[_{V} \operatorname{taox}\right]_{V} \text { ən }\right]_{V} \rightarrow\left[\left[_{V} \text { taox }+ \text { on }\right]_{V}\right.\right.$
b. $\left[{ }_{V}\left[{ }_{V} \text { pfaox }\right]_{V} \text { ən }\right]_{V} \rightarrow\left[\left[_{V} \text { pfaox }+ \text { on }\right]_{V}\right.$

In comparison with the structuralist framework, the methodology adopted in the generative model proves to be quite distinct. The most significant difference concerns the morphology-phonology interface. The access to morphological and syntactic information is allowed through the concept of boundaries. The diminutive suffix -chen is analysed as a phonological word. The velar fricative $x$ is derived from the palatal fricative $c$ by the rule of Fricative Assimilation, which applies after back vowels.

\subsubsection{Natural Generative Phonology}

In the NGP framework, rules are divided into phonologically conditioned and morphophonologically conditioned. If we focused solely on the examples given in (36), repeated below, the generalisation would be straightforward.

(47) a. hoch $[\mathrm{x}]$ "high"

b. mich $[c ̧]$ "me"

c. Milch [ç] "milk"

d. Chemie [ç] "chemistry" 
The rule of Fricative Assimilation would seem to be a good candidate for a P-rule. The context of the change is transparent and the rule itself is "natural" due to its assimilatory character (a velar consonant appearing after a back vowel). Yet, every P-rule is supposed to be exceptionless. This is not the case in the process under consideration, as illustrated by the examples presented in (37) and repeated below.
(48) a. Kuchen [x] "cake" - Kuhchen [ç] "cow" (dimin.)
b. tauchen [x] "dive" - Tauchen [ç] "rope" (dimin.)
c. pfauchen [x] "hiss" - Pfauchen [ç] "peacock" (dimin.)

In the NGP framework, phonological rules are not allowed to have access to morphological or syntactic information. Thus, the solution adopted in SPE (the analysis of the suffix -chen as a phonological word; see Chapter 4, section 4.2.5) is not a possible solution in NGP. Besides, in accordance with the True Generalization Condition (Hooper 1976), the rules should be based directly on surface forms. Therefore, the analysis offered by Standard Generative Phonology seems to be too abstract for the NGP framework.

As a consequence, the problematic case of dorsal fricatives in German would be analysed as an instance of a morphophonemic rule stated below.

$$
\left\{\begin{array}{l}
c \\
\mathrm{x} \\
\varsigma
\end{array}\right\} \rightarrow\left\{\begin{array}{l}
\mathrm{c}]_{\text {diminutive suffix -chen }} \\
\mathrm{x}] \mathrm{V} \\
{[+ \text { back }]} \\
c]_{\text {elsewhere }}
\end{array}\right\}
$$

The environments of MP-rules are described in morphosyntactic or lexical terms, that is, they refer to morphological or syntactic categories, such as plural, past, noun, and verb (see Chapter 1 , 
section 1.5). Thus, the analysis at stake would be carried out on the morphophonemic level. In practice, the analysis consists in listing the alternants and the contexts in which they occur, without an attempt to postulate a generalisation regarding the potential relatedness of the two analysed sounds.

\subsubsection{Lexical Phonology}

The analysis that I carry out in the first part of this section is based on the assumptions of Lexical Phonology presented by Borowsky (1986), where the concept of resyllabification (Selkirk 1982 ) is employed. As an alternative view, I conduct the analysis in accordance with the principles of Kiparsky (1982), Booij and Rubach (1987) and Rubach (1996). In the latter case, the crucial concepts are cyclic versus postcyclic lexical rules (Booij and Rubach 1987), and ambisyllabicity (Kahn 1976, Rubach 1996). Finally, Hall's (1989) solution to the German fricative problem is presented in the third part of this section.

Resyllabification moves phonetic material from the unstressed to the stressed syllable. It applies throughout phonology, in both the lexical and postlexical components, whenever its context (the foot environment) is met (see Chapter 2, section 2.1.7.1).

(50)

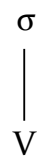

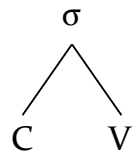
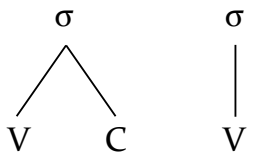

A resyllabification analysis of Fricative Assimilation (FA), and in particular - the non-application of this process in words such as Kuhchen, raises certain objections. It is assumed that the rule of FA applies when ç is moved via Resyllabification to the coda of the preceding stressed syllable. If we apply Resyllabification to the word Kuchen, we obtain the intended result, namely, FA occurs. 
(51)

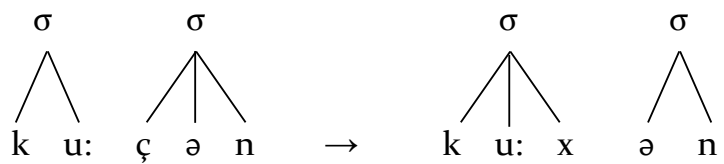

Yet, the principle of Structure Preservation (Kiparsky 1985), which Borowsky adopts, forbids the introduction of a non-distinctive segment in the lexical component. Borowsky's solution is to postulate the word cycle on the unaffixed word, and then on Level 2, Structure Preservation no longer blocks the derivation of $x$, as presented below.

$$
\text { / / k u: ç ə n // }
$$

Lexical component

blocked by SP

FA

Postlexical component

[k u: ç ə n]

/k u: ç ə $\mathrm{n} /$

$\mathrm{k} \mathrm{u}: \mathrm{x} \partial \mathrm{n}$

FA

[k u: $x$ $ə \mathrm{n}]$

However, the same procedure leads to the application of FA in the word Kuhchen, which is not the desired result. The segment $c$ appears in the coda (as resyllabification applies whenever its structural description is met) and gives incorrect results, with FA applying. Consequently, the analysis must have an intermediate representation.

(53)

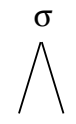

$\mathrm{k} \mathrm{u}$ : \#\#
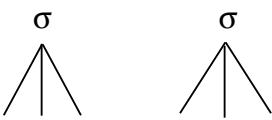

$\mathrm{u}: \mathbf{x} \# \#$

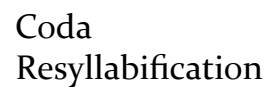

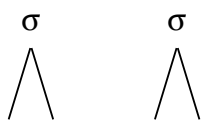

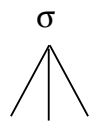

Onset

Resyllabification

The analysis turns out to be highly abstract, as its intermediate representation seems to be unjustified. The argument is the same 
as the one developed by Rubach (1996) for the analysis of the Bill-Billy alternation (see Chapter 2, section 2.1.7.2).

Let us therefore compare the predictions of the model in which ambisyllabicity is involved. Rubach (1996) argues that there are two types of ambisyllabicity rules, namely Coda Ambisyllabicity and Onset Ambisyllabicity (see Chapter 2, section 2.1.7.2). The status of both rules is different, hence their distinct properties. Onset Ambisyllabicity is postlexical as it applies across word boundaries, while Coda Ambisyllabicity does not. Thus, the latter rule is postcyclic.

The view that may be adopted is that FA takes place when ç is ambisyllabic with the preceding vowel. Assuming (in line with Bloomfield and SPE) that the diminutive suffix -chen is a phonological word, ${ }^{69}$ the attention is focused on the word boundary. Yet, the phrase weil du Chemie studierst-[u:ç] "because you study chemistry" is the evidence that the process of Fricative Assimilation does not apply in that context. The example comes from Hall (1989:5). Given that the word $d u$ ends in a vowel, whereas the following, Chemie, begins with a consonant, the phrase $d u$ Chemie seems to be the context for Coda Ambisyllabicity. It is not the case, though. As Rubach (1996) points out, the rule of Coda Ambisyllabicity is postcyclic, and not postlexical (in contrast to Onset Ambisyllabicity). Coda Ambisyllabicity assures that assimilation does not apply in Kuhchen, and that it does so in Kuchen. Onset Ambisyllabicity cannot apply in Kuhchen for the context for this rule is not met, with the first phonological word ending in a vowel and the next phonological word beginning with a consonant. The analyses of Kuchen and Kuhchen are presented in, respectively, (54a) and (54b) below. Ambisyllabicity accounts for these facts with its Coda version.

${ }^{69}$ Alternatively, it is possible to "Chomsky-adjoin" it to the higher structure. i.e. a foot. 
(54) a. Kuchen: FA takes place

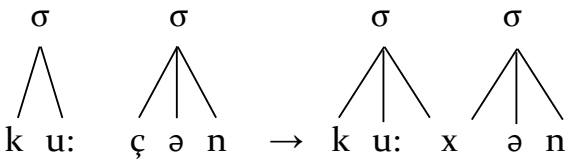

b. Kuhchen: FA does not take place (-chen is not available in the lexical component)

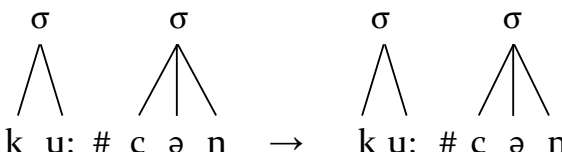

The final part of this sub-section is devoted to the presentation of the solution to the German problem in the Lexical Phonology framework as presented by Hall (1989). Hall argues that FA spreads the feature of backness from a vowel to a following tautomorphemic [-voice] and [+high] fricative and observes that the analysis is a counterexample to the Structure Preservation Hypothesis (Kiparsky 1985). The rule produces non-distinctive segments in the lexical component; thus it is non-structure-preserving. SP would predict that FA in German should apply postlexically, which is an incorrect assumption.

Hall postulates neither $x$ nor $c$ as the underlying segment. In his view, both segments are produced from a [-voice, +high] fricative that is unspecified for backness. This assumption is different from the previous analyses in which either $x$ or $c$ were employed as the underlying forms. Hall states that the majority of the linguists argued for $x$ being the basic segment, as is it less marked. Yet, as he notices more recent analysts choose the palatal form because of its wider distribution (e.g. Dressler 1976). Hall's analysis is closer to the latter option, as he employs a default rule (after FA has applied) that changes all the remaining (i.e. those that are not tautomorhemic) [+high] fricatives into palatals.

In order to account for the dorsal fricative alternation, Hall postulates the rule cited in (55) below, the context of which has to be restricted to the domain of a morpheme because of the 
problematic pairs of words of the Kuchen-Kuhchen type. Otherwise, the obtained result would be incorrect, since Kuhchen would be derived as *[kuxən]. Thus, the potential predictive power of FA without the postulated limit would be excessive. The rule of FA derives $x$ from an unspecified segment.

(55) Fricative Assimilation

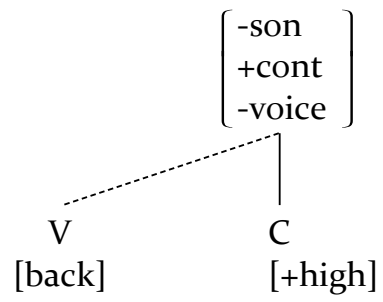

The reason for the feature [-voice] to occur in the structural description is the fact that the rule does not apply to the voiced palatal fricative [j] with the back vowel preceding, as in the examples provided by Hall. ${ }^{70}$

(56) a. Koje [ko:jə] "bunk"

b. Boje [bo:ja] "buoy"

c. Kajute [kajy:tə] "cabin”

Next, all the remaining palatal fricatives are derived by a default rule which assigns the feature [-back] to all [+high] fricatives. Hall's statement of the rule is presented below. ${ }^{71}$

(57)

$$
\left[\begin{array}{l}
\text {-son } \\
+ \text { cont } \\
+ \text { high }
\end{array}\right] \rightarrow[\text {-back }]
$$

${ }^{70}$ An alternative analysis is to assume that the fricative property of [j] is assigned in the phonetic implementation component. With this assumption, the reference to [-voice] in (51) is not necessary.

71 The appropriate order of the two rules above is determined by the Elsewhere Condition, that is, the default rule is ordered after FA. 
Hall adopts the stratal division of Giegerich (1985) and Wiese (1986) and assumes that -chen is a class II affix, as it is insensitive to stress assignment, and as such belongs to level 2 in the derivation. Furthermore, it is argued that the Umlaut rule has to crucially precede FA since it affects the backness of vowels. Were the ordering reverse, an incorrect result would be obtained in a number of words, e.g. in the word Bächlein, "brook" (dimin.). Hall provides an analysis that is based on Lieber's (1981) understanding of this process. In this view, Umlaut is a morphological rule applying in words with the suffixes that bear the diacritic feature $[+\mathrm{U}]$. The example is the word Bächlein, "brook" (dimin.), which is formed from the word Bach "brook", so it has a back vowel underlyingly. As Hall points out: "If FA were a level 1 rule, or a level 2 rule applying before the morphology, then the archiphoneme /X/ would incorrectly become a velar because at this stage in the derivation the preceding vowel is [+back]". (1989: 6). Apart from the -chen suffix, compounds are analysed at this level as well (e.g. Fotochemie), where similarly, the application of FA would be blocked. Next, it is predicted that FA does not apply at level 3, since then the derivation of the word Kuhchen would be incorrect. Finally, Hall provides the analysis of Kuchen-Kuhchen.

$$
\begin{array}{ll}
\text { Kuchen } & \text { Kuhchen } \\
\text { //ku:Xən// } & \text { //ku:// }
\end{array}
$$

level 1:

level 2:

$\begin{array}{lll}\text { morphology -chen } & - & \text { ku:]Xən } \\ \text { phonology FA } & \text { ku:xən } & - \\ \text { Default Rule } & - & \text { ku:çən } \\ & \text { [ku:xen] } & \text { [ku:çən] }\end{array}$

To summarize, in this section, selected principles within the Lexical Phonology framework have been compared. First, the principle of Structure Preservation again proves to predict the undesired results. Second, resyllabification seems to lead to unjustified 
abstractness in the representation. Ambisyllabicity, on the other hand, captures the generalisation in a more efficient way.

\subsubsection{Optimality Theory}

Merchant (1996) offers an OT analysis of the dorsal fricative problem in which he does not make use of the concepts of cyclicity or separate phonological levels. He assumes that FA occurs only tautosyllabically, with the fricative being ambisyllabic. The statements of constraints relevant for this analysis are provided in (59).

(59) a. ${ }^{*}[\mathrm{Aç}]_{\sigma}$ : The sequence of a back vowel and ç is forbidden in the same syllable.

b. $\operatorname{ALIGN}_{R}, \operatorname{ALIGN}_{(S t e m, R, \sigma, R)}$ : The right edge of every Stem coincides with the right edge of some syllable.

c. ${ }^{*}[\mathrm{x}]$ : Do not be a velar fricative.

d. IDENT ${ }_{[b a c k]}$ : Preserve the underlying [back] value of the fricative.

e. ONSET: Syllables have onsets.

f. NoCodA: Syllables do not have codas.

g. CRISP EDGE: A syllable edge must be crisp: all segments are uniquely syllabified.

The driver of FA is the ${ }^{*}[\mathrm{Aç}]_{\sigma}$ constraint, which prohibits the sequence of a back vowel followed by $c$ in the same syllable. It dominates another segmental markedness constraint, namely, *[x]. As a result, FA can apply. Merchant argues that ç will surface as $x$ only when it is in coda position, which means that a back vowel spreads its backness on the following tautosyllabic dorsal fricative. The ranking of the constraints as postulated by Merchant is presented in (60).

$$
\text { (60) * }\left[\mathrm{Aç}_{\sigma}\right]_{\sigma}>*[\mathrm{x}] \gg>\operatorname{IDENT}_{[\text {back }]}
$$

In line with the postulated ranking of the constraints, Merchant conducts the analyses of the words Buch, "book", and achten, "to observe", in which the Evaluator chooses the desired candidates. 
In both words, the fricatives and the preceding back vowels are unquestionably tautosyllabic and the fricative belongs to the coda of this syllable. As a result, FA applies as it is desired.

In Merchant's view, the process of FA is blocked when a dorsal fricative is uniquely syllabified into the onset. Thus, in words such as Frauchen, the fricative is syllable-initial. Yet, this statement seems to be arbitrary, for there is no objective reason to postulate two different syllabification patterns for Kuchen, on the one hand, and Kuhchen on the other hand, as shown in (61). ${ }^{72}$ The fricative in (61a) is ambisyllabic, while the fricative in (61b) belongs uniquely to the onset.

(61) a. Kuchen, "cake"

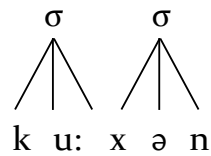

b. Kuhchen, "cow" (dimin.)

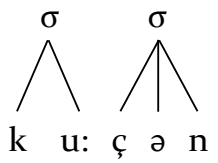

Merchant's analyses of rauchen and Frauchen are presented in (62) and (63) below.

Candidate (62a) violates the undominated ONSET, while both (62b) and (62c) satisfy this constraint. Additionally, candidate (62c) violates ALIGN $_{\mathrm{R}}$, and thus candidate (62b) is chosen as the optimal output. In this case, however, the linking of the $x$ into the onset of the following syllable is not considered as a violation of Align $_{R}$; otherwise (62c) would be the winner. ${ }^{73}$ The winning

72 Jensen (2000) argues that Merchant uses ambisyllabicity as a diacritic structure.

73 This solution is possible within the revised Alignment Theory (Itô and Mester 1994), according to which CRISP EDGE, militating against multiple linking, differs from the ALIGN constraint. 
candidate (62b) violates this low-ranked constraint, but this does not influence the result of the evaluation.

(62)

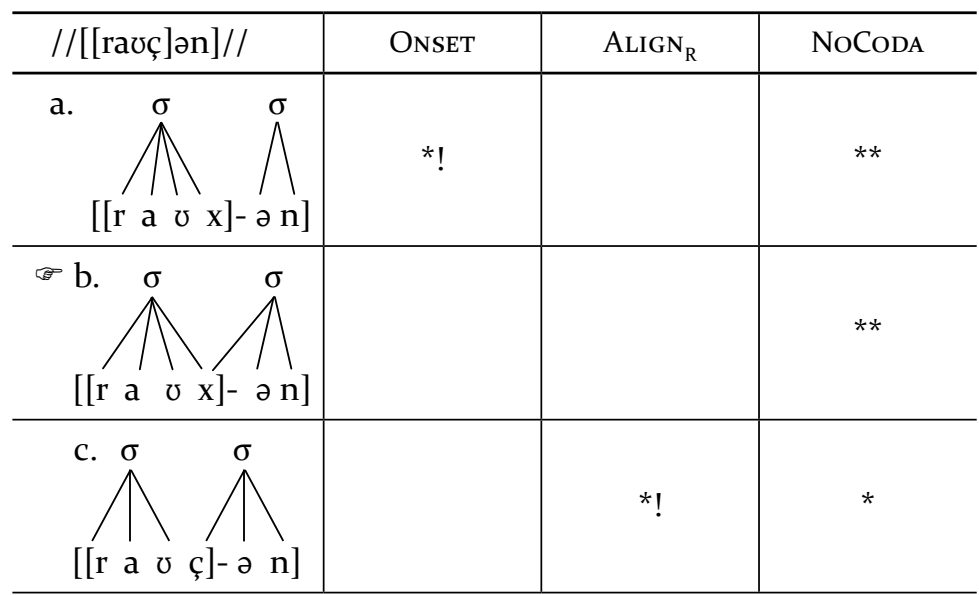

Let us now focus on Merchant's analysis of the word Frauchen (1996: 716).

(63)

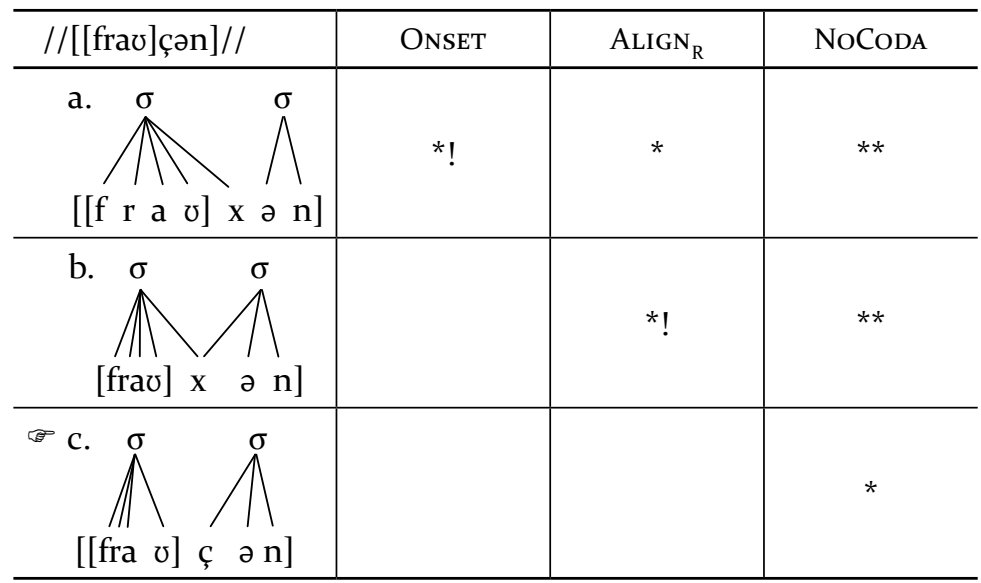


The winner, candidate (63c), satisfies $\operatorname{ALIGN}_{R}$ because the Stem boundary coincides with the syllable boundary. Merchant argues that "since the affix begins with a consonant that is uniquely syllabified into the onset of the second syllable, no constraint favours ambisyllabicity" $(1996,716)$. Consequently, the constraint * $[\mathrm{Aç}]_{\sigma}$ is mute. Candidate (63b) violates ALIGN $_{R}$. In Merchant's view, therefore, ambisyllabicity is a consequence of a segment's violation of a higher-ranked constraint $\left(\right.$ ALIGN $_{R}$ in this case). The syllabification of ç into the coda would entail the violations of both ALIGN $_{R}$ and NoCodA.

In Merchant's analysis, the distinction into Root-suffixes and Stem-suffixes is crucial, as ALIGN-R does not apply to Root edges. Jensen (2000) claims that this distinction is a roundabout way of reintroducing level ordering. ${ }^{74}$ Consequently, vowel-initial suffixes that attach to Roots can uniquely syllabify a Root-final consonant as an onset. They are not ambisyllabic, and therefore they do not undergo the process of FA.

Merchant's analysis seems to capture the distinction between Kuchen and Kuhchen or rauchen and Frauchen. However, the problematic characteristic of this analysis is the use of ambisyllabicity, which is regarded as a diacritic feature. Moreover, Optimality Theory faces problems connected with the requirement for the evaluation to be parallel. Hence, the distinction into Root-suffixes and Stem-suffixes.

\subsubsection{The problem of German ch: partial conclusions}

The problem of German ch illustrates the interrelation of morphology and phonology, with the notions of a juncture phoneme, biuniqueness and Structure Preservation being significant. Selected

${ }^{74}$ Jensen (2000) offers analyses of the fricative alternation in German, employing the concept of the foot as an alternative to ambisyllabicity. He postulates a modification of Hall's formulation of FA by arguing that the assimilating elements are in the same foot as well as in the same morpheme. 
frameworks have been compared with regard to problematic alternations, such as Kuchen-Kuhchen. The major issue is whether a given framework offers an insightful generalisation regarding the status of $x$ and ç, or whether it stops at stating the observation.

Both in Kruszewski's theory of alternations (section 4.2.2) and in the Prague School framework (section 4.2.3), the generalisation poses analytic problems. Though restricted in occurrence, both fricatives seem to be regarded as separate phonemes. In the structuralist framework (section 4.2.4), the issue causes controversies. In accordance with the classic principles, both $x$ and $c$ should be analysed as phonemes. Yet, Moulton's solution is to adopt the notion of a juncture phoneme as a roundabout way of accessing morphological information in the process of phonological analysis. Generative phonology (section 4.2.5) offers a superior solution, grasping the relatedness between morphology and phonology in a straightforward fashion by recognising morphological and syntactic boundaries. No "artificial" segments are constructed, morphological and syntactic boundaries being independently motivated and indispensable. By dividing the rules into phonologically and morphophonologically conditioned, Natural Generative Phonology (section 4.2.6) seems to go one step back in the analysis of the process at stake. Owing to the restriction on abstractness, no unitary generalisation is provided. Rather, we see a descriptive list of alternations, similar to that in pre-generative accounts. In the Lexical Phonology framework (section 4.2.7), ambisyllabicity delivers the intended result, as well as the concept of rules belonging to components. The principle of Structure Preservation again proves to be problematic. 


\section{CHAPTER 5}

\section{CONCLUSIONS}

This work has examined the notion of the basic phonological segment from the perspective of selected frameworks. It has been shown that this concept is crucially related with the entire architecture of a given phonological theory. The predictions and liabilities of the theories have been compared. Overlapping and biuniqueness (Chapter 2), the symmetry of a phonological system (Chapter 3) and levels of phonological representation (Chapter 4) constitute the major mechanisms and principles involved in the process of establishing the basic unit of phonological analysis.

The principle of biuniqueness proves to be important in the analyses of the phonological status of a flap and angma in English (Chapter 2). Angma obtains phonological status in the structuralist framework, even though its distribution is restricted and predictable. Abandoning the concept of biuniqueness in the generative framework leads to a different outcome. In generative terms, angma is not regarded as an underlying segment. Recognition of the syllable in phonological analysis enables to capture the generalisation in a more insightful way. Optimality Theory differs from other generative frameworks in that it is forced to analyse assimilation as coalescence, which is the "artefact" of this theory. The biuniqueness principle is particularly problematic in the analysis of a flap. On the other hand, generative phonology, as well as Kruszewski's theory offer a simple and unified analysis of flapping. 
The analyses of Nasal Assimilation and Nasal Gliding in Polish (Chapter 3) have shown that the ideal of the symmetry of a phonological system is crucial in structuralism. However, it is restricted to the set of observable, surface data. The goals of generativism are different. Thus, the symmetry does not play a pivotal role in the analysis. The concept of the archiphoneme in the Prague School of phonology makes insightful predictions regarding both processes under consideration, being The results of the analyses resemble some generative solutions, in particular the $\alpha$-place convention.

Voice Assimilation and the concept of a juncture phonemes have been used to discuss the levels of phonological representation (Chapter 4). Abandoning the phonemic representation makes the biuniqueness principle redundant in the generative framework. However, Structure Preservation, one of the principles of Lexical Phonology, leads to the undesirable result by artificially splitting a single generalisation. The concept of a juncture phoneme is a method in which structuralism deals with problematic manifestations of morphology-phonology interface. In generative phonology, access to morphological information is allowed, though Natural Generative Phonology comes back to some structuralist concepts by dividing the rules into phonologically conditioned and morphologically conditioned.

It seems that Baudouin de Courtenay's, Sapir's and Chomsky's references to "psychological reality" of phonological segments lead to insightful generalisations regarding phonetic facts. On the other hand, the ideal of "naturalness" (present in NGP) is to restrict unwarranted abstractness by emphasising surface data. However, in some cases, the latter approach offers nothing more than a set of alternations. Standard generative phonology focuses on different aspects of research. The major aim is to grasp the intuitions of native speakers, hence the concept of underlying representation and derivation.

Jan Rozwadowski (1925), a Polish linguist, expressed the mentalistic reasoning in an interesting way: 
Where and how does our language - sentences, words, sounds exist? This question is not as trivial as it may seem. It is true that our speech exists physically: when somebody shouts or talks loudly, uproariously or shrilly, our ears hurt. Our utterances have duration, pitch and melody, and through the airwaves these are transmitted to the ear of the listener. All this is true. However, such an utterance lasts for a very short time and it disappears quickly. In the case of talkative people, it would not be particularly difficult to establish the existence of their language. But there are also men of few words, who hardly ever open their mouths, or those who are lonely, or prisoners, who do not speak for a number of days. Yet, it is also their language that has never ceased to exist". (Rozwadowski 1925: 27) [translation mine, MK-P].

Rozwadowski concludes that the essential reality of the language is connected with the human brain (or a soul). He makes a distinction between physical and mental reality, emphasizing their significance and interrelatedness. This brings us back to the ideas of Baudouin de Courtenay and Sapir, namely, mental images of physical sounds, a notion taken over by generative grammar. 


\section{REFERENCES}

Anderson, Stephen R. 1986. Phonology in the Twentieth Century. Chicago and London: The University of Chicago Press.

Anderson, John, and Charles Jones. 1974. "Three theses concerning phonological representations". Journal of Linguistics 10 (1): 1-26.

Baudouin de Courtenay, Jan N. 1895. Versuch einer Theorie phonetischer Alternationen. Strasburg: Trübner.

Baudouin de Courtenay, Jan N. 1974 [1888]. "Mikołaj Kruszewski, jego życie i prace naukowe". In Jan Niecisław Baudouin de Courtenay. Dzieła wybrane (vol. 1), edited by Marta Jasińska, 96-175. Warszawa: Państwowe Wydawnictwo Naukowe.

Beckman, Jill. 1995. "Shona height harmony: markedness and positional identity". In University of Massachusetts Occasional Papers: Papers in Optimality Theory 18 edited by Jill Beckman, Laura Walsh Dickley and Suzanne Urbanczyk, 53-76. Amherst, Mass: GLSA.

Beckman, Jill. 1997. "Positional faithfulness, positional neutralisation and Shona vowel harmony". Phonology 14: 1-46.

Biedrzycki, Leszek. 1963. "Fonologiczna interpretacja polskich głosek nosowych". Biuletyn Polskiego Towarzystwa Językoznawczego XXII: 25-45.

Biedrzycki, Leszek. 1978. Fonologia angielskich i polskich rezonantów. Warszawa: Państwowe Wydawnictwo Naukowe.

Bloch, Bernard. 1941. "Phonemic Overlapping". American Speech 16: 278-84.

Booij, Geert and Jerzy Rubach. 1987. "Postcyclic versus postlexical rules in lexical phonology.” Linguistic Inquiry 18:1-44.

Bloomfield, Leonard. 1933. Language. New York: Holt, Rinehart and Winston.

Borowsky, Toni. 1986. “Topics in the Lexical Phonology of English”. PhD diss., University of Massachusetts.

Casali, Roderic F. 1997. "Vowel elision in hiatus contexts: Which vowel goes?" Language 73: 493-533. 
Chomsky, Noam. 1957. Syntactic structures. The Hague: Mouton.

Chomsky, Noam and Morris Halle. 1968. The Sound Pattern of English. New York: Harper \& Row.

Clements, George N. and Samuel Jay Keyser. 1983. CV phonology: A generative theory of the syllable. Cambridge, Mass.: MIT Press.

Czaykowska-Higgins, Ewa. 1988. "Investigations into Polish morphology and phonology". PhD diss., Massachusetts Institute of Technology.

Dressler, Wolfgang U. 1976. "Morphologization of phonological processes: are there distinct morphological processes?" In Linguistic studies offered to Joseph Greenberg (vol. 2), edited by Alphonse Juilland, 313-337. Saratoga: Anna Libri.

Dressler, Wolfgang U. 1984. "Explaining Natural Phonology. " Phonology Yearbook 1: 29-51.

Dziczek-Karlikowska, Hanna. 2012. Error-Based Evidence for the Phonology of Glides and Nasals in Polish with Reference to English. Frankfurt am Main: Peter Lang.

Dziubalska-Kołaczyk, Katarzyna. 1995. Phonology without the syllable. A study in the natural framework. Poznań: Motivex.

Fischer-Jørgensen, Eli. 1975. Trends in Phonological Theory. Copenhagen: Akademisk Forlag.

Giegerich, Heinz J. 1985. Metrical phonology and phonological structure: German and English. Cambridge: Cambridge University Press.

Gimson, Alfred C. 1970. An Introduction to the Pronunciation of English (2nd ed). London: Edward Arnold.

Hall, Tracy A. 1989. "Lexical Phonology and the Distribution of German [ç] and [x]". Phonology 6: 1-17.

Halle, Morris. 1959. The Sound Pattern of Russian. The Hague: Mouton.

Halle, Morris and Karuvannur P. Mohanan. 1985. "Segmental phonology of modern English”. Linguistic Inquiry 16: 57-116.

Harris, Zellig S. 1951 Methods in Structural Linguistics. Chicago: University of Chicago Press.

Harris, John and Edmund Gussmann. 1998. "Final codas: why the west was wrong". In Structure and Interpretation: studies in phonology, edited by Eugeniusz Cyran, 139-162. Lublin: Folium.

Haugen, Einar. 1951. "Directions in modern linguistics". Language 27 (3): 211-222.

Haugen, Einar. 1969. "Phonemic indeterminacy and Scandinavian Umlaut”. Folia Linguistica III: 107-19.

Hayes, Bruce. 1984. "The phonetics and phonology of Russian voicing assimilation". In Language sound structure, edited by Mark Aronoff and Richard T. Oehrle, 318-328. Cambridge, Mass.: MIT Press. 
Hockett, Charles F. 1955. A Manual of Phonology. Baltimore: Waverley Press. Hooper, Joan B. 1976. An Introduction to Natural Generative Phonology. New York: Academic Press.

Itô, Junko and Armin Mester. 1994. "Reflections on CodaCond and Alignment". In Phonology at Santa Cruz [PASC] 3: 27-46.

Iwan, Karolina. 2015. "The interaction of yer deletion and nasal assimilation in Optimality Theory". Research in Language 13 (2): 162-178.

Jakobson, Roman. 1962. Selected Writings. The Hague: Mouton.

Jakobson, Roman. 1967. "Znaczenie Kruszewskiego w rozwoju językoznawstwa ogólnego. Wstęp”. In Mikołaj Kruszewski. Wybór pism. Z przedm. Jerzego Kuryłowicza i Romana Jakobsona. Translated into Polish by Jerzy Kuryłowicz and Krystyna Pomorska, X-XXV. Wrocław, Warszawa, Kraków: Zakład Narodowy im. Ossolińskich.

Jensen, John T. 2000. “Against Ambisyllabicity”. Phonology 17: 187-235.

Jones, Daniel. 1967. The Phoneme: Its Nature and Use. Cambridge: Heffer \& Sons Ltd. Kahn, Daniel. 1976. "Syllable-based Generalizations in English Phonology". PhD diss., Massachusetts Institute of Technology.

Kaye, Jonathan. 1990. "Coda licensing”. Phonology Yearbook 7: 301-330.

Kenstowicz, Michael and Jerzy Rubach. 1987. "The phonology of syllabic nuclei in Slovak". Language 63: 463-497.

Kiparsky, Paul. 1982. "From Cyclic Phonology to Lexical Phonology". In The Structure of Phonological Representations, vol. 1, edited by Harry van der Hulst and Norval Smith, 131-175. Dordrecht: Foris.

Kiparsky, Paul. 1984. "On the lexical phonology of Icelandic". In Nordic prosody III, edited by Claes-Christian Elert, Iréne Johansson, and Eva Stangert, 135-64. Umeå: University of Umeå.

Kiparsky, Paul. 1985. "Some consequences of lexical phonology". Phonology 2: 85-138.

Kruszewski, Mikołaj. 1967 [1880]. “Uwagi językoznawcze”. In Mikołaj Kruszewski. Wybór pism. Z przedm. Jerzego Kurytowicza i Romana Jakobsona. Translated into Polish by Jerzy Kuryłowicz and Krystyna Pomorska, 13-24. Wrocław, Warszawa, Kraków: Zakład Narodowy im. Ossolińskich.

Kruszewski, Mikołaj. 1967 [1881]. “O obocznościach dźwiękowych”. In Mikołaj Kruszewski. Wybór pism. Z przedm. Jerzego Kuryłowicza i Romana Jakobsona. Translated into Polish by Jerzy Kuryłowicz and Krystyna Pomorska, 25-46. Wrocław, Warszawa, Kraków: Zakład Narodowy im. Ossolińskich.

Kruszewski, Mikołaj. 1967 [1883]. "Zarys nauki o języku”. In Mikołaj Kruszewski. Wybór pism. Z przedm. Jerzego Kuryłowicza i Romana Jakobsona. Translated into Polish by Jerzy Kuryłowicz and Krystyna Pomorska, 47-150. Wrocław, Warszawa, Kraków: Zakład Narodowy im. Ossolińskich. 
Kuryłowicz, Jerzy. 1967. “Mikołaj Kruszewski. Wstęp. ” In Mikołaj Kruszewski. Wybór pism. Z przedm. Jerzego Kuryłowicza i Romana Jakobsona. Translated into Polish by Jerzy Kuryłowicz and Krystyna Pomorska, III-IX. Wrocław, Warszawa, Kraków: Zakład Narodowy im. Ossolińskich.

Leopold, Werner F. 1948. "German ch". Language 24: 179-80.

Lieber, Rochelle. 1981. "On the organization of the lexicon". PhD diss., Massachusetts Institute of Technology.

Lightner, Theodore M. 1972. Problems in the Theory of Phonology (vol. 1). Edmonton: Linguistic Research.

Mangold, Max (ed.). 2005. Duden Aussprache Woerterbuch. Mannheim: Dudenverlag.

McCarthy, John and Alan Prince. 1993. Prosodic morphology: Constraint interaction and satisfaction. Amherst: University of Massachusetts.

Merchant, Jason. 1996. "Alignment and Fricative Assimilation in German". Linguistic Inquiry 27: 709-719.

Mohanan, Karuvannur P. and Tara Mohanan. 1984. "Lexical Phonology of the Consonant System in Malayalam". Linguistic Inquiry 15: 575-602.

Mołczanow, Janina. 2008. The Phonology of Glides in Russian. München: Lincom Europa.

Moulton, William G. 1947. "Juncture in Modern Standard German". Language 23: 212-26.

Myers, Scott. 1987. "Vowel shortening in English”. Natural Language \& Linguistic Theory 5 (4): 485-518.

Petrova, Olga, Rosemary Plapp, Catherine Ringen and Szilárd Szentgyörgyi. 2006. "Voice and aspiration. Evidence from Russian, Hungarian, German, Swedish, and Turkish". The Linguistic Review 23: 1-36.

Pike, Kenneth L. 1947. Phonemics: A technique for reducing languages to writing. Ann Arbor, MI: University of Michigan Press.

Prince Alan and Paul Smolensky. 1993. Optimality Theory: Constraint interaction in generative grammar. Tech Report, Rutgers Univ. \& Univ. Colorado Boulder. Rozwadowski, Jan. 1925. Głosownia języka polskiego. Kraków: Gebethner i Wolff. Rubach, Jerzy. 1982. Analysis of Phonological Structures. Warszawa: Państwowe Wydawnictwo Naukowe.

Rubach, Jerzy. 1984. Cyclic and Lexical Phonology. Dordrecht: Foris.

Rubach, Jerzy. 1986. "Abstract vowel in three-dimensional phonology: the yers". The Linguistic Review 5: 247-280.

Rubach, Jerzy. 1993. The Lexical Phonology of Slovak. Oxford: Clarendon Press. Rubach, Jerzy. 1996. "Shortening and Ambisyllabicity in English". Phonology 13: 197-237.

Rubach, Jerzy. 1997. "Extrasyllabic consonants in Polish: Derivational Optimality 
Theory". In Derivations and constraints in phonology, edited by Iggy Roca, 551-581. Oxford: Oxford University Press.

Sapir, Edward. 1925. "Sound Patterns in Language". Language 1: 37-51.

Schane, Sanford. 1968. French Phonology and Morphology. Cambridge, Mass.: MIT Press.

Schane, Sanford. 1971. “The Phoneme Revisited”. Language 47 (3): 503-521.

Selkirk, Elizabeth O. 1982. The Syntax of Words. Cambridge, Mass.: MIT Press. Selkirk, Elizabeth O. 1984. "On the major class features and syllable theory". In Language sound structure, edited by Mark Aronoff and Richard Oehrle, 107-136. Cambridge, Mass.: MIT Press.

Stampe, David. 1979. A dissertation on natural phonology. New York: Garland. Trager, George L. and Bernard Bloch. 1941. "The Syllabic Phonemes of English". Language 17 (3): 223-46.

Trubetzkoy, Nikolai S. 1935 Anteilung zu phonologischen Beschreibungen. Leipzig: Harrassowitz.

Trubetzkoy, Nikolai S. 1971 [1939]. Grundzüge der Phonologie [Principles of Phonology]. 2nd print. Translated into English by Christiane A. M. Baltaxe, Berkley and Los Angeles: University of California Press.

Twaddell, W. Freeman. 1935. On Defining the Phoneme. Baltimore: Waverly Press.

Vachek, Josef. 1964. “On peripheral phonemes of Modern English”. Brno Studies in English 4: 7-109.

Vennemann, Theo. 1971. "Natural Generative Phonology". Paper presented at the Annual Meeting of the Linguistic Society of America, Saint Louis, MO.

Vennemann, Theo. 1973. "Phonological concreteness in natural generative grammar”. In Toward tomorrow's linguistics, edited by Roger Shuy \& Charles J. Bailey, 202-19. Washington, D.C.: Georgetown University Press.

Wiese, Richard. 1986. "Schwa and the Structure of Words in German". Linguistics 24: 695-724.

Yearley, Jennifer. 1995. "Jer Vowels in Russian". In Papers in Optimality Theory, edited by Jill N. Beckman, Laura W. Dickey \& Suzanne Urbanczyk, 533-571. Amherst: University of Massachusetts, GLSA. 


\section{INDEX OF NAMES}

Anderson, Stephen R. 15, 19, 27, 62, 113-114, 128-129, 151

Baudouin de Courtenay, Jan N. 15-16, 94, 104, 148-149, 171-172

Beckman, Jill 144

Biedrzycki, Leszek 88, 99-102, 107, 115

Bloch, Bernard 16, 29-31, 51-52, $56-58,99,130$

Bloomfield, Leonard 15-17, 29, 31, 32, 132, 151, 155, 156, 161

Booij, Geert 45-47, 114, 134, 139-140, 159

Borowsky, Tony 19, 51-52, 60-62, 66, $68,78-83,134-135,159-160$

Casali, Roderic F. 144

Chomsky, Noam 15, 17, 34-35, 68, 75-76, 77, 104, 161, 171

Clements, George N. 17, 40

Czaykowska-Higgins, Ewa 115

Dziczek-Karlikowska, Hanna 119, 120

Fischer-Jørgensen, Eli 15, 25, 29, 32

Giegerich, Heinz J. 164

Gimson, Alfred C. 32-33
Hall, Tracy A. 159, 161-164, 168

Halle, Morris $15,17,34-35,58,68$, $75-76,77,81,124-125,128-130$, 132-133, 134, 135-136, 138

Harris, Zellig 15-16, 32

Haugen, Einar 29, 154

Havet, Louis 14

Hayes, Bruce 124

Hockett, Charles F. 16, 32

Hooper, Joan B. 15, 42-43, 77, 133, 158

Itô, Junko 167

Iwan, Karolina 116-118

Jakobson, Roman 14, 16-17, 66-67, 96

Jensen, John T. 166,168

Jones, Charles 19, 62

Jones, Daniel 14-16, 34, 56, 68, 71-74, 99, 155

Kahn, Daniel 17, 19, 37-40, 59-60, 62, 78, 159

Kenstowicz, Michael 43

Keyser, Samuel Jay 17, 40

Kiparsky, Paul 15, 44-46, 79, 81, 115, $121,134-136,139,159-160$, 162 
Kruszewski, Mikołaj 14-16, 19-22, 27, $34,52-54,55,68-70,77,84,87,88$, 90-95, 98, 120-121, 123, 126-127, $133,146,148-150,169-170$

Kuryłowicz, Jerzy 94

Leopold, Werner F. 154

Lieber, Rochelle 164

Lightner, Theodore M. 38

Mathesius, Vilém 16

McCarthy, John 15, 18

Merchant, Jason 165-168

Mester, Armin 167

Mohanan, Karuvannur P. 81, 134

Mohanan, Tara 134

Mołczanow, Janina 124

Moulton, William G. 15, 38, 152-155, 169

Myers, Scott 62-63

Petrova, Olga 145

Pike, Kenneth L. 16, 28, 33

Plapp, Rosemary 145

Prince, Alan 15, 18, 48, 49

Ringen, Catherine 145

Rozwadowski, Jan 171-172
Rubach, Jerzy $11,15,16,19,23,30$, 36-37, 43, 45-47, 51-52, 60, 62-66, $85,88,103-108,114,134,139-140$, 159, 161

Sapir, Edward 15, 17, 34, 51, 68, 71-72, $74,78,104,171-172$

Saussure, Ferdinand de 14

Schane, Sanford 41-42, 109-111, 113, 124, 131-133

Selkirk, Elizabeth O. 19, 60, 62, 84, 135,159

Smolensky, Paul 15, 18, 48, 49

Swadesh, Morris 16

Szentgyörgyi, Szilárd 145

Trager, George L. 16, 31

Trubetzkoy, Nikolai S. 15-16, 22-27, $55,96,98,128-130,150,154$

Twaddell, W. Freeman 16, 29

Vachek, Josef 70

Vennemann, Theo 15, 42, 77

Wiese, Richard 164

Yearley, Jennifer 117 


\section{INDEX OF SUBJECTS}

Ambisyllabicity 19, 60, 62-65, 67, 159, $161,165,166,168-169$

Angma 13, 33, 68-87, 170

Archiphoneme 16, 25-27, 70-71, $75,80,96-98,121,129-130,164$, 171

\section{b-deletion $81-83$}

Biuniqueness $13,29-30,50,51$, $56-58,68,70,73,74,78,87,88,99$, $104,108,115-116,120-121,130-$ $131,138-139,146,151-152,168$, $170-171$

Boundaries 18, 29, 32, 34-38, 43-45, 47-48, 53-54, 64, 76-77, 89, 91, 99, 104, 109, 114-115, 121, 123-125, 127, 129, 133-134, 138-139, 151, 154-157, 161, 168-169

Bracket Erasure Convention 18, 44, 136

Coda Ambisyllabicity 63-64, 161

Complementary distribution 25, 27-28, 30, 73, 74, 130, 147-148, 151-152

Contrastive distribution $24,28-30,32$, $73,74,130,151$

Correlatives 19-22, 27, 52-53, 91-95, $123,126-127,133,149-150$
CV-tier 40

Cyclic rules 45-48, 64, 114, 159

Derivational Optimality Theory 19,85 , $118,120,122$

Directionality $142-147$

Distributional structuralism 15,16 , 27-34, 56-58, 71-74, 99-103, 121, 130-131, 151-156

Divergents $16,19-20,52-54,56$, $91,93-95,123,126-128,133,148$, 149-150

Early Generative Phonology (Sound Pattern of English phonology) 15, 17, 34-40, 58-60, 74-77, 103-108, 156-157

Economy of the inventory 32-33, 153-156

e-deletion (Yer-deletion) 37, 42, 43-45, 106-107, 111-112, 117

Faithfulness constraints 49-50, 116$117,119,140-142,144-146$

Final Devoicing 26, 41, 46-47, 125, 132 Flapping $17,32,41,51-68,111$, 170

Free variation $28,30,152$

Fricative Assimilation 149-150, 156-163 
$g$-deletion $76-77,81-83,85,87,103$, 108,110

Juncture phoneme 13-14, 31-32, 123, 154-156, 168-169, 171

Kazan School 13, 15-16, 19-22, 51-55, 56, 69-70, 88, 90-95, 124, 126-128, $147-150$

Levels of phonological representation 123-169, 171

Lexical Phonology 15, 18, 43-48, 51-52, 60-66, 78-83, 114-116, 121, 134-141, 147, 159-165, 169, 171

Lexical rules 18, 46-47, 114-115, 121-122, 134, 136-137, 159

London School 34

Markedness constraints 49-50, 116, $119,140,165$

Minimal pair $16,28-33,40,58,73$, 99-100, 102, 131, 148, 151, 153-154, 156-157

Morphology-phonology interface 108 Morphophoneme 16, 26, 34

Morphophonemic representation 131 Morphophonologically-conditioned rules $60,78,109,112-113,123,133$, 157-159, 169

Nasal Assimilation 13, 37, 75, 80-87, 88-96, 99, 103, 106-112, 115-121, 171

Nasal Deletion 41

Nasal Gliding 13, 88-91, 93, 95-97, 101-106, 108-109, 111-115, 119121,171

Nasalisation 119-120

Natural Generative Phonology 15-16, $18,19,41-43,60,77-78,87-88$,
109-114, 122, 123, 133-134, 146$147,157-159,169,171$

Neutralisation $16,25-27,29,30,70$, $84,96,129$

No Ordering Condition 109, 111, 122

Once a phoneme, always a phoneme 28-30, 56, 58, 70, 102, 120, 151

Onset Ambisyllabicity 63-64, 161

Oppositions 16, 22-26, 29-31, 33-34, 55, 95-96

Optimality Theory $13,15,18,19$, 48-50, 66-67, 83-87, 88, 116-120, $140-147,165-168,170$

Overlapping $13,30,50,51-52,56-58$, $87,123,170$

Phonemic representation 29, 34, 37, 57-58, 110, 123-147, 151-152, 171

Phonologically-conditioned rules 41, $60,78,109,113,123,133$

Postcyclic rules 46-48, 64, 114-115, 139-140, 159, 161

Postlexical rules 18, 44-45, 47-48, 114,134

Prague School 15-16, 22-27, 30-31, 33-34, 55-56, 70-71, 75, 88, 95-98, $121,124,128-130,146-147,150-$ $151,169,171$

Predictability $29-30,74,78,85-86$, $103-107,112,115,121-122$

r-deletion 17, 37-39

Regressive Devoicing 37, 42-45

Resyllabification 19, 60-66, 79, 159$160,164-165$

Second Velar Palatalisation 21-22

Sound Pattern of English phonology $\rightarrow$ Early Generative Phonology 
Strict Layer Hypothesis $84-87$

Strong Domain Hypothesis 81, 134139

Strong Naturalness Condition 42, 77, 109, 112-113, 122

Structure Preservation Principle 13-14, $45,62,83,88,115-116,135-139$, $147,160,162,164-165,168-169$, 171

Surface Palatalisation $45-46$

Symmetry of the system $13,33,50$, 88-122, 170-171
Underlying representation $35-37,38$, $42,43,75,80,85,104-107,112,171$

Velar Palatalisation 20-22

Via-rules 41

Voice Assimilation 13-14, 37, 102, 123128, 130-131, 134-143, 146-147, 171

Word-Formation rule 44-47, 135-140, 154

Yer-deletion $\rightarrow$ e-deletion 
The work discusses the notion of the basic phonological segment from the perspective of selected European and American phonological theories. The discussion consists in the analyses of specific phonological problems in accordance with the tenets of a given framework, starting with the Kazan School and ending with the Optimality Theory. The goal of this study is to show the differences in the methodology and predictions of each framework that prove significant in the process of establishing the basic phonological unit. The dissertation elaborates on the data from English, Polish, German, and Russian. The main body of the work comprises the issues of biuniqueness and overlapping, the symmetry of a phonological system and levels of phonological representation.

Monika Konert-Panek, PhD, works as Assistant Professor at the Institute of Specialised and Intercultural Communication at the University of Warsaw. She was also a Visiting Scholar at the University of Bologna, University of Trier and KU Leuven. Her current research interests cover the areas of sociophonetics, phonology and stylistics, with the focus on singing accent properties from the usage-based perspective.

The book makes a relevant contribution to the discussion on phonological theory. Monika Konert-Panek consistently demonstrates differences between basic concepts, levels of representation and explanatory potential of frameworks, starting from the influential ideas of the Kazan School, advocated in the second half of the 19th century, to Optimality Theory, which constitutes one of the main formal approaches nowadays. Clarity and accessibility of presentation make it possible for the reader to understand the nature of a topic as complex and diversified as phonology. Therefore, the book is recommended not only for scholars and students interested in phonology but also for readers interested in general linguistics.

prof. Paula Orzechowska

The discussion presented in the book consists in the analyses of selected phonological problems from the perspective of a given framework. Not only does this approach allow the readers to examine classic theories from the perspective of their successors, but it also makes it possible to enter the minds of old masters to resolve some later-emerged problems with their analytical tools.

prof. Klementina Jurančič 